DOI: $10.1002 /(($ please add manuscript number $))$

Article type: Review

\title{
Graphene and related materials for resistive random access memories
}

By Fei Hui, Enric Grustan-Gutierrez, Shibing Long, Qi Liu, Anna K. Ott, Andrea C. Ferrari, and Mario Lanza*

Ms. Fei Hui, Dr. Enric Grustan-Gutierrez, Prof. Mario Lanza*

Institute of Functional Nano and Soft Materials (FUNSOM), Collaborative Innovation Center of Suzhou Nanoscience and Technology, Soochow University, 199 Ren-Ai Road, Suzhou, 215123, China

[*] Corresponding author Email: mlanza@suda.edu.cn

Fei Hui and Enric Grustan-Gutierrez contributed equally to this work

Prof. Shibing Liu, Prof. Qi Liu

Key Laboratory of Microelectronic Devices \& Integrated Technology, Institute of Microelectronics of Chinese Academy of Sciences, Beijing 100029, China

Dr Anna K. Ott, Prof. Andrea C. Ferrari

Cambridge Graphene Centre, University of Cambridge, Cambridge, CB3 0FA, UK

Keywords: RRAM, GRM, graphene, resistive switching, non-volatile memory

\begin{abstract}
Graphene and related materials (GRMs) are promising candidates for the fabrication of resistive random access memories (RRAM). Here, we analyze, classify and evaluate this emerging field, and summarize the performance of the RRAM prototypes using GRMs. Graphene oxide, amorphous carbon films, transition metal dichalcogenides, hexagonal boron nitride and black phosphorous can be used as resistive switching media, in which the switching can be governed either by the migration of intrinsic species or penetration of metallic ions from adjacent layers. Graphene can be used as electrode to provide flexibility and transparency, as well as an interface layer between the electrode and dielectric to block atomic diffusion, reduce power consumption, suppress surface effects, limit the number of conductive filaments in the dielectric, and improve device integration. GRMs-based RRAMs fit some non-
\end{abstract}


volatile memory technological requirements like low operating voltages $<1 \mathrm{~V}$ and switching times $<10$ ns but others, like retention $>10$ years, endurance $>10^{9}$ cycles and power consumption $\sim 10 \mathrm{pJ} /$ transition still remain a challenge. More technologyoriented studies including reliability and variability analyses may lead to the development of GRMs-based RRAMs with realistic possibilities of commercialization.

\section{List of acronyms}

a-C amorphous-Carbon

ALD Atomic Layer Deposition

APTES 3-Aminopropyltriethoxysilane

BD Dielectric Breakdown

BLG Bilayer Graphene

BP Black Phosphorous

CAFM Conductive Atomic Force Microscopy

CBRAM Conductive Bridge Random Access Memory

CF Conductive Filament

CL Current Limitation

CMOS Complementary Metal Oxide Semiconductor

CVD Chemical Vapor Deposition

CVS Constant Voltage Stresses

1D1R One Diode One Resistor

DRAM Dynamic Random Access Memory

ECM Electrochemical Metallization

FET Field Effect Transistor 


\begin{tabular}{|c|c|}
\hline GB & Grain Boundary \\
\hline GFET & Graphene Field Effect Transistor \\
\hline GIG & Graphene/Insulator/Graphene \\
\hline GO & Graphene Oxide \\
\hline GODs & Graphene Quantum Dots \\
\hline GO-PVK & Poly (N-vinylcarbazole) derived Graphene Oxide \\
\hline GRMs & Graphene and Related Materials \\
\hline h-BN & Hexagonal Boron Nitride \\
\hline HRS & High Resistance State \\
\hline ITO & Indium Tin Oxide \\
\hline ITRS & International Technology Roadmap for Semiconductors \\
\hline LM & Layered Material \\
\hline LPE & liquid phase exfoliation \\
\hline LRS & Low Resistance State \\
\hline $\mathrm{MC}$ & Micromechanical Exfoliation \\
\hline MIM & Metal/Insulator/Metal \\
\hline MLG & Multilayer Graphene \\
\hline MRAM & Magnetoresistive Random Access Memory \\
\hline NVM & Non-Volatile Memory \\
\hline PCBM & 6-Phenyl-C61 Butyric acid Methyl ester \\
\hline PCRAM & Phase Change Random Access Memory \\
\hline PET & Poly(ethylene Terephthalate) \\
\hline PMC & Programmable Metallization Cells \\
\hline PMMA & Polymethyl Mechacrylate \\
\hline PVP & Polyvinylpyrrolidone \\
\hline
\end{tabular}


RGO Reduced Graphene Oxide

RRAM Resistive Random Access Memory

RS Resistive Switching

SLG Single Layer Graphene

STTM-RAM Spin Transfer Torque Magnetic Random Access Memory

ta-C tetrahedral amorphous-Carbons

TEM Transmission Electron Microscopy

TMDs Transition Metal Dichalcogenides

TMO Transition Metal Oxide

TPAPAM Triphenylamine-based Polyazomethine

VCM Valence Change Memory

ReRAM Redox Random Access Memory

XPS X-ray Photoelectron Spectroscopy

ZnONRs $\quad$ ZnO Nanorods

\section{Introduction}

The impressive technology-driven development of modern societies during the last half-a-century has been possible thanks to the creation of new electronic devices (computers, smart phones, vehicles, medical equipments), which allow performing multiple complex operations (calculations, interpolations, statistics), leading to the apparition of new services (Email, GPS, data mining) that create new jobs and. ${ }^{[1]}$ Nonvolatile memories (NVM) are essential elements in most modern electronic devices and integrated circuits, as they allow storing enormous amounts of data $\left(5.62 \times 10^{10}\right.$ Bits $\left./ \mathrm{cm}^{2}\right)^{[2]}$ in a fast $(<\mathrm{ns} / \mathrm{bit})^{[3]}$ and cheap $(\sim 0.019 \$ / \mathrm{GB})^{[4]}$ way. For this reason, the memory market has been estimated to reach 47 billion USD in $2016 .{ }^{[5]}$ The most used 
NVM device nowadays is called NAND Flash. ${ }^{[6]}$ It stores one bit of information in a capacitor (integrated in the floating gate of a field effect transistor, FET). ${ }^{[6]}$ The charge/discharge of the capacitor can be used to simulate the ones/zeros of the binary code, therefore to store information. Over the past 25 years technological advances have been linked to the scaling down of the NAND Flash memory, a process that enormously improved its size (from $2 \mu \mathrm{m}$ node in 1980 to $7 \mathrm{~nm}$ node in 2015 ), ${ }^{[7]}$ switching speed (from $1 \mathrm{MB} / \mathrm{s}$ in 1985 to $10 \mathrm{~GB} / \mathrm{s}$ in 2012 ) $^{[8]}$ and cost (from $437,500 \$ / \mathrm{GB}$ in 1980 to $0.019 \$ / G B$ in 2016). ${ }^{[4]}$ As the size approaches the nanometer range, leakage currents in the capacitor become prohibitive, leading to severe information loss. ${ }^{[9-10]}$ Therefore, in order to continue the exponential growth of information storage, new devices using non-capacitive working principles need to be developed.

According to the International Technology Roadmap for Semiconductors (ITRS), ${ }^{[2]}$ the performance requirements for any NVM technology are (see Table 1): i) low operating voltages $(<1 \mathrm{~V})$; ii) low power consumption $(\sim 10 \mathrm{pJ}$ per state transition); iii) high operation speed ( $<10 \mathrm{~ns} /$ transition); iv) high endurance $>10^{9}$ cycles. This is defined as the number of times a NVM can be switched on/off before one of the states becomes irreversible; $\left.{ }^{[2]} v\right)$ long state retention time $>10$ years $\left(>310^{8}\right.$ s). This is defined as the time before the state is lost (i.e. a state change without the application of any electrical stress happens); ${ }^{[2]}$ vi) small size below $600 \mathrm{~nm}^{2}$ (this refers to the cell that stores 1 bit of information, not the whole NVM); vii) good integration, with a capacity density larger than $10^{11} \mathrm{bits} / \mathrm{cm}^{2}$; and viii) simple structure, which usually brings associated low fabrication costs. Several new memory concepts are being developed to achieve these targets, ${ }^{[1-2]}$ including dynamic RAM (DRAM), ${ }^{[11-12]}$, ferroelectric RAM, ${ }^{[13-14]}$ phase change RAM (PCRAM), ${ }^{[15-16]}$ magnetoresistive RAM (MRAM), ${ }^{[17-18]}$ resistive RAM (RRAM), ${ }^{[19-20]}$ conductive bridge RAM, ${ }^{[21-22]}$ 
carbon nanotube RAM, ${ }^{[23-24]}$ spin transfer torque magnetic RAM (STTM-RAM), ${ }^{[25-}$ ${ }^{26]}$ molecular memories, ${ }^{[27-28]}$ and Mott memories. ${ }^{[29-30]}$ A comparative review of the different technologies being considered for future information storage can be found in Ref. ${ }^{[1]}$ Until now the RRAM has shown the most advanced performances (see Table 1). ${ }^{[2,31-33]}$

RRAM is a simple and industry-compatible structure formed by a matrix of metal/insulator/metal (MIM) nanojunctions,${ }^{[34]}$ in which the sandwiched dielectric enables reversible electrical resistance changes (see Fig. 1). This phenomenon, called resistive switching (RS), ${ }^{[34]}$ can be used to induce two logic states: the high resistance state (HRS) and the low resistance state (LRS). ${ }^{[35]}$ Cyclic transitions between these two resistive states can also be used to simulate the ones and zeros of the binary code, without the need of a capacitor, making possible the storage of digital information. ${ }^{[36]}$ Before stable cycling between HRS and LRS can be achieved (i.e. 50 electrical pulses applied to the MIM cell produce 50 state changes without resistance mismatch), most RRAMs require a one-time activation process called forming. ${ }^{[34]}$ This is defined as the first generation of a reversible dielectric breakdown (BD) in the insulator. ${ }^{[2]}$ The RS phenomenon can be classified in: i) unipolar/bipolar if the electrical stresses that produce the state change are of the same/opposed polarity; ${ }^{[37]}$ and ii) local/distributed if the atomic rearrangements that produce the state change take place at few/most locations within the area under stress. ${ }^{[36,38]}$

State of the art RRAMs use transition metal oxides (TMO) as insulator, including $\mathrm{HfO}_{2},{ }^{[39-42]} \mathrm{Al}_{2} \mathrm{O}_{3},{ }^{[43-46]} \mathrm{TiO}_{2}{ }^{[47-50]}$ and $\mathrm{TaO}_{\mathrm{X}} \cdot{ }^{[51-52]}$ In these cells the $\mathrm{RS}$ is related to the formation and dissolution of a nanosized conductive filament (CF) across the insulator, ${ }^{[35]}$ leading to an effective connection/separation of the two electrodes. In this case the RS is a local phenomenon. The physical mechanisms inducing the 
formation/dissolution of the CF depend on the materials that compose the MIM cell (not only the insulator, but also the metal), ${ }^{[53]}$ and it is thought that mainly two phenomena are predominant. ${ }^{[54-58]}$ The first is the movement of oxygen vacancies in the TMO as a consequence of the applied field, leaving behind an oxygen-free metallic path. ${ }^{[54]}$ These devices have been called valence change memories (VCM $)^{[55]}$ and/or redox random access memory $(\mathrm{ReRAM})^{[56]}$. And the second is the generation of a CF made of metallic ions from the adjacent electrodes, which can penetrate into the dielectric when the MIM structure is polarized; ${ }^{[57]}$ these devices are called electrochemical metallization (ECM) memories, ${ }^{[55]}$ programmable metallization cells $(\mathrm{PMC})^{[58]}$ and/or conductive bridge random access memory (CBRAM) ${ }^{[59]}$, even though all these names refer to the same device structure.

Over the last decade many RRAM prototypes with different characteristics have been reported. ${ }^{[39-52]}$ Amongst them, the most remarkable performances are: $i$ ) Ultra fast $(<20 \mathrm{~ns})$ logic state transitions; ${ }^{[31-32,44-45,60]}$ the reset (LRS-to-HRS transition) process is usually much slower (60 ns) than the set (HRS-to-LRS transition) one. ${ }^{[61-62]}$ Ref. $^{[32]}$ achieved sub-nanosecond (300 ps) set/reset transitions in $\mathrm{HfO}_{\mathrm{X}}$-based RRAMs. ii) Energy consumption per state transition as small as $0.1 \mathrm{pJ},{ }^{[31,44]}$ lower than that of other technologies, such as PCRAM ${ }^{[63]}$ and MRAM. ${ }^{[64]}$ iii) Long cycling endurance up to $10^{12}$ cycles. Ref. ${ }^{[33]}$ achieved $10^{12}$ cycles using $\mathrm{Ta}_{2} \mathrm{O}_{5-\mathrm{X}} / \mathrm{TaO}_{2-\mathrm{X}}$ bilayer structures coupled with Pt electrodes. iv) Long data retention. ${ }^{[46]}$ Ref. ${ }^{[65]}$ indicated that RRAMs can retain the resistive state even at high temperatures (up to $200{ }^{\circ} \mathrm{C}$ ). v) As the switching takes place though nanosale $\mathrm{CFs}^{[35]}$ the area of the cell is just limited by the area of the CF (typically tens $\mathrm{nm}) .{ }^{[31]}$ E.g., Ref. ${ }^{[31]}$ reported a $10 \mathrm{~nm} \times 10 \mathrm{~nm}$ TiN/Hf/HfOX/TiN RRAM with fast ns-range on/off switching times at low-voltages below $3 \mathrm{~V}$, switching energy $<0.1 \mathrm{pJ} /$ bit, excellent endurance $>5 \times 10^{7}$ cycles, current 
on/off ratios $\left(\mathrm{I}_{\mathrm{ON}} / \mathrm{I}_{\mathrm{OFF}}\right)>50$. The devices also showed $30 \mathrm{~h}$ retention at $200{ }^{\circ} \mathrm{C}$. $\mathrm{RS}$ has been observed in even smaller areas $\left(\sim 10 \mathrm{~nm}^{2}\right)$ using the tip of a conductive atomic force microscope $(\mathrm{CAFM}) ;{ }^{[35]}$ vi) Simple fabrication process, as the structure basically consists of a capacitor. The materials that form the RRAM have been used in the complementary metal oxide semiconductor (CMOS) technology for years. This favours their three dimensional integration. ${ }^{[66]}$ RRAM have also shown potential multi bit storage per unit cell, ${ }^{[43,67]}$ highly desired for future NVM technologies. ${ }^{[2]}$

All these performances, which can be found summarized in Table 1, have been observed in RRAMs made of different materials (e.g. TaOx provides the highest endurance, $\mathrm{HfO}_{\mathrm{X}}$ the fastest transitions and lowest power consumption), but no single RRAM device has yet shown all NVM technology requirements simultaneously. ${ }^{[1-2]}$ The most critical tradeoffs in RRAM technology are speed-retention, power-speed and endurance-retention. ${ }^{[1]}$ Crossbar Inc. ${ }^{[68]}$ claimed the development of RRAMs covering all these capabilities, but no details about the composition of the core cell have been revealed to date. ITRI $,{ }^{[65]} \mathrm{NEC},{ }^{[69]}$ and Fujitsu ${ }^{[70]}$ have also announced similar devices, with no commercial device yet available. Panasonic has commercialized the MN101L RRAM Embedded 8-bit microcontroler unit, ${ }^{[71]}$ Adesto is distributing their Mavriq 45 nm CBRAM, ${ }^{[72]}$ and Nantero developed a RRAM memory using MIM cells integrated on CNTs, but their use is still limited to few applications (mainly sensors). ${ }^{[73]}$ More information about commercial RRAMs can be found in Ref. ${ }^{[1]}$

Despite these developments, reliability issues (endurance, retention) and variability (cycle-to-cycle and device-to-device) of essential parameters like set/reset voltages (among others), as well as the understanding of failure mechanisms are still hindering RRAM large scale manufacturing. ${ }^{[1-2]}$ Therefore, the reproducibility and uniformity of RS in RRAMs still remains an area of active research, with the need to 
optimize the materials that form MIM cells.

One promising approach consists in replacing the metallic and/or insulating films of the MIM structures by novel materials with enhanced capabilities which, at the same time, could provide new features to the devices, such as transparency and flexibility. ${ }^{[74-75]}$ Along these lines, graphene and related materials (GRMs) are at the centre of an ever increasing research area due to their unique electronic, ${ }^{[76]}$ physical, ${ }^{[77]}$ chemical, ${ }^{[78]}$ mechanical, ${ }^{[79]}$ optical, ${ }^{[80]}$ magnetic ${ }^{[81]}$ and thermal ${ }^{[82]}$ properties. ${ }^{[83]}$ The term GRMs encompasses graphene, graphene oxide (GO), transition metal dichalcogenides (TMDs), hexagonal boron nitride ( $h$-BN), black phosphorous (BP) and any other layered material (LM) atomically thin (less than 20 layers) relative to graphene, with independency of its fabrication method, sheet size and thickness. ${ }^{[83]}$ Furthermore a variety of thin carbon films have been considered for the implementation of RRAMs, ranging from $\mathrm{sp}^{2}$ rich amorphous carbons $(\mathrm{a}-\mathrm{C}),{ }^{[84-87]}$ to $\mathrm{sp}^{3}$ rich tetrahedral amorphous carbons (ta-C). ${ }^{[88-89]}$

Here we will review the use of GRMs to build RRAMs, providing a working tool for many microelectronic engineers and materials scientists. In the following sections we describe the fabrication process of RRAM devices using GRMs (section 2), the advantages of using graphene as top/bottom electrode (section 3), the performances achieved using graphene oxides (section 4) and amorphous carbons (section 5), as well as recent observations of RS in other novel LMs, including TMDs, $h$-BN and BP, among others (section 6). The status and prospects of GRMs-based RRAM technology are discussed in section 7 .

\section{Fabrication of RRAMs using GRMs}

A detailed description of the different approaches for the preparation of GRMs 
can be found in Refs. ${ }^{[83,90]}$. The aim of this section is to emphasize which methods have been used to implement GRMs-based RRAMs, with special emphasis on those that are scalable. We also include practical information for device integration.

\subsection{Device architecture}

Different device architectures to achieve NVM using GRMs have been suggested. The first used NVM configuration based on graphene-FETs (GFETs), such as floating gate and charge-trap memories. ${ }^{[91-99]}$ RRAMs based on redox-switchable functionalized graphene nanoribbons, ${ }^{[100]}$ stripes of thin $(<10 \mathrm{~nm})$ graphitic material grown by chemical vapor deposition $(\mathrm{CVD})^{[101]}$ and graphene/metal contacts ${ }^{[103]}$ were also proposed.

The first reports using GRMs in MIM-like RRAMs did not use the vertical MIM structure, but planar configurations containing a transversal insulating nanogap. ${ }^{[101-105]}$ (see Figs. 2a and 2b). Ref. ${ }^{[103]}$ fabricated a planar device with two electrodes connected by a single layer graphene (SLG) placed on a $300 \mathrm{~nm} \mathrm{SiO}_{2} / \mathrm{Si}$ substrate by micromechanical exfoliation (MC), very similar to a single back gate GFET. ${ }^{[106]}$ By applying between 2.5 and $4 \mathrm{~V}$, the breakdown of the SLG channel (physical fracture) was induced ${ }^{[103]}$ By applying a reverse bias from 0.1 up to $5 \mathrm{~V}$, reproducible transitions between a HRS and LRS could be observed. Ref. ${ }^{[104]}$ improved this performance using 5-10 nm thick films of graphitic material (consisting of discontinuous graphene sheets grown by CVD) and reported bistability in current vs. voltage (I- $V$ ) curves with ION/IOFF up to $10^{7}$ and switching times as fast as $1 \mu$ s. Ref. ${ }^{[105]}$ further enhanced the capabilities of planar bilayer graphene (BLG) switching devices by coating a $10 \mathrm{~nm}$ layer of conducting 3-Aminopropyltriethoxysilane (APTES) molecules over the surface of the insulating region $\left(\mathrm{SiO}_{\mathrm{X}}\right)$. Nevertheless, the difficulty in controlling the size of the 
nanogap ${ }^{[104-106]}$ and the probably large device-to-device variability (statistical information has never been reported), made most works concentrate on the vertical MIM-like RRAMs (like that shown in Fig. 2b), which is by far the most widespread and competitive device architecture developed until now for RS-based NVMs. ${ }^{[107-112]}$

The core cell of state-of-the-art RRAMs consist of a matrix of vertically aligned MIM structures ${ }^{[34-35]}$ (see Fig. 2b). These can be fabricated by sequentially depositing each material on a desired substrate, using standard industrial processes such as atomic layer deposition (ALD), ${ }^{[113]}$ sputtering ${ }^{[107]}$ and/or electron-beam evaporation. ${ }^{[114]}$ GRMs can be used in multiple parts of RRAMs (see Figs. 2c-2f): i) replacing one/all layers in the MIM structure, leading to alternative configurations such as, e.g., graphene/insulator/graphene (GIG) or metal/ $h$-BN/metal structures; and $i i)$ introducing one/few additional GRM layer/s within the standard MIM cell, leading to MGIM, MIGM, MGIGM, GMIM, MIMG and GMIMG (where $G$ denotes a generic GRM). Another possible configuration is the MIGIM structure, in which the GRM is used for charge trapping purposes ${ }^{[115-116]}$ (see Fig. $2 \mathrm{~g}$ ). In all cases, the goal is to improve the NVM performance (i.e. switching speed, retention time, endurance, power consumption) as well as to provide the device with some of the genuine properties of the GRM (i.e. transparency ${ }^{[74]}$ and flexibility; ${ }^{[75]}$ enhanced thermal heat dissipation, ${ }^{[117]}$ and chemical stability has been achieved using GRMs in other devices like FETs, ${ }^{[18]}$ meaning that these properties may be also achieved in RRAMs).

\subsection{Insertion of GRMs in the RRAM structure}

The main challenge associated to the fabrication of vertical RRAMs using GRMs is that the GRM cannot be introduced in the MIM structure using the conventional fabrication tools above mentioned. First, a large portion of the reports on 
GRMs used non-scalable techniques, like MC. ${ }^{[119-120]}$ MC can produce flakes with a very low amount of defects, ${ }^{[121-122]}$ but this is not industrially scalable yet. This strongly limits its application in RRAMs, and only allows RS studies using local techniques, such as CAFM. ${ }^{[124]}$ Industrially scalable GRM production methodologies, ${ }^{[83]}$ such as liquid phase exfoliation (LPE) ${ }^{[83,90,124]}$ and CVD ${ }^{[90,124-125]}$ are now available, and are the most used for the fabrication of RRAMs. ${ }^{[126-129]}$

LPE gives GRMs flakes of different sizes and thicknesses (with sizes typically below $1 \mu \mathrm{m}$ in diameter and 1-20 layers thick) ${ }^{[83,90,124,130]}$. They have been introduced in RRAMs by drop casting, ${ }^{[131]}$ spin coating, ${ }^{[132]}$ or ink-jet printing, ${ }^{[133]}$ which leads to 15-500 nm thick films. ${ }^{[126-129]}$ LPE is cheap and scalable, ${ }^{[83]}$ but the rough surface of the samples obtained by this method (typically RMS $>20 \mathrm{~nm})^{[134]}$ may be an important source of variability, ${ }^{[135-137]}$ which is one of the main concerns of RRAM technology. ${ }^{[1]}$ The lack of variability analyses in all LPE based-RRAM reports published to date ${ }^{[138-141]}$ indicates the need of further studies.

CVD is the most widely used technology to produce GRMs for electronic devices, as it allows wafer scale production. ${ }^{[83]}$ GRMs can be grown by CVD on different substrates. In the case of SLG, metals with low carbon solubility and catalytic activity (such as $\mathrm{Cu}, \mathrm{Ir}, \mathrm{Co}, \mathrm{Ni}$ ) are necessary. ${ }^{[142-144]}$ Some reports claim direct CVD growth on $\mathrm{SiO}_{2}{ }^{[145-147]}$. For $\mathrm{MoS}_{2},{ }^{[148-152]} \mathrm{TiS}_{2},{ }^{[153]} \mathrm{TaS}_{2},{ }^{[154]} \mathrm{WS}_{2},{ }^{[155]}, \mathrm{MoSe}_{2}{ }^{[156-157]}$ and $\mathrm{WSe}_{2}{ }^{[158]}$ direct CVD growth on insulating substrates like $\mathrm{SiO}_{2}$ and $\mathrm{Al}_{2} \mathrm{O}_{3}$ is preferred because their lattice constants offer a good match to that of the GRM. ${ }^{[148-158]}$ CVD-growth of $h$-BN was also reported on $\mathrm{Cu},{ }^{[159]} \mathrm{Fe},{ }^{[160]}$ and $\mathrm{Pt} .{ }^{[161]} \mathrm{Ref}^{[162]}$ reported the CVD growth of BP on a Si substrate using a red phosphorous powder source.

When working with insulating GRMs (like $h$-BN) grown by CVD, the metallic substrate used for the CVD growth can be used as bottom electrode. ${ }^{[163]}$ This facilitates 
the fabrication of the RRAM device, and the top electrode can be then deposited by photolithography or shadow mask, plus metal evaporation. However, the underlying metal can have large roughness $(\mathrm{RMS} \sim 30 \mathrm{~nm})^{[164]}$ due to the polycrystallization suffered during the CVD growth at high temperatures, usually not below $800^{\circ} \mathrm{C} .{ }^{[142-}$ 144,148-152] Therefore, the growth of insulating GRMs on ultra-flat metal-coated wafers is of utmost importance to avoid roughness-induced variability, as well as to offer better integration with the industry. In general, the thermal budget may be an issue for the fabrication of GRMs-based RRAMs. On the contrary, when working with conductive GRMs (like graphene), the metallic substrate used during the CVD growth is a burden for RRAM fabrication because sometimes the presence of the GRM is required on substrates that are not favourable for its CVD growth, e.g. $\mathrm{HfO}_{2}$ and other TMOs). ${ }^{[106]}$ One approach is to transfer the GRM on the desired substrate using polymer scaffolds, being polymethyl mechacrylate (PMMA) the most commonly used. ${ }^{[83,90,165-167]}$ The problems associated with this technique are: i) local physical breakdown of the GRM, ${ }^{[168-169]}$ producing cracks within its area, which may locally alter the properties of the devices. ${ }^{[170-171]}$ E.g., a MGIM device in which the GRM contains holes may lead to local MIM structures; and ii) polymer residuals on the GRM surface. Although this may not produce the failure of the device, since the polymer is insulating, this can be understood as a decrease of the effective area of the MIM device (capacitor). The introduction of annealing processes $\left(\right.$ at $\left.\sim 300^{\circ} \mathrm{C}\right){ }^{[172]}$ may contribute to the removal of these impurities, but may produce the polycrystallization of TMOs in the RRAM (if any), leading to unwanted inhomogeneities and thickness fluctuations. ${ }^{[135-137]}$ Polymerfree transfer techniques, such as electrostatic graphene/substrate attraction can be used, ${ }^{[173]}$ but this may increase the complexity of the process. ${ }^{[174-175]}$

Other methodologies to grow GRMs are physical vapour deposition, ${ }^{[176]}$ growth 
on $\mathrm{SiC},{ }^{[177]}$ and hydrothermal method ${ }^{[178]}$ but, to the best of our knowledge, their use in the RRAM technology has not been reported yet.

The deposition of insulators on GRMs is also problematic. According to Ref. ${ }^{[179]}$ TMOs cannot be deposited directly by atomic layer deposition (ALD) on defectfree SLG, due to the lack of dangling bonds or functional groups. Ref. ${ }^{[180]}$ observed that, when trying to grow $\mathrm{HfO}_{2}$ by $\mathrm{ALD}$ on $\mathrm{MoS}_{2}, \mathrm{HfO}_{2}$ did not form a homogeneous film, but islands on the $\mathrm{MoS}_{2}$ surface, probably located at $\mathrm{MoS}_{2}$ defects (where there are dangling bonds that allow $\mathrm{HfO}_{2}$ agglutination). ${ }^{[181]}$ One possible approach is the functionalization of the GRM surface, ${ }^{[182-185]}$ which may enhance the homogeneity of the TMO film at the interface. The most common strategies to achieve a uniform SLG/high-k interface are: functionalization with $\mathrm{NO}_{2},{ }^{[182]}$ metal seed layer, ${ }^{[183]}$ organic seed layers ${ }^{[184]}$ and ozone $\left(\mathrm{O}_{3}\right) .{ }^{[182-184]}$ An interesting method to generate a SLG$\mathrm{TiO}_{\mathrm{x}} / \mathrm{Al}_{2} \mathrm{O}_{3} / \mathrm{TiO}_{2}-\mathrm{SLG}$ cell was proposed in Ref. ${ }^{[185]} \mathrm{A}$ seed Ti layer was first deposited on the bottom SLG electrode by e-beam evaporation and then oxidized to $\mathrm{TiO}_{\mathrm{x}}$ in air. Then the $\mathrm{Al}_{2} \mathrm{O}_{3} / \mathrm{TiO}_{2}$ stack was deposited by $\mathrm{ALD}$, and the top SLG electrode was transferred. Another similar GIG device was fabricated in Ref. ${ }^{[186]}$ by depositing a bilayer insulating film made of $\mathrm{Ta}_{2} \mathrm{O}_{5-\mathrm{x}} / \mathrm{TaO}_{\mathrm{y}}$ on a CVD-SLG using radio-frequency and reactive sputtering (respectively), followed by another CVD-SLG transfer.

For devices designed to be tested in a probe station, the use of top metallic electrodes is unavoidable, as placing the large tip on a SLG top electrode may damage it. Therefore, the GI interface is in fact a MGI. One method able to measure the SLG electrodes without the need of metal deposition is the use of CAFM, which controls very accurately the tip/sample contact force and does not damage the GRM surface. ${ }^{[187]}$ CAFM can also allow the investigation of ultra scaled RRAMs. ${ }^{[35]}$

\section{Use of graphene as top/bottom electrode}




\subsection{Transparency}

One motivation for using graphene in electronic devices is to provide them with flexibility ${ }^{[75]}$ and transparency. ${ }^{[74]}$ For transparent devices, indium tin oxide (ITO) has been traditionally the most preferred electrode material, ${ }^{[188-190]}$ but its brittle nature makes it unsuitable for flexible/foldable devices. One alternative is using organic materials, such as conductive polymers, ${ }^{[191]}$ but in this case the NVM performance (i.e. retention times of just $10^{4} \mathrm{~s}$ and endurance below 100 cycles) are usually much lower than the state-of-the-art TMO-based RRAMs. ${ }^{[1,31-33]}$

Ref. ${ }^{[192]}$ fabricated transparent MLG/Dy2 $\mathrm{O}_{3} /$ ITO structures by transfer of CVDgrown multilayer graphene (MLG) patterned in a subsequent photolithography step. The devices showed forming-free unipolar RS with $\mathrm{I}_{\mathrm{ON}} / \mathrm{I}_{\mathrm{OFF}} \sim 10^{5}$, low set and reset voltages ( 0.4 and $0.2 \mathrm{~V}$ respectively), endurance $>100$ cycles, retention time $>10^{4} \mathrm{~s}$ and typical switching power and speed of $4.4 \mu \mathrm{W}$ and $60 \mathrm{~ns}$. Furthermore, the devices showed a transparency $\sim 80 \%$. The performance as RRAMs of these devices overcomes that of other graphene-free cells, such as ITO/ZnO/ITO, ${ }^{[188]}$ ITO/AlN/ITO, ${ }^{[189]}$ ITO $/ \mathrm{Gd}_{2} \mathrm{O}_{3} / \mathrm{ITO},{ }^{[190]}$ and other transparent prototypes like Ga-doped ZnO.${ }^{[193]}$ Ref. $^{[105]}$ further improved the optical performance by building $\mathrm{BLG} / \mathrm{SiO}_{\mathrm{X}} / \mathrm{BLG}$ structures, with a transmittance $>90 \%$ (see Figs. 3a-3c). Ref. ${ }^{[7]}$ also achieved good RRAM functionality with an overall light absorptance $<25 \%$ in devices made of ITO/SLG/ZnO/ITO, which also showed better RS uniformity than its graphene-free counterparts. Ref. ${ }^{[75]}$ used MLG with a transmittance up to $92 \%$ to fabricate a flexible organic memory device. The characteristics of transparent and flexible graphene-based RRAM devices found in the literature are summarized in Table 2. Coupling graphene electrodes with organic RS media seems to provide the highest transparency $\sim 92 \%,{ }^{[194]}$ maintaining high $\mathrm{I}_{\mathrm{ON}} / \mathrm{I}_{\mathrm{OFF}} \sim 10^{6}$ and long retention $\sim 10^{4} \mathrm{~s}$. All graphene based 
transparent devices were fabricated by CVD plus transfer (see Table 2).

\subsection{Flexibility}

Graphene can be used to increase the flexibility of RRAM cells. Ref. ${ }^{[105]}$ reported $\mathrm{BLG} / \mathrm{SiO}_{\mathrm{X}} / \mathrm{BLG}$ cells with no $\mathrm{RS}$ degradation after bending $>300$ times at a bending radius $\left(\mathrm{r}_{\mathrm{b}}\right) \sim 1.2 \mathrm{~cm}$ (see Fig. 3d). Ref. ${ }^{[195]}$ presented a flexible organic device based on SLG sandwiched by two insulating poly(ethylene terephthalate) polymer (PET) layers. ${ }^{[195]} \mathrm{A}$ Ni/PMMA/SLG/PMMA/ITO/PET cell fabricated by transferring a CVD-SLG and spin-coating the PMMA layers. In this case SLG was used as a charge storage medium. The electric measurements indicate a good memory performance including endurance $>1.5 \times 10^{5}$ cycles, $\mathrm{IoN}_{\mathrm{ON}} / \mathrm{I}_{\mathrm{OFF}}>10^{6}$, and retention time $>1 \times 10^{5} \mathrm{~s}$. Especially significant was the lack of interference observed for scaled-down devices with SLG, as well as the ability of the devices to maintain similar switching characteristics (set/reset voltages and $\left.\mathrm{ION}_{\mathrm{ON}} / \mathrm{I}_{\mathrm{OFF}}\right)$ even after being bent $\left(\mathrm{r}_{\mathrm{b}} \sim 1 \mathrm{~cm}\right)$ over 1.5 $\times 10^{5}$ times. Ref. ${ }^{[75]}$ designed $8 \times 8$ cross-bar array-type flexible organic RRAMs on PET using MLG electrodes coupled with two different active layers: one polyimide and the other 6-phenyl- $\mathrm{C}_{61}$ butyric acid methyl ester (PCBM). Typical write-once-readmany characteristics and high Ion/IOFF up to $10^{6}$ were achieved; for $>1000$ mechanical cycles ( $\mathrm{r}_{\mathrm{b}}$ between 4.2 and $27 \mathrm{~mm}$ ) the devices maintained a retention time $>10^{4} \mathrm{~s}$ with $<12.5 \%$ resistance fluctuations in both HRS and LRS. ${ }^{[75]}$ Comparing the RS performance of all flexible RRAMs exposed to mechanical stresses is complex because these may have been applied using different bending radius and times. The influence of the bending time in flexible RRAM was not reported to date, while most works report $\mathrm{r}_{\mathrm{b}}{ }^{[75,105,195-196]}$ Smaller $\mathrm{r}_{\mathrm{b}}$ should produce more damage to the devices, as they introduce higher stresses. Therefore, from Table 2 it can be concluded that the RRAMs with the 
best performance under bending are those in Ref. ${ }^{[195]}$

\subsection{Blocking layer for atomic diffusion}

The most common electrode materials in RRAMs are $\mathrm{Al}, \mathrm{Pt}, \mathrm{Au}, \mathrm{Cu}$, Ti and Ni. ${ }^{[197-202]}$ These not only serve as contacts, but they play an essential role on the physics, ${ }^{[53]}$ kinetics ${ }^{[202]}$ and statistical distribution ${ }^{[203-204]}$ of the RS. E.g., different metallic electrodes can alter the number of CFs in the RS media, which has an impact on the shape (sharp or progressive) of the reset process, among others. ${ }^{[53]}$ One strategy to tune the switching characteristics of RRAMs is the use of active metal electrodes (like Ti or $\mathrm{Zr}$ ) that can interact with the species from the insulator. E.g. in $\mathrm{Pt} / \mathrm{Ti} / \mathrm{HfO}_{2} / \mathrm{Pt}$ cells ${ }^{[205-207]}$ oxygen atoms from the $\mathrm{HfO}_{2}$ layer can interact with the Ti electrode. This allows the observation of bipolar RS thanks to the movement of oxygen in-and-out of the $\mathrm{HfO}_{2}$ film, forming an $\mathrm{O}$-vacancies based $\mathrm{CF}$ with the narrower end at the cathode side. ${ }^{[206]}$ On the contrary, in $\mathrm{Pt} / \mathrm{HfO}_{2} / \mathrm{Pt}$ devices ${ }^{[205-207]}$ the O-vacancies movement towards the electrode is difficult, generating a CF that can only be disrupted by applying large currents, ${ }^{[205-206]}$ which melt the filament by Joule effect. ${ }^{[208]}$ In this case, the forming event is sharper, which leads to a higher $\mathrm{ION} / \mathrm{IOFF} \sim 10^{4}$ for $\mathrm{Pt} / \mathrm{HfO}_{2} / \mathrm{Pt}$ instead of $\sim 12$ for $\mathrm{Pt} / \mathrm{Ti} / \mathrm{HfO}_{2} / \mathrm{Pt}$, but the endurance may be worse due to the generation of avalanche current, ${ }^{[209]} \mathrm{BD}$ spot propagation, ${ }^{[210]}$ thermal heat, ${ }^{[211]}$ insulator contamination by metal migration $^{[212]}$ and dielectric breakdown induced epitaxy ${ }^{[213]}$. Comparing the performance of $\mathrm{Pt} / \mathrm{Ti} / \mathrm{HfO}_{2} / \mathrm{Pt}$ and $\mathrm{Pt} / \mathrm{HfO}_{2} / \mathrm{Pt}$ cells Refs. [205-217] observed that, while the LRS currents in Ti-free devices were linear and the filament was symmetric, those including inserted $\mathrm{Ti}$ layers drove exponential currents representative of partially formed conical filaments, with the narrower end at the $\mathrm{HfO}_{2} / \mathrm{Ti}$ interface. This was confirmed by fitting the experimental $I-V$ curves to the 
Quantum Point Contact model. ${ }^{[214]}$ Moreover, at larger electrical fields, the movement of metallic ions may also be activated, allowing their penetration in the TMO and producing even larger changes in the device conductivity than the motion of oxygen vacancies. ${ }^{[40]}$ Therefore, as SLG is impermeable ${ }^{[77,215]}$, introducing SLG between metal and insulator alters these interactions. ${ }^{[108,216]}$

Ref. ${ }^{[107]}$ observed that inserting CVD-SLG in $\mathrm{Al} / \mathrm{WO}_{3} / \mathrm{Al}$ structures stabilized the characteristics of the RRAM devices (see Figs. 4a,b), reducing the variability of the set/reset voltages and currents, as well as enhancing the endurance. In the SLG-free cells, when positive bias is applied to the top electrode, oxygen ions from the $\mathrm{Al} / \mathrm{WO}_{3}$ interface are pushed into the oxide bulk, leading to the formation of CFs rich in oxygen vacancies (which can be charged by electrons). During the reset process, the oxygendeficient region is reoxidized. Ref. ${ }^{[107]}$ suggested that SLG blocks the diffusion of oxygen ions into the reactive Al layer, which reduces the cycle-to-cycle variability in $I$ $V$ curves. The dissolution of oxygen in SLG is very scarce and it presents a high potential barrier for oxygen diffusion. ${ }^{[56]}$ Both factors impede the diffusion of oxygen ions through SLG, avoiding the interaction with the metallic top electrode. Ref. ${ }^{\text {[217] }}$ suggested that the electric field applied during the set operation can move the oxygen ions towards the metal/oxide interface, but they cannot penetrate into the Ti electrode due to the presence of the interfacial SLG (see Fig. 4c). At most, the oxygen ions could form covalent bonds with the SLG defects (missing atoms and/or dangling bonds $\left.{ }^{[185,217]}\right)$, leading to a p-type doping that can be released during the reset transition. However, Ref. ${ }^{[55]}$ reported the migration of metallic ions from the electrode into the dielectric in ECMs, even with the presence of interfacial SLG. Ref. ${ }^{[5]}$ reported that, in ECM cells based on $\mathrm{Ta} / \mathrm{SLG} / \mathrm{TaO}_{\mathrm{X}} / \mathrm{Pt}$ stacks, the switching is influenced by the formation of Ta ions and their interaction with the $\mathrm{TaO}_{\mathrm{X}}$ active layer. Nevertheless, Ref. 
${ }^{[55]}$ used large device areas ranging between $25 \times 25$ and $1000 \times 1000 \mu \mathrm{m}^{2}$. The presence of cracks and leaky grain boundaries is something usual in CVD-grown and transferred $\mathrm{SLG}^{[218]}$, thus MLG may provide a better protection than SLG.

\subsection{Lowering power consumption}

The out-of-plane SLG contact resistance is larger than that of metallic electrodes, ${ }^{[219]}$ which can be used to reduce the currents in both resistive states of the RRAMs, lowering power consumption. Ref. ${ }^{[217]}$ analyzed bipolar $\mathrm{RS}$ in TiN/Ti/SLG/HfO $\mathrm{X} / \mathrm{Pt}$ RRAMs. The cyclic voltammograms obtained indicated a reduction of the reset current by a factor $\sim 11$ compared to the SLG-free device (Fig. 5a), further corroborated using cumulative probability plots. Despite this improvement, the plots indicate that the HRS currents under positive polarity for the SLG-based devices increase, which is an unwanted effect. Ref. ${ }^{[217]}$ pointed out that comparisons between SLG-based and SLG-free cells using similar current limitations (CL, defined as the threshold current used during the forming/set processes to limit the BD truculence) were not reliable due to the low endurance of SLG-free cells at such low $(100 \mu \mathrm{A})$ current levels. To solve this problem, Ref. ${ }^{[217]}$ compared the typical RS cycles using the optimal CL for each cell $(10 \mu \mathrm{A}$ for the SLG-based cell and $100 \mu \mathrm{A}$ for the SLG-free one), understanding suitable as the one that produces a lower cycle-to-cycle variability (Fig. 5b), and concluded that: i) The CLneeded to stabilize RS in the SLG-based device is lower, which from the power consumption point of view is an advantage. Despite the current in HRS being the same, the LRS current was reduced more than one order of magnitude. This implies that, when the filament is completely formed in LRS, its size (diameter) is much smaller using SLG-based electrodes. ii) The reduction of LRS current reduces ION/IOFF. iii) SLG avoids current overshoot during the set process, which 
also reduces the maximum current during the reset transition $\left(I_{R E S E T}\right)$ : in the SLG-based RRAM, $I_{R E S E T}$ was half CL, while in SLG-free, $I_{R E S E T}$ was 2-3 times larger than CL (see Fig. 5b).

Ref. ${ }^{[98]}$ fabricated a Pt/Ti/TiO $/$ /SLG RRAM and reported similar results as Ref. ${ }^{[217]}$ (Fig. 5c). I IN/ $\mathrm{I}_{\mathrm{OFF}}$ as well as both HRS and LRS currents were reduced. Therefore, from Refs. ${ }^{[98,217]}$, SLG helps to stabilize RS at lower CLs, which reduces the reset current (probably due to the formation of narrower CFs) and the overall power consumption.

Ref. $^{[55]}$ also observed that lower CLs $(10 \mu \mathrm{A})$ stabilize $\mathrm{Pt} / \mathrm{Ta} / \mathrm{SLG} / \mathrm{TaO} / \mathrm{Pt}$ RRAMs (Fig. 5d), producing an increase of the on the reset current and Ion/IOFF in the SLG-based cell (compared to SLG-free). These results are surprising because the CL used for the SLG-based cells was smaller, and it is usual for the reset to take place at currents similar to CL in all kinds of RRAMs (including ECMs, VCMs) ${ }^{[55]}$ Indeed, Fig. $5 \mathrm{~d}$ shows a current overshoot. We cannot tell how reproducible these observations are because, unlike Ref. ${ }^{[217]}$, Ref. ${ }^{[55]}$ did not include the evolution with the number of cycles. On the other hand, Ref. ${ }^{[217]}$ observed reset currents smaller than CL in SLGbased devices. More work is thus necessary to confirm these observations.

\subsection{Suppression of surface effects}

Most devices based on TMOs are influenced by surface effects, ${ }^{[220]}$ including surface band bending, ${ }^{[221]}$ chemisorption/photodesorption, ${ }^{[22]}$ and surface roughness. ${ }^{[223]}$ The barrier for species diffusion provided by SLG was used by several groups. E.g., Ref. ${ }^{[74]}$ inserted SLG into an ITO/ZnO/ITO stack to explore the device performance variation under different atmospheres (see Fig. 6). $\mathrm{O}^{2-}$ chemisorption happened at the top surface of the MIM structures (in contact with the environment), 
resulting in defects associated to the oxygen partial pressure. Due to oxygen ion chemisorption, the partial pressure of oxygen can influence the TMOs electrical properties, as more $\mathrm{O}_{2}$ molecules are chemisorbed with increased partial pressure. ${ }^{\text {[224- }}$ 227] $\mathrm{O}_{2}$ molecules are absorbed at the TMO surface defects, ${ }^{[224]}$ such as oxygen vacancies, ${ }^{[228]}$ acting as electron acceptors to form chemisorbed oxygen ions, which will contribute to decrease the conductivity of metal oxide. However, the introduction of SLG (i. e. forming an ITO/SLG/ZnO/ITO structure) protects the $\mathrm{ZnO}$ film from chemisorption of $\mathrm{O}_{2}$ molecules, avoiding the surface effect. The effect of oxygen ions chemisorption on the switching properties of RRAMs was analyzed in Ref. ${ }^{[74]}$ by comparing the resistance in HRS and LRS with and without SLG electrodes under various ambient conditions. Without SLG, HRS shifts to a higher resistance as it can interact with the atmospheric $\mathrm{O}_{2},{ }^{[224]}$ because of the oxygen ions chemisorbed induce lower conductivity near the $\mathrm{ZnO}$ surface. ${ }^{[224,226]}$ As the oxygen ions concentration increases, the surface band bending effect is more pronounced. However, with the SLG introduction at the ITO/ZnO interface the variation of HRS resistance is suppressed, ${ }^{[74]}$ and it almost completely decouples the average variation of the HRS resistance from atmospheric conditions. ${ }^{[74]}$ This improves device reliability, such as endurance $>10^{2}$ cycles and retention time $>10^{4} \mathrm{~s}$.

\subsection{Functionalization of graphene electrodes}

Different functionalization strategies can be followed to achieve specific performances. E.g., SLG can be used as blocking interfacial layer to avoid metal/insulator interactions. ${ }^{[229]}$ If SLG is intentionally patterned with selected amounts of holes or defects, the properties of the cell at those locations can be modified, leading to specific local phenomena, like local (instead distributed) O-vacancies scavenging. 
Ref. ${ }^{[170]}$ functionalized the SLG in a MGIM structure by using controlled $\mathrm{Ar}^{+}$ionassisted bombardment, which generated different amounts of defects, depending on the bombardment energy. ${ }^{[230]}$ By means of CAFM Ref. ${ }^{[170]}$ showed that the leakage current in functionalized samples was much more confined than in pristine ones (see Fig. 7), probably due to the larger conductivity of the SLG-free locations (i.e. the holes patterned in SLG). MGIM devices with $\mathrm{Ar}^{+}$ion bombarded SLG had smaller variability than those without in the set and reset voltages, and more stable currents in each state. ${ }^{[170]}$ This strategy was further studied in Ref. ${ }^{[171]}$ by tuning ionic transport in $\mathrm{Pd} / \mathrm{Ta} / \mathrm{SLG} / \mathrm{Ta}_{2} \mathrm{O}_{5} / \mathrm{Pd}$ RRAMs using SLG with engineered nanopores. SLG was grown by $\mathrm{CVD}$ on $\mathrm{Cu}$ and transferred with the assistance of a polymer scaffold..$^{[165-167]}$ The migration of oxygen ions in the device was controlled by opening some nanopores in SLG, which allowed to tune the properties of the devices. ${ }^{[171]}$ However, since the nanopores are patterned with e-beam lithography, the process is less scalable than that in Ref. ${ }^{[170]}$, which used ion-assisted-reaction treatment after transfer of MLG to etch residues as well as induce defects in SLG. In all, it was demonstrated that inserting a functionalized SLG in the structure of RRAM devices is a good approach to tune their properties.

Ref. ${ }^{[231]}$ reversed the manufacturing order of the RRAM stack (from $\mathrm{MLG} / \mathrm{TaO}_{\mathrm{y}} / \mathrm{Ta}_{2} \mathrm{O}_{5-\mathrm{x}} / \mathrm{MLG}$ to $\left.\mathrm{MLG} / \mathrm{Ta}_{2} \mathrm{O}_{5-\mathrm{x}} / \mathrm{TaO}_{\mathrm{y}} / \mathrm{MLG}\right)$. In this case, the conventional linear bipolar RS became highly non-linear due to the bottom MLG electrode being oxidized at $400^{\circ} \mathrm{C}$ in an $\mathrm{Ar} / \mathrm{O}_{2}$ plasma during the reactive sputtering deposition of $\mathrm{TaO}_{\mathrm{y}}$. Due to the low currents driven by these devices $(0.5 \mathrm{~mA}$ at $8 \mathrm{~V})$, they show promising application as threshold switching and/or selector elements.

Another potential advantage of SLG electrode engineering is that the Fermi energy can be controlled, which is not possible in standard MIM structures. Using this 
approach, Ref. ${ }^{[98]}$ engineered the tunnelling barrier width and height at the interface of a Pt/Ti/TiO $/ 2 / \mathrm{SLG} / \mathrm{Pt}$ RRAM device, resulting in three orders of magnitude reduction of the switching power (from $10^{-5} \mathrm{~W}$ to $10^{-2} \mathrm{~W}$ ).

\subsection{Integration}

One advantage when building NVMs using simple MIM structures is the potential for stackability and integration. One common approach ${ }^{[113,232-233]}$ consists in fabricating a nanostructured material with alternate metallic and insulating films. Then, a vertical aperture (hole) is patterned and the RS media is deposited. ${ }^{[113,232-233]}$ Finally, the rest of the hole is filled with another metal, leading to vertically aligned MIM cells in which the vertical electrode serves as common electrode, and each horizontal metallic film is the specific electrode of each (independent) MIM cell. ${ }^{[113,232]}$ In this structure the thickness of each insulating film should be high enough to avoid crosstalk noise from cell-to-cell, therefore it cannot be reduced below a safe value (in the case of $\left.\mathrm{SiO}_{2} \sim 6 \mathrm{~nm}\right) .{ }^{[113]}$ On the contrary, the thickness of the metal should be low enough to ensure good in-plane conductivity. SLG is thus a promising building block because: $i)$ it is only $0.34 \mathrm{~nm}$ thick $^{[113]}$ and its in-plane conductivity is excellent $(\sim 3,000$ $\left.\mathrm{Wm}^{-1} \mathrm{~K}^{-1}\right)$; ${ }^{[234]}$ and $i$ ) the lateral connection between SLG and the RS media provides a lower contact resistance (compared to metals). Ref. ${ }^{[235]}$ used FETs with metallic electrodes that contacted the SLG channel laterally, and observed a mobility of 140,000 $\mathrm{cm}^{2} / \mathrm{Vs}$, which is much higher than that of similar devices in which the SLG channel is connected vertically $\left(40,000 \mathrm{~cm}^{2} / \mathrm{Vs}\right),{ }^{[236]}$ and it is very close to the phonon limited model. ${ }^{[235]}$ The reason is that the in-plane bonding is covalent, while metallic electrodes deposited on top of SLG rely on weaker Van der Waals interactions. A similar methodology can be used in RRAMs, employing SLG as planar electrode contacted 
from the side (see Fig. 8). ${ }^{[113]}$ Using this principle, Ref. ${ }^{[233]}$ fabricated RRAM devices with $\mathrm{I}_{\mathrm{ON}} / \mathrm{I}_{\mathrm{OFF}}>80$, low reset currents $\sim 20 \mu \mathrm{A}$ and low set/reset voltages ( 2 to $4 \mathrm{~V}$ ).

Ref. ${ }^{[186]}$ used a similar structure consisting of SLG as edge electrode to investigate the scaling limit of RRAM integration. In this case, the RS medium was a superstructure made of $\mathrm{Ta}_{2} \mathrm{O}_{5-\mathrm{x}} / \mathrm{TaO}_{\mathrm{y}}$ and, as in Ref. ${ }^{[233]}$, SLG was grown by CVD and transferred on $\mathrm{SiO}_{2}$ by an electrochemical approach. ${ }^{[237]}$ The Pt column and SLG serve as pillar and edge electrodes respectively. As a result, SLG edge electrodes allowed a larger density of three dimensional RRAM integration.

\section{Graphene oxide based switching media for RRAM}

Even though the electrodes are a crucial elements defining the performance of RRAMs, the switching medium is the dominant one. ${ }^{[34]}$ Apart from TMOs, a wide variety of materials have been proposed as switching media in RRAMs, including organic materials, ${ }^{[238]}$ polymers, ${ }^{[239]}$ perovskites ${ }^{[240]}, \mathrm{GRMs}^{[241]}$ and amorphous carbons. ${ }^{\left[{ }^{84-89]}\right.}$ Mixture/alloys of some of them, such as polymers with high density of graphene flakes ${ }^{[195]}$ or organic polymers, ${ }^{[239]}$ were also used.

GO and reduced GO (RGO) have been widely investigated for RS applications. [132-133, 241-253] GO films consisting of interconnected flakes are typically produced by LPE and spin coated on the surface of a substrates (which serves as top electrode), with subsequent deposition of top contacts on the GO surface ${ }^{[254]}$ (see Figs. 9 and 10). This contrasts with the atomically flat CVD-SLGs, and could have implications in terms of device-to-device variability.

Ref. $^{[241]}$ prepared a GO compound by Hummers method ${ }^{[255]}$ and the resulting product was transferred onto $\mathrm{Pt} / \mathrm{Ti} / \mathrm{SiO}_{2} / \mathrm{Si}$ substrates, followed by top $\mathrm{Cu}$ electrodes evaporation. The resulting $\mathrm{Cu} / \mathrm{GO} / \mathrm{Pt}$ RRAMs contained a $30 \mathrm{~nm}$ thick $\mathrm{GO}$ film (see 
Fig. 10), which showed $\mathrm{I}_{\mathrm{ON}} / \mathrm{I}_{\mathrm{OFF}}>10$, long retention times $>10^{4} \mathrm{~s}$, and low switching threshold $<1 \mathrm{~V}$. The ability of GO to changes its electrical resistance when subjected to voltage stresses was later confirmed by in Al/GO/ITO cells. ${ }^{[249,256-257]}$ Refs. ${ }^{[126,258-}$ ${ }^{262]}$ combined a GO active layer with diverse electrode metals (Pt, Au, Al), which allowed tuning the RS characteristics of the devices. ${ }^{[126,258-262]}$

Two competing hypothesis have been proposed to interpret the bipolar switching observed in GO films. ${ }^{[242,263]}$ The first ${ }^{[242,263]}$ resembles that of ECM cells using active metallic electrodes, in which metallic ions can diffuse from the electrodes towards the GO layer, leading to the formation/dissolution of a CF. The independence of the LRS resistance with temperature and the proportionality of the currents to the electric field support this mechanism. ${ }^{[242,263]}$ An X-ray photoelectron spectroscopy (XPS) study of an $\mathrm{Al} / \mathrm{GO} / \mathrm{ITO}$ stack, detected $\mathrm{Al}$ atoms along the $\mathrm{GO}$ film when the device was working in LRS, pointing to mass transfer during the cyclic switching. ${ }^{[249]}$ The second ${ }^{[241]}$ is similar to that of homogenous VCM for inorganic materials, and suggests that absorption and desorption of oxygen functional groups could induce RS in the GO film. ${ }^{[264]}$ In most cases, GO is associated to various oxygen groups, such as carboxyl, ${ }^{[265]}$ hydroxyl, and epoxide, with their oxygen ions usually contributing to form the conduction path. ${ }^{[264-265]}$ Two states $\mathrm{sp}^{3}$ and $\mathrm{sp}^{2}$ exist in these oxygen groups, the latter has larger conductivity due to the introduction of $\pi$-electrons from the removed oxygen groups. ${ }^{[264]}$ The change of the oxygen bonding state in the GO film usually causes a variation of the leakage currents. ${ }^{[241]}$ This interpretation received partial support from e-beam-induced current profile at the GO/metal interface and XPS depth profiles of oxygen and metals in HRS and LRS, which displayed distinct oxygen bonding near the interface. ${ }^{[126,266]}$ However, the spatial distribution of the oxygen functional groups can vary in each resistive state. Furthermore, the experiments on 
devices with different sizes indicate that the current leakage is proportional to the cell size. ${ }^{[105]}$ Therefore, both results suggest that oxygen migration plays a dominant role in the switching of GO-based RRAMs. ${ }^{[241]}$

Ref. ${ }^{[267]}$ observed different switching polarities, switching modes or the absence of them depending on the active metallic electrode used ( $\mathrm{Al}, \mathrm{Cu}, \mathrm{Ni}, \mathrm{Ti})$. The switching directions are characterized by the different area, field and temperature dependences between them. Except for Ni electrodes (which did not show RS), ${ }^{[267]}$ all the other electrodes (Al, $\mathrm{Cu}$ and $\mathrm{Ti}$ ) showed bipolar switching under positive set (applied at the top electrode, bottom grounded). ${ }^{[267]} \mathrm{Ti}$ showed additional negative setting bipolar switching under negative set, and Al showed additional unipolar switching. ${ }^{[267]}$ The bipolar RS under negative set might be related to the absorption/release of oxygen based functional groups, ${ }^{[241,268]}$ while the bipolar RS under positive set may be associated to metallic ions diffusion.

The main performances shown by GO based RRAMs are compared in Table 3. The highest ION/IOFF was achieved in ITO/GO/Ag ${ }^{[242]}$ and $\mathrm{p}-\mathrm{Si} / \mathrm{GO} / \mathrm{Ag}{ }^{[247]}$ structures. The use of Ag electrodes seems to provide the lowest switching voltages ${ }^{[133,153,242,245]}$, but this contrasts Ref. ${ }^{[251]}$, which shows operating voltages $\sim 6.7 \mathrm{~V}$ (the thickness of the GO film in Ref. ${ }^{[251]}$ was $\sim 15 \mathrm{~nm}$, while in Refs. ${ }^{[133,242]}$ was not indicated). By comparing the rows 2 to 5 in Table $3,{ }^{[248]}$ it can be concluded that $\mathrm{Cu}$ electrodes provide higher Ion/Ioff than $\mathrm{Ti}, \mathrm{Ag}$ and $\mathrm{Au}$, probably due to the higher diffusivity of $\mathrm{Cu}$ atoms in the GO film, which may result in a more effective CF disruption during the reset process. It would be interesting to try $\mathrm{ITO} / \mathrm{GO} / \mathrm{Cu}$ and $\mathrm{p}-\mathrm{Si} / \mathrm{GO} / \mathrm{Ag}$ RRAM structures. The ITO/GO/Al RRAMs from Ref. ${ }^{[249]}$ show retention times $>10^{7}$, but they are still insufficient for RRAM technology (see Table 1). ${ }^{[2]}$ By comparing the ITO/GO/Al RRAMs from Ref. ${ }^{[249]}$ with the ITO/GO/Ag from Ref. ${ }^{[242]}$ it looks like Ag electrodes 
cannot provide long retention (the values are $10^{7}$ vs. $10^{3}$ ), which is consistent with the lower operation voltages for Ag electrodes. ${ }^{[133,153,242,245]}$ In any case, the long retention observed in Ref. ${ }^{[249]}$ requires further corroboration (as well as the high operating voltages observed in Ref. ${ }^{[251]}$ ). The use of semiconductor electrodes in RRAMs, e.g. $\mathrm{Si} / \mathrm{GO} / \mathrm{Al}{ }^{[250]}, \mathrm{Ge} / \mathrm{GO} / \mathrm{Al} \quad{ }^{[250]}$ and $\mathrm{p}-\mathrm{Si} / \mathrm{GO} / \mathrm{AG}^{[247]}$ show (unwanted) high operation voltages of $-5.5 \mathrm{~V},-8.7 \mathrm{~V}$ and $3.5 \mathrm{~V}$ (respectively). While $\mathrm{Si} / \mathrm{GO} / \mathrm{Al}{ }^{[250]}, \mathrm{Ge} / \mathrm{GO} / \mathrm{Al}{ }^{[250]}$ show low $\mathrm{ION}_{\mathrm{O}} / \mathrm{IOFF}_{\mathrm{OFF}}<120, \mathrm{p}-\mathrm{Si} / \mathrm{GO} / \mathrm{AG}^{[247]}$ reached $10^{4}$. Further confirmation of the results in Ref. ${ }^{[247]}$ is necessary. It is very striking that, despite all papers using spin coating resulted in thick $>10 \mathrm{~nm}$ layers, ${ }^{[241,245,249,250]}$ the endurance for all RRAMs in Table 3 is just $\sim 100$ cycles. This value, which may be related to the large amount of defects (missing bonds) in the GO film, ${ }^{[269]}$ is very far from the technology requirements for NVMs $\left(10^{9}\right.$ cycles, see Table 1$) \cdot{ }^{[2]}$ Similarly, despite all papers in Table 3 claiming that GO may be interesting for future nano RRAM devices, the RRAM sizes was $>7500 \mu \mathrm{m}^{2}$, and we are not aware of any CAFM-based RS study (like those compiled in Ref. ${ }^{[35]}$ ) in GO films. The data in Table 3 needs to be corroborated in smaller MIM cells.

The endurance can be enhanced by using RGO instead GO, as it can be observed by comparing Tables $3-4$. Ref. ${ }^{[262]}$ reported unipolar RS in ITO/RGO/ITO cells (5 $\mu \mathrm{m}$ in diameter), with endurance $>10^{5}$ cycles. The replacement of one of the ITO electrodes by $\mathrm{Au}^{[270]}$ did not alter the operation voltage $(2 \mathrm{~V})$ and retention time $\left(10^{5}\right)$, indicating that in these structures the RGO (not the electrode) plays a dominant role in the charge transport. ${ }^{[270]}$ The use of one Al electrode in conjunction with the RGO/TIO stack does not significantly alters the switching time ${ }^{[260]}$ (compared to ITO/RGO/ITO) ${ }^{[262]}$ even in much larger cells $\left(\sim 3 \mathrm{~mm}\right.$ in diameter). When both electrodes are made of $\mathrm{Al}^{[271-272]}$ the devices showed much lower $\mathrm{I}_{\mathrm{ON}} / \mathrm{I}_{\mathrm{OFF}}<100$. This observation correlates with a reduction 
of the operating voltages $(\sim 0.6 \mathrm{~V}) .^{[271-272]}$ The use of Pt electrodes shows high operation voltages $<1.9 \mathrm{~V}$ and high $\mathrm{ION}_{\mathrm{ON}} / \mathrm{IOFF}^{[273]}$ similar to those of $\mathrm{Au}$ electrodes. This is reasonable because both $\mathrm{Au}$ and $\mathrm{Pt}$ are noble metals with low reactivity with the species in the GO film. In agreement with these observations, RGO-based RRAMs using Al electrodes showed the smallest retention times. ${ }^{[260,34271,374]}$ A device with Ag electrodes showed the lowest $\mathrm{I}_{\mathrm{ON}} / \mathrm{I}_{\mathrm{OFF}}(10)$ and endurance $(100){ }^{[254]}$

GO and RGO can be combined with additional layers with the aim of further improving the performance of RRAMs. ${ }^{[194,264,275-278]}$. Prototype RRAM cells combining ZnO-graphene quantum dots (GQDs) ${ }^{[194]}$ metallic $\left(\mathrm{Ni}^{[278]}, \mathrm{Au}^{[243]}\right)$ nanoparticles and nanocrystalline cellulose/GO ${ }^{[277]}$ have been reported. Ref. ${ }^{[194]}$ introduced ZnO-GQDs as active components and demonstrated a solution-processed organic NVM array with one diode one resistor (1D1R) architecture. The switching mechanism of the $\mathrm{ZnO}-$ GQDs devices was governed by thermally activated transport before the turn-on process. ${ }^{[194]}$ The 1D1R cell showed typical unipolar switching and with low cross-talk noise. An analogous architecture of $\mathrm{ZnO}$ nanorods (ZnONRs) with GO displayed a significant reduction of the operating voltages $(2.1 \mathrm{~V})$ compared to the cell without ZnONRs (3.9V), indicating enhanced concentration of oxygen vacancies in the GO due to the incorporation of ZnONRs. ${ }^{[246]}$ Ref. ${ }^{[278]}$ used Ni-incorporated GO to fabricate RRAM devices with endurance $>100$ cycles, and Ref. ${ }^{[243]}$ combined GO with Au nanoparticles, which lead to bipolar RS with retention times $\sim 10^{4} \mathrm{~s} .{ }^{[243]}$

The combination of GO with polymers such as poly (N-vinylcarbazole) derived GO (GO-PVK), ${ }^{[275]}$ triphenylamine-based polyazomethine (TPAPAM), ${ }^{[274]}$ showed typical bistable electrical conductivity and nonvolatile rewritable memory effects, with a turn-on voltage $\sim-1 \mathrm{~V}$ and ION/IOFF $>10^{3}$. Ref. ${ }^{[264]}$ presented a RRAM-based on solution-processed $\mathrm{GO} / \mathrm{Pr}_{0.7} \mathrm{Ca}_{0.3} \mathrm{MnO}_{3}$ forming a cell of $\mathrm{Pt} / \mathrm{GO} / \mathrm{PCMO} / \mathrm{Pt}$. In this 
structure, two active layers are necessary because GO or PCMO independently sandwiched by metal electrodes cannot reach stable RS. E.g., the Pt/PCMO/Pt control sample showed no RS, ${ }^{[264]}$ due to the almost Ohmic contact between each layer, and the $I-V$ characteristics of single $\mathrm{Pt} / \mathrm{GO} / \mathrm{Pt}$ device displayed an irreversible $\mathrm{BD}$. However, the device with two active layers exhibited intrinsic and reversible bipolar RS, along with the conduction mechanisms associated to oxygen ions movement between the two active layers (see Fig. 11). Three different phases can be detected from $I-V$ characteristics collected in these devices: i) An initial linear behaviour at low voltages. ii) A sudden current increase that switches the device to LRS, probably related to the movement of oxygen ions from the GO towards the PCMO surface, which contains large amounts of oxygen vacancies compared to the bulk region. And iii) the resistance of the PCMO layer is decreased by reducing the oxygen vacancy concentration, inducing the reset and transition back to HRS. Therefore, the electrical pulses can cyclically induce HRS to LRS transitions, and vice versa.

Refs. ${ }^{[243,258]}$ reported that GO can also result in multiple stable resistive states when incorporating either polyimide ${ }^{[258]}$ The presence of more than one resistive state allows for a higher information storage density as, instead of bits, multiple digits can be stored. Up to four differentiated levels and retention times of at least $10^{4} \mathrm{~s}$ have been achieved. ${ }^{[243]}$ The performances of RRAMs using GO, RGO-polymer and mixed structures as RS media are summarized in Table 5. Outstanding performance in terms of endurance $\left(10^{8}\right.$ cycles) is achieved in Refs. ${ }^{[275-276]}$ using GO-polymer composites sandwiched by ITO-Al electrodes, which approach but not fit the NVM technology requirement $\left(10^{9}\right)$. These two cells ${ }^{[275-276]}$ also show high retention times $>10^{4} \mathrm{~s}$ and ION/IOFF $\sim 10^{3}$, being only surpassed by the RGO/P3HT:PCBM/Al structures shown in Ref. ${ }^{[279]}\left(10^{4}-10^{5}\right)$. 
GO can also provide flexibility and transparency to the devices. E.g., ITO/GO/Ag were reported as RRAMs with $\mathrm{ION} / \mathrm{I}_{\mathrm{OFF}} \sim 10^{3}$ and stable retention characteristics for $>10^{3}$ s within 1000 cycles for $r_{b}>4$ mm ${ }^{[249]}$. Ref. ${ }^{[262]}$ fabricated RGO-based RRAMs by dip-coating, and obtained $\sim 80 \%$ transparency from 425 to 900nm. These devices exhibited unipolar RS characteristics with $\mathrm{I}_{\mathrm{ON}} / \mathrm{I}_{\mathrm{OFF}}>10^{5}$, endurance $\sim 10^{5}$ cycles for each state, retention times $>10^{5} \mathrm{~s}$ and multilevel capability. The performance of flexible RRAMs using GO and RGO as RS media is summarized in Table 6. Outstanding performance $\left(\mathrm{ION} / \mathrm{IOFF}_{\mathrm{OF}}>10^{3}\right.$, retention $>10^{5} \mathrm{~s}$ and endurance $>10^{3}$ cycles) was achieved in PEN/Ti/Pt/GO/Ti/Pt RRAMs ${ }^{[280]}$ with MIM cells $\sim 100 \mathrm{~nm} \times$ $100 \mathrm{~nm}$, making these values more reliable. This is an important step towards enabling future transparent device applications based on GO and its derivatives.

\section{Amorphous carbon as switching media for RRAM}

Carbon is a very versatile element that can crystallize in forms of diamond, where it is fully $\mathrm{sp}^{3}$ bonded, or graphite, where it is fully $\mathrm{sp}^{2}$ bonded. Non-crystalline carbons are referred to as amorphous carbons. When the $\mathrm{sp}^{3}$ fraction is higher than $50 \%$, the amorphous carbon is called tetrahedral-amorphous carbon, ta-C. ${ }^{\text {[281-284] }}$.

Amorphous carbons can change resistance by applying unipolar electrical pulses or voltage sweeps. RS in amorphous carbons has led to their addition to the selection of emerging memory technologies in the 2014 ITRS. ${ }^{[2]}$ The switching mechanism, however, is still under debate. Several mechanisms have been put forward, such as $\mathrm{sp}^{2}$ clustering ${ }^{[86,285]}, \mathrm{sp}^{2}$ filament formation ${ }^{[286-289]}$, metal filament formation ${ }^{[85,290]}$ and electron trapping/detrapping ${ }^{[291]}$.

In 1972 Ref. $^{[292]}$ first reported $\mathrm{RS}$ in $10 \mathrm{~nm}$ thick evaporated a-C films sandwiched between Al electrodes, reporting 100,000 switching cycles. Ref. ${ }^{[292]}$ found 
that a forming step is needed to create a CF and activate RS. Switching only occurred by applying a positive voltage to the bottom $\mathrm{Al}$ electrode, while opposite polarity was needed for the RESET ${ }^{[292]}$. RS was attributed to metal filament formation, since $\mathrm{Al}$ is a diffusive metal and amorphous carbon produced by evaporation has usually very low $\mathrm{sp}^{3}$ content and switching in $\mathrm{sp}^{2}$ rich amorphous carbon has been found not to be reversible ${ }^{[285]}$.

Non-volatile RS in doped amorphous carbon films was demonstrated by several groups. ${ }^{[84-89,293-300]}$. This includes RS in nitrogen ${ }^{[88-89,295-296]}$, hydrogen ${ }^{\text {[84-87], }}$ oxygen ${ }^{[294,301]}$, silicon ${ }^{[302]}, \mathrm{Co}^{[297]}$ and $\mathrm{Cu}^{[298-300]}$ incorporated amorphous carbon films. Table 8 summarizes the literature RS data in doped amorphous carbons.

Refs. $^{\left[{ }^{88-89]}\right.}$ reported a reversible NVM effect in nitrogen doped tetrahedral amorphous carbon, ta-C:N, with write times down to $100 \mu \mathrm{s} .{ }^{[90]}$ They attributed the switching to the promotion of electrons from acceptor states in the gap to higher donor states. However, the LRS retention was poor, only one year, ${ }^{[90]}$ too short for commercial applications. Ref. ${ }^{[295]}$ prepared nanoporous nitrogen doped amorphous carbon and studied a $\mathrm{Pt} / \mathrm{C}: \mathrm{N} / \mathrm{Cu}$ device structure. Set and reset occurred at opposite voltage polarities. ${ }^{[295]}$ Decreasing the amount of nitrogen led to a reduction of switching voltages down to $+0.6 \mathrm{~V}$ for set and $-0.5 \mathrm{~V}$ for reset. ${ }^{[295]}$ Over 1000 switching cycles and a retention $>80$ days at room temperature were reported, still not good enough to meet industry requirements. ${ }^{[295]}$ The switching mechanism was attributed to the formation and rupture of $\mathrm{Cu}$ filaments. ${ }^{[295]}$ Ref. ${ }^{[296]}$ reported the effect of nitrogen implantation on $\mathrm{RS}$ of amorphous carbon to analyze the role of $\mathrm{sp}^{2}$ filamentation and clustering. Nitrogen implantation made the films more conductive with an increase in $\mathrm{sp}^{2}$ bonding and clustering, facilitating the SET process. ${ }^{[296]}$

Several groups reported reversible, non-volatile switching in hydrogenated 
amorphous carbon, a-C:H, [85-88], with the results summarized in Table 7. RESET within 30ns and SET in $\sim 30 \mathrm{~ns}$ were reported, ${ }^{[86]}$ long data retention $>10^{5} \mathrm{~s},{ }^{[85]} 10^{7}$ switching cycles ${ }^{[87]}$ and IoN/IOFF $\sim 10^{3} .{ }^{[86]}$ The RS mechanism was attributed to different processes: Ref. ${ }^{[85]}$ assigned $\mathrm{RS}$ in $\mathrm{Pt} / \mathrm{a}-\mathrm{C}: \mathrm{H} /$ metal structures, with the metal top electrode being $\mathrm{Cu}, \mathrm{Ag}$ or $\mathrm{Au}$, to the formation and rupture of metal filaments, due to diffusion of the top electrode metal into the a-C:H film. ${ }^{[85]}$ Ref. ${ }^{[86]}$ studied RS in a-C:H with TiN as bottom and $\mathrm{Cu}$, Pt or $\mathrm{W}$ as top electrodes, and assigned RS to thermally induced conductive $\mathrm{sp}^{2}$ clusters filament formation. ${ }^{[86]}$ Ref. ${ }^{[87]}$ attributed the switching to a $\mathrm{sp}^{2}$ carbon $\mathrm{CF}$ formation in a TiN/a-C:H/Pt structure. RESET was achieved by applying the opposite voltage polarity to the bottom TiN electrode and attributed to hydrogen atoms pulled from the Pt top electrode and absorbed by double bonds in $\mathrm{sp}^{2}$ carbon. ${ }^{[87]}$

A limiting factor in a-C:H RS is the need of a forming step, where the material needs to be biased at the breakdown electric field. ${ }^{[303]}$ The breakdown results from a capacitive discharge current, which can be $10-20 \mathrm{~mA}^{[86,303]}$ and occurs within a few ns. ${ }^{[86,303]}$ Therefore, an on-chip resistor or transistor is needed to limit the current during forming. ${ }^{[86,303]}$ Due to the high current density during the forming step, metals from electrodes might diffuse into the carbon, if the forming is done in a dc-sweep, instead of an energy limiting short pulse. ${ }^{[85,287,295,303]}$

The influence of other dopants, such as $\mathrm{Co}$ and $\mathrm{Cu}$, was studied by Refs. ${ }^{[297-}$ ${ }^{300]}$, see Table 8. Ref. ${ }^{[297]}$ studied RS in Co doped amorphous carbon. They observed non-volatile, bipolar and reversible $\mathrm{RS}$ with $\mathrm{I}_{\mathrm{ON}} / \mathrm{I}_{\mathrm{OFF}} \sim 25$, but good retention $>10^{5} \mathrm{~s}$ at room temperature. ${ }^{[297]} \mathrm{RS}$ was attributed to a filament formed by Co ions created by an electrochemical reaction, migrating toward the top $\mathrm{Al}$ electrode through defects in the a-C film, forming a conductive path between top and bottom electrode. ${ }^{\left[{ }^{[27]}\right.}$ Refs. ${ }^{[298-300]}$ 
investigated $\mathrm{RS}$ in $\mathrm{Cu}$ doped carbon. They got $\mathrm{ION}_{\mathrm{ON}} / \mathrm{I}_{\mathrm{OFF}} \sim 10^{2}$ and retention of $10^{4} \mathrm{~s}$ at $85^{\circ} \mathrm{C}$ and $>10^{3}$ switching cycles. ${ }^{[298]}$ Ref. ${ }^{[300]}$ used a slightly different device configuration with both, top and bottom electrodes made of Pt. A forming step was needed. Subsequent set and reset processes could be achieved at $\sim+0.7 \mathrm{~V}$ and $-0.5 \mathrm{~V} .^{[300]}$ $\mathrm{RS}$ was attributed to the formation and rupture of $\mathrm{Cu}$ filaments. ${ }^{[298-300]}$

Ref. ${ }^{[294]}$ prepared oxygenated amorphous carbon, $\mathrm{a}-\mathrm{CO}_{\mathrm{x}}$, by physical vapour deposition. Ref. ${ }^{[294]}$ reported switching times $\sim 50 \mathrm{~ns}$ for SET and 10ns for RESET, with opposite voltage polarity needed. ${ }^{[294]}$ Ref. ${ }^{[294]}$ measured cycling endurance $>10^{4}$ in devices with $\mathrm{W}$ as bottom and $\mathrm{Pt}$, Ti or $\mathrm{W}$ as top electrodes, ${ }^{[294]}$ with $\mathrm{IoN}_{\mathrm{ON}} / \mathrm{I}_{\mathrm{OFF}} \sim 5 \times 10^{2}$ during retention measurements up to $10^{4} \mathrm{~s}$ at $85^{\circ} \mathrm{C}$. The RS mechanism was attributed to an electrochemical redox reaction leading to the formation of a conductive carbon filament. ${ }^{[294]}$ The choice of metal electrode material was crucial for the reset process, with strong dependence on the electron affinity of the metal electrode. ${ }^{[294]}$ To make the reduction reversible, two electrode materials were needed to store and release oxygen. One with similar electron affinity to carbon, such as $\mathrm{W}$, and the other with higher electron affinity, such as Pt. ${ }^{[294]}$

$\mathrm{RS}$ in amorphous carbons with different $\mathrm{sp}^{2} / \mathrm{sp}^{3}$ ratio was reported by several groups. ${ }^{[285,304-312]} \mathrm{RS}$ in $\mathrm{sp}^{2}$ rich a-C was studied in a Si/TiN/a-C devices, using a CAFM as top contact. ${ }^{[282]}$ The key parameters of RS devices based on pure amorphous carbon are reported in Table 9. RS was assigned to an electro- thermally induced (Joule heating) increase in the $\mathrm{sp}^{2}$ cluster size and was non-reversible. ${ }^{[285]} \mathrm{RS}$ in a-C was shown to be polarity independent. ${ }^{[304-307]}$ Ref. $^{[306]}$ studied the influence of the top metal electrode material on RS, and assigned this to metal filamentation in devices with $\mathrm{Cu}$ top electrodes. Pt, W and Ni top electrodes did not show switching. ${ }^{[306]}$ This was attributed to the less diffusive nature of those metals. ${ }^{[306]}$ Data retention $>10^{5} \mathrm{~s},{ }^{[304]}$ low switching 
voltage of $2 \mathrm{~V}^{[306]}$ within pulses of $1 \mu \mathrm{s},{ }^{[306]} \mathrm{ION} / \mathrm{IOFF} \sim 70,{ }^{[305]}$ endurance $\sim 110^{[305]}$ and device structures down to $50 \times 50 \mu \mathrm{m}^{2}{ }^{[306]}$ were demonstrated.

ION/IOFF as well as endurance are the main challenges faced by RRAMs based on a-C. The issue of a low ION/IOFF can be overcome by using ta-C. Ref. ${ }^{[308]}$ demonstrated high $\mathrm{I}_{\mathrm{ON}} / \mathrm{I}_{\mathrm{OFF}}$ in $\mathrm{Pt} / \mathrm{ta}-\mathrm{C} /(\mathrm{SLG}) / \mathrm{Au}$ devices. Devices with an interfacial SLG reached $\mathrm{I}_{\mathrm{ON}} / \mathrm{I}_{\mathrm{OFF}} \sim 4 \times 10^{5}$, while maintaining low switching power density of $14 \mu \mathrm{W} / \mu \mathrm{m}^{2}{ }^{[308]}$ This was attributed to the reduction of leakage currents due to the low SLG density of states near the Dirac point. ${ }^{[308]}$ Refs. ${ }^{[288-289]}$ explained the switching in terms of nanoscale $\mathrm{sp}^{2}$ filament formation and rupture through field-induced dielectric breakdown and thermal fuse effect, i.e. an electro-thermally driven set process and a thermally driven reset process. Low switching voltages of $0.4 \mathrm{~V}$ for reset within $10 \mathrm{~ns}$ and $1.2 \mathrm{~V}$ for set within $50 \mathrm{~ns},{ }^{[288]} 10^{13}$ read cycles at $75^{\circ} \mathrm{C},{ }^{[286]}>10^{6}$ s retention ${ }^{[290]}$ with device sizes of $50 \mathrm{~nm}$ diameter ${ }^{[289]}$ and $10^{3}$ switching cycles ${ }^{[288]}$ were also demonstrated. The presence of multiple resistive states was reported by Ref. ${ }^{[308]}$. Multilevel storage is of particular interest as it allows to store more than one bit per cell, while the memristive behaviour can be exploited to provide a range of signal processing/computing-type operations, such as implementing logic, providing synaptic and neuron-like mimics, i.e. circuits that simulate brain-like neurological functions, and performing analogue signal processing functions, paving the way for non-von-Neumann computer architectures, in which processing and non-volatile storage are carried out simultaneously. ${ }^{[313-314]}$

Endurance is one of the major challenges for a-C based switching devices. A comparative study by Ref. ${ }^{[301]}$ of RA in ta-C and a-CO ${ }_{x}$ with Pt bottom electrodes and W top electrodes suggested that by incorporating oxygen the endurance could be enhanced to 40000 , but at the expense of bipolar operation. ${ }^{[301]}$ In ta-C devices, SET and RESET were achieved with pulses of 50 and $4 \mathrm{~ns}$ and switch energies of 15 and $3 \mathrm{pJ}$, 
while a-CO $\mathrm{CO}_{\mathrm{x}}$ could be set and reset with 40 and 4 ns pulses with switch energy of 2 and $1 \mathrm{pJ}$, respectively. ${ }^{[301]}$ Both, ta-C and a- $\mathrm{CO}_{\mathrm{x}}$ showed good data retention of $10^{4} \mathrm{~s}$ at $85^{\circ} \mathrm{C} \cdot{ }^{[294,301]}$

Refs. $^{[301-302,311-312]}$ theoretically studied the switching mechanism in amorphous carbons, and assigned $\mathrm{RS}$ to heat driven $\mathrm{sp}^{2}$ clustering and filament formation.

Ref. $^{[303]}$ pointed out that one of the biggest advantages of carbon based memory devices might be the high temperature retention $250^{\circ} \mathrm{C}$, making them attractive for automotive and harsh conditions. ${ }^{[303]}$ Another advantage of carbon based memories is that devices do not rely on rare mineral extraction, with easier disposal/recycling, and low total energy production compared to other electronics materials. ${ }^{[280]}$

\section{Layered materials}

Non-carbon based LMs have also been introduced into the structure of RRAMs, manly TMDs (like $\mathrm{MoS}_{2}{ }^{[315-316]}$ and $\mathrm{MoSe}_{2}{ }^{[317]}$ ) and $h$-BN. ${ }^{[163]}$ Ref. ${ }^{[318]}$ reported a RRAM prototype using BP flakes.

TMDs are naturally semiconducting materials, ${ }^{[319]}$ thus they are not ideally suited for RRAMs. For this reason, these materials need to be functionalized in order to form an insulating layer. ${ }^{[319]}$ Ref. ${ }^{[320]}$ suggested to combine TMDs with an insulator (such as polymers) whereby the TMD would act as dopant of the insulating layer. In Ref. $^{[320]}$ a stack of $\mathrm{RGO} / \mathrm{MoS}_{2}-\mathrm{PVP} / \mathrm{Al}$ in which the PVP (polyvinylpyrrolidone), typically used to assist the exfoliation of $\mathrm{MoS}_{2}$, became the dielectric RS-driving layer. The devices were fabricated using spin coating of the $\mathrm{MoS}_{2}-\mathrm{PVP}$ solution on the RGO film, resulting on a thickness of $70 \mathrm{~nm}$, and large $0.2 \times 0.3 \mathrm{~mm}^{2}$ electrodes were 
thermally evaporated. The RRAM devices show ION/IOFF $\sim 10^{2}$. Ref. ${ }^{[320]}$ claimed the switching as due to charge trap and de-trap of the $\mathrm{MoS}_{2}$ embedded in the PVP. However, Refs. $^{[321-322]}$ reported RS also in structures with pure PVP as active layers, while Ref. ${ }^{[273]}$ detected RS in RGO. We note that Ref. ${ }^{[320]}$ did not provide temperature nor area analyses, which makes it difficult to discern if the RS in these devices is a local or distributed phenomenon. Therefore, the ability of $\mathrm{MoS}_{2}$ to drive the RS is questionable. Similar studies were developed by Ref. ${ }^{[323]}$ in a

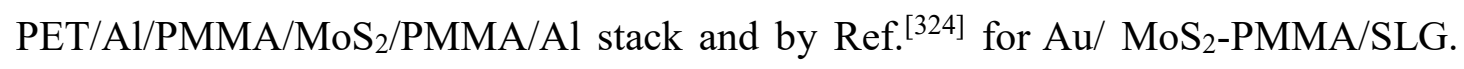
These achieved IoN/IOFF $\sim 10^{4}$ and $2.5 \times 10^{3}$ (respectively). However the need for a TMD to be combined with PMMA is doubtful. Ref. ${ }^{[325]}$ demonstrated that $\mathrm{MoS}_{2}$-free Ag/PMMA/ITO devices can also achieve reproducible $\mathrm{RS}\left(\mathrm{I}_{\mathrm{ON}} / \mathrm{I}_{\mathrm{OFF}} \sim 10^{2}\right.$ ), which is driven by the penetration of metallic ions into the polymer, leading to a reversible CF though it. The combination of $\mathrm{MoS}_{2}$ and GO resulted on a similar $\mathrm{I}_{\mathrm{ON}} / \mathrm{I}_{\mathrm{OFF}} \sim 10^{2}$ for the RRAM device. ${ }^{[326]}$ Ref. $^{[327]}$ produced printable RRAM memories with tuneable performances using $\mathrm{Ag} / \mathrm{MoS}_{2}-\mathrm{MoO}_{\mathrm{x}} / \mathrm{Ag}$ stacks, with $\mathrm{ION}_{\mathrm{ON}} / \mathrm{I}_{\mathrm{OFF}}>10^{6}$, retention times $>8000$ s, and non RS degradation after bending $>10^{4}$ times. As in Refs. ${ }^{[324,326]}$, the RS in Ref. ${ }^{[320]}$ does not seem to be attributable to the $\mathrm{MoS}_{2}$ sheets, which served to homogenize the interface between the MoOx and $\mathrm{Ag}$ bottom electrode. A different approach was reported in Ref. ${ }^{[328]}$, which used $\mathrm{MoS}_{2}$ flakes, also giving RS. In this case, the resistance changes were attributed to tunnelling across junction barriers. Very similar devices, but using $\mathrm{MoSe}_{2}$ nano-islands, were studied in Ref. ${ }^{[317]}$, which showed ION/IOFF $\sim 12$ and low currents $(>1 \mu \mathrm{A})$ in LRS.

RS driven by $\mathrm{MoS}_{2}$ was reported by Refs. ${ }^{[315-316]}$ Ref. $^{[317]}$ used three-terminal horizontal devices similar to FETs (see Figs. 12a and 12b), with a grain boundary (GB) in the $\mathrm{MoS}_{2}$ extending in the channel. Ref. ${ }^{[320]}$ considered GB different configurations, 
including parallel and perpendicular to the channel, as well as intersecting. In all cases, ION $/$ IOFF $>10^{2}$ was achieved. RS in these devices was assigned to the motion of $\mathrm{S}$ vacancies in the $\mathrm{MoS}_{2}$, which tend to accumulate at the GBs. ${ }^{[320]}$ However, the reproducibility of this phenomenon was not firmly established, as Ref. ${ }^{[315]}$ reported only 15 cycles. On the other hand, Ref. ${ }^{[316]}$ compared two vertical $\mathrm{Ag} / \mathrm{MoS}_{2} / \mathrm{Ag}$ devices using a $550 \mathrm{~nm} \mathrm{MoS}$ film formed by $\mathrm{MoS}_{2}$ flakes dispersed in propanol solvent and spin-coated on a $\mathrm{Ag}$ foil, followed by a thermal treatment at $130^{\circ} \mathrm{C}$ for $12 \mathrm{~h}$ and $0.1 \mathrm{~mm}^{2}$ top electrode deposition using Ag paste (Figs. 12c and 12d). The differences between the two devices was the $\mathrm{MoS}_{2}$ phase, in one case $1 \mathrm{~T}$ flakes, and in the other $2 \mathrm{H}$ bulk. Despite the methodologies not being ideal for scaling and integration (deposition of electrodes by Ag paint using a shadow mask is to be avoided because it can lead to contaminants at the interface, inhomogeneous shapes and cracks in the 2D material) the devices using $1 \mathrm{~T}-\mathrm{MoS}_{2}$ showed good RS behaviour with $\mathrm{I}_{\mathrm{ON}} / \mathrm{I}_{\mathrm{OFF}}>10^{3}$ during 100 cycles. Ref. ${ }^{[316]}$ assigned the RS to the migration of Mo and S ions under electrical field. Ref. ${ }^{[316]}$ also included a modification of this device using $\mathrm{Ag} / \mathrm{MoS}_{2} / \mathrm{Ag} / \mathrm{MoS}_{2} / \mathrm{Ag}$ vertical structures, showing the possibility reducing the current at low voltages $(<0.2$ V) by negative differential resistance, which may be useful to avoid sneak path current in crossbar arrays. Nevertheless, none of the $\mathrm{MoS}_{2}$-based works to date presents a conclusive memristive analysis. E.g. Ref. ${ }^{[316]}$ claims 1000 cycles, but no variability analyses (like e.g. those in Refs. ${ }^{[315-317,324]}$ ) are presented (just $3 I-V$ curves are displayed). More information on the different TMDs-based RRAMs is in Table 10, including dependence on critical parameters, such as device area, working temperature, top electrode material and current limitations (among others). The RS parameters are still far from those reported for state-of-the-art TMO-based RRAM memories (see Table 1). ${ }^{[2,31-33]}$ 
The use of $h$-BN in RRAM is even more incipient. In principle, as $\mathrm{BN}$ is an insulator, ${ }^{[163]}$ if a reversible $\mathrm{CF} / \mathrm{BD}$ can be induced through it, the RS behaviour should be more accentuated (larger $\mathrm{I}_{\mathrm{ON}} / \mathrm{I}_{\mathrm{OFF}}$ ) due to the larger resistivity in HRS (the constriction would be more insulating than in semiconducting materials). Nevertheless, this is in principle not an easy task, as the BD may become irreversible depending on the atomic structure of the $h$-BN stack. One should clearly distinguish between research articles using layered $h$-BN ${ }^{[163]}$ (see Figs. 13c and 13d), and those in which amorphous BN was used (Figs. 13a and 13b). ${ }^{[329]}$ Ref. ${ }^{[329]}$ claimed the fabrication of RRAMs using multilayer $h$-BN stacks, but the layered nature of the film is not supported by the crosssectional TEM images, and the layer looks more like an amorphous BN film (see Figs. $13 \mathrm{a}$ and $13 \mathrm{c})$. This is very important because the amorphous BN film may not hold the properties of the $h$-BN stack, such as transparency, ${ }^{[330]}$ flexibility, ${ }^{[331]}$ high thermal conductivity ${ }^{[32]}$ and high chemical stability ${ }^{[333]}$. Ref. ${ }^{[316]}$ fabricated a family of RRAMs using $h$-BN as RS medium. By tuning the $h$-BN stack thickness and the $h$-BN domain size Ref. ${ }^{[163]}$ achieved forming-free operation, low switching voltages down to $0.5 \mathrm{~V}$, high $\mathrm{I}_{\mathrm{ON}} / \mathrm{I}_{\mathrm{OFF}}$ up to $10^{6}$, retention times $>10$ hours and low device-to-device variability (i.e. deviations of $V_{S E T} / V_{R E S E T}<10 \%$ ). In Ref. ${ }^{[163]}$ the RS was attributed to the migration of $\mathrm{B}$ atoms towards the electrodes, as well as metallic ions penetration into the $h$-BN stack to form and disrupt one/few CFs. These atomic diffusions are more abundant at GBs, which are defect-rich locations (missing bonds, missing atoms, pentagonal/heptagonal lattices ${ }^{[334]}$ that can favour atomic rearrangements at lower potentials (compared to the grains), leading to a softer BD that may be easier to recover. ${ }^{[335]}$ The formation of B-vacancies at the GBs of polycrystalline $h$-BN stacks (see Fig. 13c) presents an interesting parallelism to O-vacancies at the GBs of polycrystalline TMOs. ${ }^{[335]}$ The key role of the GBs in the RS is supported by the fact 
that the $\mathrm{BD}$ process in single crystalline $h$-BN flakes is an irreversible phenomenon that leads to the removal of the material, ${ }^{[336]}$ with the formation of holes during a characteristic layer-by-layer BD process. Therefore, it is unlikely that a perfect single crystalline $h$-BN would offer RS capabilities. Ref. ${ }^{[107]}$ investigated a RRAM comprising a monolayer CVD-grown $h$-BN flake inserted between the top electrode and the dielectric of an $\mathrm{Al} / \mathrm{WO}_{3} / \mathrm{Al}$ cell, but the performance was worse than the $h-\mathrm{BN}$ free counterpart ( $\left.\mathrm{ION}_{\mathrm{ON}} / \mathrm{I}_{\mathrm{OFF}}<10\right)$. Probably the reason is it is difficult to create $\mathrm{CFs}$ in $h$ $\mathrm{BN} / \mathrm{WO}_{3}$ superstructures, i.e. the $\mathrm{CF}$ is only created at large electrical fields that produce the irreversible $\mathrm{BD}$ in the $h-\mathrm{BN} / \mathrm{WO}_{3}$ stack. Ref. ${ }^{[337]}$ reported indications of RS in layered $\mathrm{Ti} / h-\mathrm{BN} / \mathrm{Cu}$ stacks (Fig. 13c). The devices exploited the $\mathrm{Cu}$ substrate used to grow the $h$-BN as bottom electrode, avoiding the need for transfer. ${ }^{[316]}$ When applying constant voltage stresses (CVS) at $2.5 \mathrm{~V}$ to the devices, the current vs. time (I-t) curves show sudden changes of the electronic resistance (up to $10^{3}$ ) similar to unipolar RS characteristics. ${ }^{[337]}$ A detailed comparison of the RS capabilities of $h$-BNbased devices in literature is presented in Table 11. Ref. ${ }^{[338]}$ also observed unipolar RS transitions in planar nanogap-based $h$-BN obtained by MC. However, thus far, the use of planar structures in RRAM technology is very limited due to the difficulty to control the rupture kinetics of the nanogaps, which may result in a poor RS endurance and prohibitive device-to-device variability. We note that statistical information of the RS in planar devices made of any GRM has not yet been reported. Moreover, MC is not an scalable technique. Ref. ${ }^{[337]}$ reported layer-by-layer $\mathrm{BD}$ at the grains by means of CAFM, while at the same time measuring reproducible conductivity changes at the device level, which may be related to the presence of GBs. As the use of LM-dielectrics provides a flatter interface to graphene and TMDs than high-k dielectrics, ${ }^{[179-180]} \mathrm{RS}$ applications of $h$-BN should be deeper investigated. 
$\mathrm{BP}$ is a layered semiconductor prone to degradation when exposed to atmosphere. ${ }^{[339]}$ The degradation of the surface is generated by the insertion of oxygen groups, leading to a POx structure. ${ }^{[339-340]}$ This layer provides RS capability, as reported by Ref. ${ }^{[318]}$. Ref. ${ }^{[318]}$ exfoliated BP using both $\gamma$-butyrolactone and isopropanol and the devices were fabricated by spin-coating on a ITO/PET flexible and transparent substrate, followed by top circular ( $500 \mu \mathrm{m}$ in diameter) Ag electrode deposition by magnetron sputtering using a shadow mask. Ref. ${ }^{[318]}$ observed that, after some days/months of exposure to atmosphere, reproducible RS with ION/IOFF up to $10^{3}-10^{4}$ can be achieved (Fig. 14). Ref. ${ }^{[318]}$ attributed this to the formation of $\mathrm{Ag}$ conductive filaments across the oxidized and insulating POX superficial layer. However, Ref. ${ }^{[318]}$, was just a proofof-concept, lacking important RRAM parameters, specially variability. Ref. ${ }^{[19]}$ reported the observation of $\mathrm{RS}$ in (PET)/Au/BPQD-PVP/Ag structures, with ION $/ I_{\text {OFF }}>10^{4}$ and endurance $>1100$ cycles. Both BP-based RRAM devices (in Refs. ${ }^{[119,318]}$ ) were fabricated by LPE and spin coating and showed flexible capability. The characteristics of these two prototypes are summarized in Table 12. Unfortunately, none of these works show endurance analyses, they just concentrate on the proof-of-concept and IoN/IOFF ratio, which makes it difficult to know the real usefulness of this material in RRAMs.

\section{Discussion, challenges and prospects}

The most advanced RRAMs use MIM structures formed by metallic electrodes (Ti, $\mathrm{Au}, \mathrm{Ag}, \mathrm{Cu}, \mathrm{Ni}, \mathrm{Pt})$ coupled with TMOs $\left(\mathrm{HfO}_{2},{ }^{[39-42]} \mathrm{Al}_{2} \mathrm{O}_{3},{ }^{[43-46]} \mathrm{TiO}_{2}{ }^{[47-50]}\right.$ and $\left.\mathrm{TaO}_{\mathrm{X}}\right) \cdot{ }^{\left[{ }^{[1-52]}\right.} \mathrm{RS}$ in metal/TMO/metal structures was first observed in $1962,{ }^{[341]}$ and RSbased memories were proposed in $1967 .{ }^{[342]}$ After more than 50 years of research, devices with high operation speeds ( 300 ps/transition), ${ }^{[32,44-45,60]}$ low power 
consumption $(\sim 0.1 \mathrm{pJ} /$ transition $),{ }^{[32,44]}$ good endurance (above $10^{12}$ cycles), ${ }^{[33,111,346-}$ ${ }^{347,364]}$ long data retention times (above 10 years), ${ }^{[46,364]}$ small size (down to $10 \mathrm{~nm} \times 10$ $\mathrm{nm}),{ }^{[31,296]}$ and high integration capacity $\left(>1 \times 10^{11} \mathrm{bits} / \mathrm{cm}^{2}\right)^{[2]}$ have been developed. GRMs were firstly introduced in the structure of RRAMs in $2008,{ }^{[103]}$ and in less than a decade the performance of some GRM-based RRAMs prototypes have fit some of the NVM technology requirements (low operation voltages $<1 \mathrm{~V},{ }^{[163,251]}$ high switching speeds down to $1 \mathrm{~ns},{ }^{[286,273,280]}$ endurance $>10^{9}$ cycles, ${ }^{[286]}$ and small cell size $\left(8.5 \mathrm{~nm}^{2}\right)$. [296]

Table 1 compares the best performances reported for TMO-based and GRMbased RRAM devices. These are similar for both types of RRAMs, and in one case (endurance) one GRM-based RRAM achieved record values. Several GRM-based RRAMs showed low $(<1 \mathrm{~V})$ operating voltages, ${ }^{[163,248,253]}$ and acceptable switching speeds. ${ }^{[286,273,280]}$ In contrast, the number of TMO-based RRAMs that fit at least one technology requirement is much larger (Table 1 only displays few of them). Therefore, more work in the direction of GRMs-based RRAMs is necessary.

\subsection{Fabrication}

The fabrication methods used for GRMs-based RRAMs should be improved. E.g., one of the best endurances reported for RRAMs using non-carbon GRMs $\left(10^{3}\right.$ cycles in $\left.\mathrm{Ag} / \mathrm{MoS}_{2} / \mathrm{Ag}\right)^{[316]}$ was observed using $\mathrm{Ag}$ foils as bottom electrode, and top electrodes deposited with Ag paint and MIM cell sizes $\sim 0.1 \mathrm{~mm}^{2}$. None of these processes/parameters are compatible with industry, and the knowledge extracted from such works may not be applicable to real ultra scaled (state-of-the-art) RRAMs. Future work in GRMs-based RRAMs should concentrate on the use of industry-compatible methodologies (i.e. for the deposition of electrodes evaporation/ and/or sputtering are 
preferred) and smaller device sizes (so that the conclusions extracted can be applicable to nanosized devices).

Furthermore, in most works using transferred SLG as interface electrode (see, e.g, Table 2) the device size is very large $\left(>8000 \mu \mathrm{m}^{2}\right)$. Under such large areas, it is common that SLG layers show cracks, especially after the transfer. ${ }^{[168-169]}$ As the transversal electrical resistance of the MGI junction (non cracked region) is larger than that of the MI one (at the cracked region), ${ }^{[170-171]}$ and because the forming/BD is a stochastic process that always takes place at the electrically weakest location of the area under stress (less insulating), ${ }^{[343-344]} \mathrm{CFs}$ in these devices are more prone to be formed at SLG cracked locations (e.i. MIM, instead MGIM). Moreover, as the currents measured through the devices (specially in LRS) are mainly driven by the CFs, the $I-V$ characteristics of many RRAMs using transferred SLG may refer to these nanosized MI junctions, and they may not be representative of the MGI structures under study. Ref. ${ }^{[217]}$ reported that the insertion of SLG electrodes in TMO-based RRAMs reduces $I_{H R S}$ 1-3 orders of magnitude due to an increase of the out-of-plane resistance (noncracked regions). Since the endurance and retention time is related to the CF properties, the presence of cracks should have a major influence. Future works using transferred SLG should prove that no cracks are present. One route could be to reduce the device area, which lessens the probability of finding a crack. Another option is to use MLG, which presents less cracks and is more resistant to mechanical fractures during transfer. [163]

Many GRMs-based RRAMs works based on polymer-scaffold-assisted transfer did not evaluate the presence of residues on the GRM surface after polymer removal. These may result in an effective reduction of the device size, given their high thickness $>10 \mathrm{~nm}$ and insulating nature. ${ }^{[345]}$ This process is random, but can be reduced 
by using better cleaning processes, ${ }^{[172]}$ which may device-to-device variability problems. ${ }^{[135-137]}$ Future works should include nanoscale surface characterization techniques, such as topographic AFM maps. Including annealing treatments after the transfer to remove rests of polymer may be an option.

Therefore, GRM transfer should be avoided when possible, not only due to device performance concerns, but also because it slows down the fabrication process (making it more expensive). The ideal solution would be to develop transfer-free processes, but the direct growth of GRMs on TMOs is a longer term goal. The use of insulating LMs as RS medium is preferred because, first, they do not need transfer, ${ }^{[163]}$ and second, the absence of cracks can be corroborated by the observation of a forming and/or set process. ${ }^{[329]}$ Present works on CVD-grown $h$-BN reported transfer-free RRAM devices, ${ }^{[163,329]}$ but they still used metallic foils. The direct growth of GRMs by CVD (or any other scalable technique) on metal coated flat wafers is highly desired. Another option is to use LPE GRM insulators that can be spin coated on arbitrary substrates, but that may present variability concerns given their large roughness (typically $\sim 20 \mathrm{~nm})^{[134]}$, much larger than flat GRMs prepared by CVD (graphene, $h$ $\mathrm{BN})$. The use of coating methods that reduce the roughness below $1 \mathrm{~nm}$ is necessary. Note that the roughness of TMOs for RRAM (usually grown by ALD) is $\sim 0.2 \mathrm{~nm}$. $[35,62,135]$

\subsection{Characterization}

Many papers on GRMs-based RRAMs only focused on RS proof-of-concept, showing acceptable $>10^{2} \mathrm{I}_{\mathrm{ON}} / \mathrm{I}_{\mathrm{OFF}}$ in very large $>1 \mathrm{~mm}^{2}$ devices. ${ }^{[196,316]}$ Information on the number of devices tested in each work and variability analyses is missing. Usually the reports do not concentrate on the study of the technology requirements (note that 
high $\mathrm{ION}_{\mathrm{ON}} / \mathrm{I}_{\mathrm{OFF}}$ is not a technology requirement, i.e. just one order of magnitude is enough to reliably distinguish HRS and LRS). ${ }^{[2]}$ E.g., we did not find any GRM-based RRAM report giving the power consumption in units of Energy (e.g. Joules) per transition, which are the values demanded by the industry ${ }^{[2]}$. Similarly, most GRMs-based RRAMs works do not focus enough on the switching times (e.g. detailed zoomed in plots at the set/reset transition are often missing). Sometimes, endurance and retention plots are shown, but the values $\left(<10^{3}\right.$ cycles $^{[351]}$ and $>10^{7} \mathrm{~S}^{[249]}$, respectively) are still insufficient to meet the industry requirements. ${ }^{[2]}$ The only paper showing excellent switching times and power consumption (Ref. ${ }^{[286]}$ Table 1) comes from industry. Future works should study several device parameters, such as RS medium thickness, electrode material and current limitation, as well as provide information on endurance, retention, temperature, variability analyses performed with probestation, modelling and CAFM. The use of CAFM to demonstrate the switching between HRS and LRS in some GRMs-based reports is very deficient, as no statistical analyses of the CF current/size of the CFs is provided. The methods for a correct characterization of RS using CAFM are described in Ref. ${ }^{[35]}$. Similarly, the structure of LMs-based RS is often not well supported, as explained in Fig. 13. Furthermore, the type of electrical stresses applied to most of the devices ( $I-V$ curves) are suitable only for proof-of-concept, but real devices work under fast $(<10 \mathrm{~ns})$ voltage pulses. ${ }^{[34]}$

Many GRMs-based RRAM reports do not present variability analyses (just typical values are shown), which raises concerns on the reliability and reproducibility of the results. Device-to-device variability was rarely reported (see e.g. Refs. ${ }^{[163]}$ ). In the future, more information about the dispersion of $V_{S E T}$ and $V_{R E S E T}$ in groups of more than 20 devices is needed. The inclusion of atomistic simulations and physical modelling to further complement the experimental observations is also necessary. For 
example, the QPC model, ${ }^{[210]}$ one of the most widespread for studying the different conductance levels in HRS and LRS in RRAMs, ${ }^{[205-206]}$ has been used in very few GRMs-based devices. ${ }^{[163,308]}$

\subsection{Technology viability}

The number of TMO-based RRAMs reporting performances above the technology requirements is much larger than for GRM-based ones. For this reason, TMO-based RRAMs are more reliable and (still) superior to GRM-based RRAMs. Moreover, as for TMO-based RRAMs, there is still not a GRM-based RRAM fitting all technology requirements simultaneously, indicating that more research is required. Nevertheless, the faster optimization speed of GRM-based RRAMs as well as the superior electronic, ${ }^{[76]}$ physical, ${ }^{[77]}$ chemical, ${ }^{[78]}$ mechanical, ${ }^{[79]}$ optical, ${ }^{[80]}$ magnetic ${ }^{[81]}$ and thermal ${ }^{[82]}$ properties. ${ }^{[83]}$ of GRMs (compared to TMOs) are strong arguments to further explore this technology.

\section{Conclusions}

GRMs have been introduced in the structure of RRAMs with the objectives of i) enhancing their performance as NVM (endurance, retention, switching time, power consumption, operation voltages) and ii) provide additional capabilities (flexibility, transparency, high chemical stability, thermal heat dissipation). On one hand, graphene can be used as electrode to provide flexibility and transparency to the devices, and/or as a interface layer between the electrode and the RS medium to reduce the cycle-tocycle variability by avoiding atomic diffusion between the electrode and insulator, reduce the power consumption due to its high out-of-plane contact resistance (compared to metallic electrodes), suppress surface effects by avoiding chemisorption and/or photodesorption and surface band bending, allow tuning the properties of the devices 
by functionalization, and reducing the thickness of the electrodes and improving the three dimensional stackability. On the other hand, GO, a-C, TMDs, $h$-BN and BP can be used as active RS medium to induce the resistivity changes either by migration of intrinsic species (such as oxygen in GO and sulfur in $\mathrm{MoS}_{2}$ ) or by penetration of metallic ions from adjacent electrodes. Graphene is usually produced by CVD and inserted in the RRAMs by polymer-assisted transfer. When using $h$-BN as RS medium, the standard transfer can be avoided, and the catalyst substrate for CVD growth can be used as bottom electrode. GO and BP are usually produced by LPE and spin coated on conductive wafer, which serves as bottom electrode. TMDs have been inserted in RRAMs either by CVD plus transfer and LPE plus spin coating. In all cases, top electrodes can be easily evaporated on top using an evaporator/ sputtering coupled with an standard photolithography step.

GRMs-based RRAMs have shown reproducible unipolar and bipolar RS with high $\mathrm{ION}_{\mathrm{ON}} / \mathrm{I}_{\mathrm{OFF}}>10^{5}$, low operating voltages $<1 \mathrm{~V}$ and fast switching times $(<30 \mathrm{~ns})$. In most reports the switching is attributed to the formation/disruption of CFs in the RS medium, and the atomic rearrangements in each state transition are related to the movement of intrinsic species and/or penetration of metallic ions from adjacent layers, showing parallelism with TMO-based RRAMs. GRMs have also been mixed/embedded with polymers, nanoparticles, nanorods and quantum dots in order to enhance the performance (mainly retention and endurance) of the devices, but in many cases it is unclear the real need/usefulness of the GRMs for the RRAM device. Despite all efforts, NVMs technological requirements like endurance $>10^{9}$ cycles and data retention $>10$ years still remain a challenge. Only one report using a-C as dielectric demonstrated excellent endurance above $10^{9}$ cycles, and we are not aware of any GRMs-based RRAM showing retention times $>10$ years. From the point of view of 
flexibility, GRMs-based RRAMs showed the ability to hold RS under more than $>10^{5}$ bending stresses with radius down to few $\mathrm{mm}$ (no technological requirements in this sense have been established). Moreover, GRMs-based RRAMs with transparencies $>92 \%$ have been reported. The benefits of other GRMs properties (such as high chemical stability and thermal heat dissipation) on the performance of RRAMs have not been discussed.

Most of RS studies in GRMs concentrated on poof-of-concept demonstrations using large area $\left(>2000 \mu \mathrm{m}^{2}\right)$ devices, which makes difficult to extrapolate to real ultrascaled RRAMs. Future GRMs-based studies should use smaller $\left(<1 \mu \mathrm{m}^{2}\right)$ sizes, focus on demonstrating performances (i.e. endurance, retention, switching time and power consumption) above the NVM technology requirements, and include reliability and variability analyses. The use of atomistic simulations and physical modelling to support/explain the experimental observations is also necessary.

Nevertheless, the fact that GRMs-based devices already fit some NVM technology requirements (operating voltages, endurance and switching times) makes this field worth of further investigation.

\section{Acknowledgements}

We acknowledge support from the Young 1000 Global Talent Recruitment Program of the Ministry of Education of China, the National Natural Science Foundation of China (grants no. 61502326, 41550110223), the Jiangsu Government (grant no. BK20150343), the Ministry of Finance of China (grant no. SX21400213), the Young 973 National Program of the Chinese Ministry of Science and Technology (grant no. 2015CB932700), the Collaborative Innovation Center of Suzhou Nano 
Science \& Technology, the Jiangsu Key Laboratory for Carbon-Based Functional Materials \& Devices, the Priority Academic Program Development of Jiangsu Higher Education Institutions, the National Natural Science Foundation of China under Grant Nos. 61521064, 61322408, 61422407, the Beijing Training Project for the Leading Talents in S\&T under Grant No. ljrc201508, the Opening Project of Key Laboratory of Microelectronic Devices \& Integrated Technology, Institute of Microelectronics, Chinese Academy of Sciences, the EU Graphene Flagship, FP7 Grant CARERAMM, ERC Grants Hetero2D and Highgraink, EPSRC Grants EP/K01711X/1, EP/K017144/1, EP/N010345/1, EP/M507799/1, EP/L016087/1, EP/M013243/1. All the members of Prof. Lanza group are acknowledged for literature review.

\section{References}

[1] A. Chen, Solid-State Electron. 2016, DOI: 10.1016/j.sse.2016.07.006.

[2] International Technology Roadmap for Semiconductors, 2013 Edition, Process Integration, Devices, and Structures section (last accessed online February $11^{\text {th }}$ 2015, website: www.itrs.net).

[3] D. Kumar, Preprints 2016, DOI: 10.20944/preprints201607.0093.v1

[4] http://www.statisticbrain.com/average-cost-of-hard-drive-storage/

[5] Web-Feet Research: http://www.webfeetresearch.com (Accessed: May $8^{\text {th }}$ of 2016).

[6] D. Kahng, S. M. Sze, Bell Syst. Tech. J. 1967, 46, 1288.

[7] "IBM Reports Advance in Shrinking Chip Circuitry". The Wall Street Journal. July 9, 2015. Retrieved July 9, 2015.

[8] Equipment and Tool Institute, http://eti-home.org/Newsletter-V02/The-Bus-is- 
Full.html, 2010.

[9] S. Okhonin, M. Nagoga, E. Carman, R. Beffa, E. Faraoni in IEEE Int. Electron Dev. Meeting, Washington, DC, USA, 10-12 December, 2007.

[10] C. Navarro, M. Bawedin, F. Andrieu, S. Cristoloveanu, IEEE Electron Device Lett. 2015, 36, 5.

[11] T. Atsumi, S. Nagatsuka, H. Inoue, T. Onuki, T. Saito, Y. Ieda, Y. Okazaki, A. Isobe, Y. Shionoiri, K. Kato, T. Okuda, J. Koyama, S. Yamazaki, 4th IEEE Int. Memory Workshop, 2012, 99.

[12] Y. Li, Y. Z. Wang, Q. Cui, J. Renewable Sustainable Energy 2016, 8, 015901.

[13] C. T. Chu, Y. K. Wang, P. K. Liao, 5th International Symposium on NextGeneration Electronics (ISNE), 4-6 May, 2016.

[14] Authenticating ferroelectric random access memory (F-RAM) device and method US 9330251 B1, May 3, 2016.

[15] Z. Xu, B. Liu, Y. F. Chen, Z. H. Zhang, D. Gao, H. Wang, Z. T. Song, C. Z. Wang, J. D. Ren, N. F. Zhu, Y. H. Xiang, Y. P. Zhan, S. L. Feng, Solid-State Electron. 2016, 116, 119.

[16] P. M. Palangappa, J. Y. Li, K. Mohanram, IEEE Transactions on Computers 2016, 65, 1025 .

[17] P. K. Amiri, K. L. Wang, Proc. 6th IEEE Int. Memory Workshop, 2014, 10.

[18] Utilization of the anomalous hall effect or polarized spin hall effect for MRAM application, US 9269415 B1, 2016.

[19] A. Calderoni, S. Sills, N. Ramaswamy, Proc. 6th IEEE Int. Memory Workshop, 2014, 5 .

[20] W. J. Ma, Electron. Lett. 2016, 52, 9.

[21] A. Belmonte, A. Fantini, A. Redolfi, M. Houssa, M. Jurczak, L. Goux, Solid- 
State Electron. 2016, 125, 189.

[22] N. Gonzales, J. Dinh, D. Lewis, N. Gilbert, B. Pedersen, D. Kamalanathan, J. R. Jameson, S. Hollmer, Memory Workshop (IMW), 2016 IEEE 8th Internationl.

[23] L. Li, D. Z. Wen, Organic Electron. 2016, 34, 12.

[24] S. Y. Ning, T. O. Iwasaki, S. Hachiya, G. Rosendale, M. Manning, D. Viviani, T. Rueckes, K. Takeuchi, Jpn. J. Appl. Phys. 2016, 55, $04 \mathrm{EE01.}$

[25] W. Zhao, E. Belhaire, C. Chappert, P. Mazoyer, ACM Trans. Embedded Comput. Syst. 2009, 9, 1.

[26] J. J. Nowak, R. P. Robertazzi, J. Z. Sun, G. Hu, J. H. Park, J. Lee, A. J. Annunziata, G. P. Lauer, R. Kothandaraman, E. J. O’Sullivan, P. L. Trouilloud, Y. Kim, D. C. Worledge, IEEE MAGNETICS LETTERS, 2016, 7.

[27] Z. Liu, A. A. Yasseri, J. S. Lindsey, D. F. Bocian, Science 2003, 302, 1543.

[28] W. G. Kuhr, A. R. Gallo, R. W. Manning, C. W. Rhodine, MRS Bulletin, 2004, 29,805 .

[29] L. Cario, C. Vaju, B. Corraze, V. Guiot, E. Janod, Adv. Mater. 2010, 22, 5193.

[30] J. Tranchant, E. Janod, L. Cario, B. Corraze, E. Souchier, J. L. Leclercq, P. Cremillieu, P. Moreau, M. P. Besland, Thin Solid Films 2013, 533, 61.

[31] B. Govoreanu, G. S. Kar, Y. Y. Chen, V. Paraschiv, A. Fantini, I. P. Radu, L. Goux, S. Clima, R. Degraeve, N. Jossart, In IEEE Int. Electron Dev. Meeting, Washington, DC, USA, 5-7 December, 2011.

[32] H. Y. Lee, Y. S. Chen, P. S. Chen, P. Y. Gu, Y. Y. Hsu, S. M. Wang, W. H. Liu, C. H. Tsai, S. S. Sheu, P. C. Chiang, W. P. Lin, C. H. Lin, W. S. Chen, F. T. Chen, C. H. Lien, and M.-J. Tsai, In IEEE Int. Electron Dev. Meeting, San Francisco, CA, USA, 6-8 December, 2010.

[33] M. J. Lee, C. B. Lee, D. S. Lee, S. R. Lee, M. Chang, J. H. Hur, Y. B. Kim, C. 
J. Kim, D. H. Seo, S. Seo, U. I. Chung, I. K. Yoo, K. Kim, Nat. Mater. 2011, 10, 625.

[34] R. Waser, D. Ielmini, H. Akinaga, H. Shima, H.-S. P. Wong, J. J. Yang, S. Yu, in Resistive Switching: From Fundamentals of Nanoionic Redox Processes to Memristive Device Applications, Vol. 1 (Eds: D. Lelmini, R. Waser), WileyVCH, Berlin, 2016, p. 1.

[35] M. Lanza, Materials 2014, 7, 2155.

[36] E. Gale, Semicond. Sci. Technol. 2014, 29, 10.

[37] K. Tsunoda, Y. Fukuzumi, J. R. Jameson, Z. Wang, P. B. Griffin, Y. Nishi, Appl. Phys. Lett. 2007, 90, 113501.

[38] A. Sawa, Mater. Today 2008, 11, 28.

[39] S. B. Long, L. Perniola, C. Cagli, J. Buckley, X. J. Lian, E. Miranda, F. Pan, M. Liu, J. Sune, Sci. Rep. 2013, 3, 2929.

[40] X. Wu, S. Mei, M. Bosman, N. Raghavan, X. X. Zhang, D. Y. Cha, K. Li, K. L. Pey, Adv. Electro. Mater. 2015, 1, 1500130.

[41] U. Chand, K. C. Huang, C. Y. Huang, C. H. Ho, C. H. Lin, T. Y. Tseng, J. Appl. Phys. 2015, 117, 184105.

[42] D. Duncan, B. Magyari-Kope, Y. Nishi, Appl. Phys. Lett. 2016, 108, 043501.

[43] B. Sarkar, B. Lee, V. Misra, Semiconductor Sci. Technol. 2015, 30, 105014.

[44] C. Ahn, Z. Jiang, C. S. Lee, H. Y. Chen, J. Liang, L. S. Liyanage, H. S. P. Wong, IEEE Trans. Electron Devices 2015, 62, 2197.

[45] J. Zhou, F. Cai, Q. Wang, B. Chen, S. Gaba, W. D. Lu, IEEE Trans. Electron Devices 2016, 37, 404.

[46] L. G. Wang, X. Qian, Y. Q. Cao, Z. Y. Cao, G. Y. Fang, A. D. Li, D. Wu, Nano Research Lett. 2015, 10, 135. 
[47] H. Y. Jeong, S. K. Kim, J. Y. Lee, S. Y. Choi, J. Electrochem. Soc. 2011, 158, 979.

[48] J. Shim, I. Kim, K. P. Biju, M. Jo, J. Park, J. Lee, S. Jung, W. Lee, S. Kim, S. Park, H. Hwang, J. Appl. Phys. 2011, 109, 033712.

[49] J. J. Huang, C. W. Kuo, W. C. Chang, T. H. Hou, Appl. Phys. Lett. 2010, 96, 262901.

[50] H. Y. Jeong, Y. I. Kim, J. Y. Lee, S. Y. Choi, Nanotechnology 2010, 21, 115203.

[51] M. X. Yu, Y. M. Cai, Z. W. Wang, Y. C. Fang, Y. F. Liu, Z. Z. Yu, Y. Pan, Z. X. Zhang, J. Tan, X. Yang, M. Li, R. Huang, Sci. Rep. 2016, 6, 21020.

[52] Y. D. Zhao, P. Huang, Z. Chen, C. Liu, H. T. Li, W. J. Ma, B. Gao, X. Y. Liu, J. F. Kang, in IEEE Silicon Nanoelectronics Worshop, Kyoto, Japan, 14-15 June 2015.

[53] B. Gao, W. Y. Chang, B. Sun, H. W. Zhang, L. F. Liu, X. Y. Liu, R. Q. Han, T. B. Wu, J. F. Kang, in Int. Symp. VLSI Technol., Syst., Appl., Hsinchu, China, 26-28 April 2010.

[54] G. Bersuker, D. C. Gilmer, D. Veksler, P. Kirsch, L. Vandelli, A. Padovani, L. Larcher, K. McKenna, A. Shluger, V. Iglesias, M. Porti, M. Nafria, J. Appl. Phys. 2011, 110, 124518.

[55] M. Lubben, P. Karakolis, V. I. Sougleridis, P. Normand, P. Dimitrakis, I. Valov, Adv. Mater. 2015, 27, 6202.

[56] R. Waser, R. Dittmann, G. Staikov, K. Szot, Adv. Mater. 2009, 21, 2632.

[57] T. Hino, T. Hasegawa, K. Terabe, T. Tsuruoka, A. Nayak, T. Ohno, M. Aono, Sci. Technol. Adv. Mater. 2011, 12, 013003.

[58] U. Russo, D. Ielmini, A. L. Lacaita, M. N. Kozicki, IEEE Trans. Electron Devices 2009, 56, 5. 
[59] I. Valov, R. Waser, J. R. Jameson, M. N. Kozicki, Nanotechnology 2011, 22, 254003.

[60] N. Xu, L. F. Liu, X. Sun, C. Chen, Y. Wang, D. D. Han, X.Y. Liu, R.Q. Han, J. F. Kang, B. Yu, Semicond. Sci. Technol. 2008, 23, 075019.

[61] B. Gao, W.Y. Chang, B. Sun, H. W. Zhang, L. F. Liu, X. Y. Liu, R. Q. Han, T. B. Wu, J. F. Kang, In International Symposium on VLSI Technology Systems and Applications, Taiwan, China, 26-28 Apirl 2010.

[62] M. Lanza, G. Bersuker, M. Porti, E. Miranda, M. Nafría, X. Aymerich, Appl. Phys. Lett. 2012, 101, 193502.

[63] R. Annunziata, P. Zuliani, M. Borghi, G. De Sandre, L. Scotti, C. Prelini, M. Tosi, I. Tortorelli, F. Pellizzer, in IEEE Int. Electron Dev. Meeting, Baltimore, MD, USA, 7-9 December, 2009.

[64] K. Tsuchida, T. Inaba, K. Fujita, Y. Ueda, T. Shimizu, Y. Asao, T. Kajiyama, M. Iwayama, K. Sugiura, S. Ikegawa, T. Kishi, T. Kai, M. Amano, N. Shimomura, H. Yoda, Y. Watanabe, in IEEE Int. Solid-State Circuits Conference Digest of Technical Papers, San, Francisco, CA, USA, 7-11 February 2010.

[65] H. Y. Lee, P. S. Chen, T. Y. Wu, Y. S. Chen, C. C. Wang, P. J. Tzeng, C. H. Lin, F. Chen, C. H. Lien, M. J. Tsai, in IEEE Int. Electron Dev. Meeting, San Francisco, CA, USA, 25-17 December, 2010.

[66] Q. Luo, X. X. Xu, H. T. Liu, H. B. Lv, T. C. Gong, S. B. Long, Q. Liu, H. T. Sun, W. Banerjee, L. Li, J. F. Gao, N. D. Lu, S. S. Chung, J. Li, M. Liu, in IEEE Int. Electron Dev. Meeting, Washington, Dc, USA, 7-9 December, 2015.

[67] T. Breuer, A. Siemon, E. Linn, S. Menzel, R. Waser, V. Rana, Adv. Electron. Mater. 2015, 1, 1500138. 
[68] The Crossbar RRAM Advantage: Simply Fast, Simply Scalable, Simply Reliable: http://crossbar-inc.com/technology/rram-advantages/ (Accessed: August $25^{\text {th }}$ of 2016)

[69] Y. Sakotsubo, S. Sagamihara, M. Terai, S. Kotsuji, Y. Saito, M. Tada, Y. Yabe, H. Hada, VLSI Technology (VLSIT), Honolulu, Hawaii, USA, 15-17 June 2010.

[70] T. Yamamoto, T. Kubo, T. Sukegawa, E. Takii, Y. Shimamune, N. Tamura, T. Sakoda M. Nakamura, H. Ohta, T. Miyashita, H. Kurata, S. Satoh, M. Kase, T. Sugii, IEEE International Electron Devices Meeting, Washington DC, USA, 1012 December 2007.

[71] Website of Panasonic: (Microcontrollers) https://na.industrial.panasonic.com /products/semiconductors/microcontrollers/8-bit-low-power-microcomputersmn1011-series.

[72] Website of Adesto Technologies: http://www.adestotech.com/products/mavriq/

[73] Website of Nantero: http://nantero.com/technology/

[74] P. K. Yang, W. Y. Chang, P. Y. Teng, S. F. Jeng, S. J. Lin, P. W. Chiu, J. H. He, in Proceedings of the IEEE 2013, 101, 1732.

[75] Y. Ji, S. Lee, B. Cho, S. Song, T. Lee, ACS Nano 2011, 5, 5995.

[76] A. H. C. Neto, F. Guinea, N. M. R. Peres, K. S. Novoselov, A. K. Geim, Rev. Mod. Phys. 2009, 81, 109.

[77] E. Stolyarova, D. Stolyarov, K. Bolotin, S. Ryu, L. Liu, K.T. Rim,M. Klima,M. Hybertsen, I. Pogorelsky, I. Pavlishin, K. Kusche, J. Hone, P. Kim, H.L. Stormer, V. Yakimenko, G. Flynn, Nano Lett. 2009, 9, 332.

[78] S. Chen, L. Brown, M. Levendorf, W. Cai, S.-Y. Ju, J. Edgeworth, X. Li, C. W. Magnuson, A. Velamakanni, R. D. Piner, J. Kang, J. Park, R. S. Ruoff, $A C S$ Nano 2011, 5, 1321. 
[79] C. Lee, X. Wei, J. W. Kysar, J. Hone, Science 2008, 321, 385.

[80] F. Bonaccorso, Z. Sun, T. Hasan, A. C. Ferrari, Nat. Photonics 2010, 4, 611.

[81] N. Tombros, C. Jozsa, M. Popinciuc, H. T. Jonkman, B. J. van Wees, Nature 2007, 448, 571 .

[82] A. Balandin, S. Ghosh, W. Bao, I. Calizo, D. Teweldebrhan, F. Miao, C. N. Lau, Nano Lett. 2008, 8, 902.

[83] A.C. Ferrari et al. Nanoscale 2015, 7, 4598.

[84] R. U. A. Khan, S. R. P. Silva, Diamond Relat. Mater. 2001, 10, 1036.

[85] F. Zhuge, W. Dai, C. L. He, A. Y. Wang, Y. W. Liu, M. Li, Y. H. Wu, P. Cui, R. W. Li, Appl. Phys. Lett. 2010, 96, 163505.

[86] L. Dellmann, A. Sebastian, P. Jonnalagadda, C. A. Santini, W. W. Koelmans, C. Rossel, E. Eleftheriou, Proc. Eur Solid-state Device Res. Conf. 2013, 268.

[87] Y. J. Chen, H. L. Chen, T. F. Young, T. C. Chang, T. M. Tsai, K. C. Chang, R. Zhang, K. H. Chen, J. C. Lou, T. J. Chu, J. H. Chen, D. H. Bao, S. M. Sze, Nanoscale Res. Lett. 2014, 9, 52.

[88] E. G. Gerstner, D. R. McKenzie, Diamond Relat. Mater. 1998, 7, 1172.

[89] E. G. Gerstner, D. R. McKenzie, J. Appl. Phys. 1998, 84, 5647.

[90] F. Bonaccorso, A. Lombardo, T. Hasan, Z. Sun, L. Colombo, A. C. Ferrari, Mater. Today 2012, 15, 564.

[91] S. Jang, E. Hwang, J. H. Cho, Nanoscale 2014, 6, 15286.

[92] S. Jang, E. Hwang, J. H. Lee, H. S. Park, J. H. Cho, Small 2015, 11, 311.

[93] S. M. Kim, E. B. Song, S. Lee, J. Zhu, D. H. Seo, M. Mecklenburg, S. Seo, K. L. Wang, ACS Nano 2012, 6, 7879.

[94] S. Lee, E. B. Song, S. M. Kim, Y. Lee, D. H. Seo, S. Seo, K. L. Wang, Appl. Phys. Lett. 2012, 101, 1. 
[95] Y. Park, S. Park, I. Jo, B. H. Hong, Y. Hong, Org. Electron. 2015, 27, 227.

[96] S. T. Han, Y. Zhou, Q. D. Yang, L. Zhou, L. B. Huang, Y. Yan, C. S. Lee, V. A. L. Roy, ACS Nano 2014, 8, 1923.

[97] Y. N. Kim, N. H. Lee, D. Y. Yun, T. W. Kim, Org. Electron. 2015, 25, 165.

[98] Y. Park, D. Gupta, C. Lee, Y. Hong, Org. Electron. 2012, 13, 2887.

[99] N. Zhan, M. Olmedo, G. P. Wang, J. L. Liu, Appl. Phys. Lett. 2011, 99, 113112.

[100] D. Selli, M. Baldoni, A. Sgamellotti, F. Mercuri, Nanoscale 2012, 4, 1350.

[101] A. Sinitskii, J. M. Tour, ACS Nano 2009, 3, 2760.

[102] X. M. Wang, W. G. Xie, J. Du, C. L. Wang, N. Zhao, J. B. Xu, Adv. Mater. 2012, 19,2614

[103] B. Standley, W. Z. Bao, H. Zhang, J. Bruck, C. N. Lau, M. Bockrath, Nano Lett. 2008, 8,3345 .

[104] Y. B. Li, A. Sinitskii, J. M. Tour, Nat. Mater. 2008, 7, 966.

[105] J. Yao, J. Lin, Y. H. Dai, G. Ruan, Z.Yan, L. Li, L. Zhong, D. Natelson, J. M. Tour, Nat. Commun. 2012, 3, 1101.

[106] K. S. Novoselov, A. K. Geim, S. V. Morozov, D. Jiang, Y. Zhang, S. V. Dubonos, I. V. Grigorieva, A. A. Firsov. Science 2004, 306, 666.

[107] J. Kim, D. Kim, Y. Jo, J. Han, H. Woo, H. Kim, K. K. Kim, J. P. Hong, H. Im, Thin Solid Films 2015, 589, 188.

[108] A. Asamitsu, Y. Tomioka, H. Kuwahara, Y. Tokura, Nature 1997, 388, 50-52.

[109] D. C. Kim, S. Seo, S. E. Ahn, D. S. Suh, M. J. Lee, B. H. Park, I. K. Yoo, I. G. Baek, H. J. Kim, E. K. Yim, J. E. Lee, S. O. Park, H. S. Kim, U-In Chung, J. T. Moon, B. I. Ryu, Appl. Phys. Lett. 2006, 88, 202102.

[110] B. J. Choi, D. S. Jeong, S. K. Kim, C. Rohde, S. Choi, J. H. Oh, H. J. Kim, C. S. Hwang, K. Szot, R. Waser, B. Reichenberg, S. Tiedke, J. Appl. Phys. 2005, 
98, 033715.

[111] I. G. Baek, M. S. Lee, S. Seo, M. J. Lee, D. H. Seo, D. S. Suh, J. C. Park, S.O. Park, H. S. Kim, I. K. Yoo, U. I. Chung, J. T. Moon, in IEEE Int. Electron Dev. Meeting, San Francisco, CA, USA, 13-15 December 2004.

[112] D. S. Jeong, H. Schroeder, R. Waser, Electrochem. Solid-State Lett. 2007, 10, G51-G53.

[113] S. Lee, J. Sohn, Z. Jiang, H. Chen, H. S. Philip Wong, Nat. Commun. 2015, 6, 8407.

[114] C. A. Ross, H. I. Smith, T. Savas, M. Schattenburg, M. Farhoud, M. Hwang, M. Walsh, M. C. Abraham, R. J. Ram, J. Vac. Sci. Technol. B 1999, 17, 3168.

[115] Y. Ji, M. Choe, B. Cho, S. Song, J. Yoon, H. C. Ko, T. Lee, Nanotechnology 2012, 23, 105202.

[116] C. X. Wu, F. S. Li, T. L. Guo, Appl. Phys. Lett. 2014, 104, 183105.

[117] S. Ghosh, I. Calizo, D. Teweldebrhan, E. P. Pokatilov, D. L. Nika, A. A. Balandin, W. Bao, F. Miao, C. N. Lau, Appl. Phys. Lett. 2008, 92, 151911.

[118] Y. Chen, B. Zhang, G. Liu, X. D. Zhuang, E. T. Kang, Chem. Soc. Rev. 2012, $41,4688$.

[119] X. Zhang, H. Xie, Z. Liu, C. Tan, Z. Luo, H. Li, J. Lin, L. Sun, W. Chen, Z. Xu, Li.Xie, W. Huang, H. Zhang, Angew. Chem. Int. Ed. 2015, 54, 3653.

[120] Graphene-based MIM diode and associated methods, US 9202945 B2, 2015.

[121] K. S. Novoselov, D. Jiang, F. Schedin, T. J. Booth, V. V. Khotkevich, S. V. Morozov, A. K. Geim, Proc. Natl. Acad. Sci. U. S. A. 2005, 102, 10451.

[122] G. L. Yua, R. Jalilb, B. Belleb, A. S. Mayorova, P. Blakeb, Fr. Schedinb, S. V. Morozovc, L. A. Ponomarenkoa, F. Chiappinid, S. Wiedmannd, Uli Zeitlerd, M. I. Katsnelsone, A. K. Geima, K. S. Novoselova, D. C. Eliasa, PNAS, 2013, 110, 
3282.

[123] L. Britnell, R. V. Gorbachev, R. Jalil, B. D. Belle, F. Schedin, M. I. Katsnelson, L. Eaves, S. V. Morozov, A. S. Mayorov, N. M. R. Peres, A. H. C. Neto, J. Leist, A. K. Geim, L. A. Ponomarenko, and K. S. Novoselov, Nano Lett. 2012, 12, 1707.

[124] Y. Hernandez, V. Nicolosi, M. Lotya, F. M. Blighe, Z. Sun, S. De, I. T. Mcgovern, B. Holland, M. Byrne, Y. K. Gunko, J. J. Boland, P. Niraj, G. Duesberg, S. Krishnamurthy, R. Goodhue, J. Hutchison, V. Scardaci, A. C. Ferrari, J. N. Coleman, Nat. Nanotechnol. 2008, 3, 563.

[125] X. S. Li, W. W. Cai, J. H. An, S. Y. Kim, J. Nah, D. X. Yang, R. Piner, A. Velamakanni, I. Jung, E. Tutuc, S. K. Banerjee, L. G. Colombo, R. S. Ruoff, Science 2009, 324, 1312.

[126] H. Y. Jeong, J. Y. Kim, J. W. Kim, J. O. Hwang, J. E. Kim, J. Y. Lee, T. H. Yoon, B. J. Cho, S. O. Kim, R. S. Ruoff, S. Y. Choi, Nano Lett. 2010, 10, 4381.

[127] S. Porro, E. Accornero, C. F. Pirri, C. Ricciardi, Carbon 2015, 85, 383.

[128] S. Seo, Y. H. Yoon, J. H. Lee, Y. H. Park, H. Y. Lee, ACS Nano 2013, 7, 3607.

[129] M. Lotya, Y. Hernandez, P. J. King, R. J. Smith, V. Nicolosi, L. S. Karlsson, F. M. Blighe, S. De, Z. Wang, I. T. McGovern, G. S. Duesberg, J. N. Coleman, J. Am. Chem. Soc. 2009, 131, 3611.

[130] J. N. Coleman et al. Science, 2011, 311, 568.

[131] S. C. Ray, S. K. Bhunia, A. Saha, N. R. Jana, Microelectron. Eng. 2015, 146, 48.

[132] I. Banerjee, P. Harris, A. Salimian, A. K. Ray, IET Circuits, Devices \& Systems, 2015, 9, 428.

[133] S. Porro, C. Ricciardi, RSC Adv. 2015, 5, 6856. 
[134] A. Matkovic, I. Milosevic, M. Milicevic, T. Tomasevic-Ilic, J. Pesic, M. Music, M. Spasenovic, D. Jovanovic, B. Vasic, C. Deeks, R. Panajotovic, M. R. Belic, R. Gajic, 2D Mater. 2016, 3, 015002.

[135] M. Lanza, M. Porti, M. Nafría, G. Benstetter, W. Frammelsberger, H. Ranzinger, E. Lodermeier, G. Jaschke, Microelectron. Reliab. 2007, 47, 1424.

[136] J. Petry, W. Vandervorst, O. Richard, T. Conard, P. DeWolf, V. Kaushik, A. Delabie, S. V. Elshocht, Mater Res Soc Symp Proc, San Francisco, CA, USA, 13-16 April 2004.

[137] M. Lanza, M. Porti, M. Nafría, X. Aymerich, G. Benstetter, E. Lodermeier, H. Ranzinger G. Jaschke, S. Teichert, L. Wilde, P. Michalowski, IEEE Trans. Nanotechnol. 2011, 10, 344.

[138] C. L. Tan, Z. D. Liu, W. Huang, H. Zhang, Chem. Soc. Rev. 2015, 44, 2615.

[139] L. Y. Niu, J. N. Coleman, H. Zhang, H. Shin, M. Chhowalla, Z. J. Zheng, Small 2016, 12, 272.

[140] J. Q. Liu, Z. Q. Lin, T. J. Liu, Z. Y. Yin, X. Z. Zhou, S. F. Chen, L. H. Xie, F. Boey, H. Zhang, W. Huang, Small 2010, 6, 1536.

[141] P. Blake, P. D. Brimicombe, R. R. Nair, T. J. Booth, D. Jiang, F. Schedin, L. A. Ponomarenko, S. V. Morozov, H. F. Gleeson, E. W. Hill,A. K. Geim, K. S. Novoselov, Nano Lett. 2008, 8, 1704.

[142] K. S. Kim, Y. Zhao, H. Jang, S. Y. Lee, J. M. Kime, K. S. Kim, J. H. Ahn, P. Kim, J. Y. Choi, B. H. Hong, Nature, 2009, 457, 706.

[143] J. Coraus, A. T. Ndiaye, M. Engler, C. Busse, D. Wall, N. Buckanie, F. J. M. Heringdorf, R. V. Gastel, B. Poelsema, T. Michely, New J. Phys. 2009, 11, 023006.

[144] Y. Z. Xue, B. Wu, Y. L. Guo, L. P. Huang, L. Jiang, J. Y. Chen, D. C. Geng, Y. 
Q. Liu, W. P. Hu, G. Yu, Nano Res. 2011, 4, 1208.

[145] Z. W. Peng, Z. Yan, Z. Z. Sun, J. M. Tour, ACS Nano 2011, 5, 8241.

[146] D. R. Lenski, M. S. Fuhrer, J. Appl. Phys. 2011, 110, 013720.

[147] T. Kato, R. Hatakeyama, ACS Nano 2012, 6, 8508.

[148] Y. J. Zhan, Z. Liu, S. Najmaei, P. M. Ajayan, J. Lou, Small, 2012, 8, 966.

[149] S. F. Wu, C. M. Huang, G. Aivazian, J. S. Ross, D. H. Cobden, X. D. Xu, ACS Nano, 2013, 7, 2768.

[150] K. K. Liu, W. J. Zhang, Y. H. Lee, Y. C. Lin, M. T. Chang, C. Su, C. S. Chang, H. Li, Y. M. Shi, H. Zhang, C. S. Lai, L. J. Li, Nano Lett. 2012, 12, 1538.

[151] Y. H. Lee, X. Q. Zhang, W. J. Zhang, M. T. Chang, C. T. Lin, K. D. Chang, Y. C. Yu, J. T. W. Wang, C. S. Chang, L. J. Li, T. W. Lin, Adv. Mater. 2012, 24, 2320.

[152] Y. F. Yu, C. Li, Y. Liu, L. Q. Su, Y. Zhang and L. Y. Cao, Sci. Rep. 2013, 3, 1866.

[153] S. Kikkawa, R. Shimanouchi-Futagami, M. Koizumi, Appl. Phys. A 1989, 49, 105.

[154] E. S. Peters, C. J. Carmalt, I. P. Parkin, D. A. Tocher, Eur. J. Inorg. Chem. 2005, 20,4179 .

[155] C. Cong, J. Shang, X.Wu, B. C. Cao, N. Peimyoo, C. Y. Qiu, L. T. Sun, T. Yu, arXiv:1312.1418

[156] J. Xia, X. Huang, L. Z. Liu, M. Wang, L. Wang, B. Huang, D. D. Zhu, J. J. Li, C. Z. Gu, X. M. Meng, Nanoscale 2014, 6, 8949.

[157] X. Wang, Y. Gong, G. Shi, W. L. Chow, K. Keyshar, G. L. Ye, R. Vajtai, J. Lou, Z. Liu, E. Ringe, B. K. Tay, P. M. Ajayan, ACS Nano 2014, 8, 5125.

[158] J. K. Huang, J. Pu, C. L. Hsu, M. H. Chiu, Z. Y. Juang, Y. H. Chang, W. H. Chang, Y. Iwasa, T. Takenobu, L. J. Li, ACS Nano 2013, 8, 923. 
[159] L. Song, L. J. Ci, H. Lu, P. B. Sorokin, C. H. Jin, J. Ni, A. G. Kvashnin, D. G. Kvashnin, J. Lou, B. I. Yakobson, P. M. Ajayan, Nano Lett. 2010, 10, 3209.

[160] S. M. Kim, A. Hsu, M. H. Park, S. H. Chae, S. J. Yun, J. S. Lee, D. H. Cho, W. J. Fang, C. G. Lee, T. Palacios, M. Dresselhaus, K. K. Kim, Y. H. Lee, J. Kong, Nat. Commun. DOI: 10.1038/ncomms9662.

[161] Y. Gao, W. C. Ren, T. Ma, Z. B. Liu, Y. Zhang, W. B. Liu, L. P. Ma, X. L. Ma, H. M. Cheng, ACS Nano 2013, 7, 5199.

[162] J. B. Smith, D. Hagaman, H. F. Ji, Nanotechnology 2016, 27, 215602.

[163] Chengbin Pan, Yanfeng Ji, Na Xiao, Fei Hui, Kechao Tang, Yuzheng Guo, Xiaoming Xie, Francesco M. Puglisi, Luca Larcher, Enrique Miranda, Lanlan Jiang, Yuanyuan Shi, Ilia Valov, Paul C. McIntyre, Rainer Waser and Mario Lanza, Adv. Functional Mater. (submitted)

[164] M. Lanza, Y. Wang, T. Gao, A. Bayerl, M. Porti, M. Nafria, Y. B. Zhou, G. Y. Jin, Z. F. Liu, Y. F. zhang, D. P. Yu, H. L. Duan, Nano Research 2013, 6, 485.

[165] J. W. Suk, A. Kitt, C. Magnuson, Y. F. Hao, S. Ahmed, J. An, A. K. Swan, B. B. Goldberg, R. S. Ruoff. ACS Nano, 2011, 5, 6916.

[166] M. Lanza, A. Bayerl, T. Gao, M. Porti, M. Nafria, G. Y. Jing, Y. F. Zhang, Z. F. Liu, H. L. Duan. Adv. Mater. 2013, 25, 14401444.

[167] M. Lanza, T. Gao, Z. X. Yin, Y. F. Zhang, Z. F. Liu, Y. Z. Tong, Z. Y. Shen, H. L. Duan, Nanoscale 2013, 5, 10816.

[168] X. S. Li, Y. W. Zhu, W. W. Cai, M. Borysiak, B. Y. Han, D. Chen, R. D. Piner, L. Colombo, R. S. Ruoff, Nano Lett. 2009, 9, 4359.

[169] L. B. Gao, G. X. Ni, Y. P. Liu, B. Liu, A. H. Castro Neto, K. P. Loh, Nature 2014, $505,190$.

[170] K. Lee, I. Hwang, S. Lee, S. Oh, D. Lee, C. K. Kim, Y. Nam, S. Hong, C. Yoon, 
R. B. Morgan, H. Kim, S. Seo, D. H. Seo, S. Lee, B. H. Park, Sci. Rep. 2015, 5, 11279.

[171] J. H. Lee, C. Du, K. Sun, E. Kioupakis, W. D. Lu, ACS Nano 2016, 10, 3571.

[172] A. Pirkle, J. Chan, A. Venugopal, D. Hinojos, C. W. Magnuson, S. Mcdonnell, L. Colombo, E. M. Vogel, R. S. Ruoff, R. M. Wallace, Appl. Phys. Lett. 2011, 99, 122108.

[173] D. Y. Wang, I. S. Huang, P. H. Ho, S. S. Li, Y. C. Yeh, D. W. Wang, W. L. Chen, Y. Y. Lee, Y. M. Chang, C. C. Chen, C. T. Liang, C. W. Chen, Adv. Mater. 2013, 25,4521 .

[174] A. P. Esser-Kahn, P. R. Thakre, H. Dong, J. F. Patrick, V. K. Vlasko-Vlasov, N. R. Sottos, J. S. Moore, S. R. White, Adv. Mater. 2011, 23, 3654.

[175] C. G. Willson, R. R. Dammel, A. Reiser, Emerging Lithographic Technologies Proc. SPIE 1997, 28.

[176] P. Sutter, J. Lahiri, P. Zahl, B. Wang, E. Sutter, Nano Lett. 2013, 13, 276.

[177] W. Yang, G. R. Chen, Z. W. Shi, C. C. Liu, L. C. Zhang, G. B. Xie, M. Cheng, D. M. Wang, R. Yang, D. X. Shi, K. Watanabe, T. Taniguchi, Y. G. Yao, Y. B. Zhang, G. Y. Zhang, Nat. Mater. 2013, 12, 792.

[178] S. Ratha, C. S. Rout, Appl. Mater. Interfaces 2013, 5, 11427.

[179] X. R. Wang, S. M. Tabakman, H. J. Dai, J. Am. Chem. Soc. 2008, 130, 8152.

[180] S. McDonnell, B. Brennan, A. Azcatl, N. Lu, H. Dong, C. Buie, J. Kim, C. L. Hinkle, M. J. Kim, R. M. Wallace, ACS Nano 2013, 7, 10354.

[181] H. Y. Nan, Z. L. Wang, W. H. Wang, Z. Liang, Y. Lu, Q. Chen, D. W. He, P. H. Tan, F. Miao, X. R. Wang, J. L. Wang, Z. H. Ni, ACS Nano 2014, 8, 5738.

[182] A. A. Demkov, O. F. Sankey, Phys. Rev. Lett. 1999, 83, 2038.

[183] J. L. Alay, M. Hirose, J. Appl. Phys. 1997, 81, 1606. 
[184] B. Brar, G. D. Wilk, A. C. Seabaugh, Appl. Phys. Lett. 1996, 69, 2728.

[185] B. Chakrabarti, T. Roy, E. M. Vogel, IEEE Electron Dvice Letters, 2014, 35, 7.

[186] Y. Bai, H. Wu, K. Wang, R. Wu, L. Song, T. Li, J. Wang, Z. Yu, H. Qian. Sci. Rep. 2015, 5, 13785.

[187] G. Fisichella, G. Greco, F. Roccaforte, F. Giannazzo, Nanoscale 2014, 6, 8671.

[188] J. W. Seo, J.W. Park, K. S. Lim, J.H. Yang, S. J. Kang, Appl. Phys. Lett. 2008, 93, 223505.

[189] H. D. Kim, H. M. An, Y. Seo, T. G. Kim, IEEE Electron Device Lett. 2011, 32 , 1125

[190] K. C. Liu, W. H. Tzeng, K. M. Chang, Y. C. Chan, C. C. Kuo, Microelectron. Eng. 2011, 88, 1586.

[191] J. Lee, O. Kim, Jpn. J. Appl. Phys. 2011, 50, 06GF01.

[192] H. Zhao, H. Tu, F. Wei, J. Du, IEEE Electron Devices Lett. 2014, 61, 5.

[193] K. Zheng, X. W. Sun, J. L. Zhao, Y. Wang, H. Y. Yu, H. V. Demir, K. L. Teo, IEEE Electron Devices Lett. 2011, 32, 6.

[194] Y. S. Ji, S. A. Lee, A. N. Cha, M. Goh, S. Bae, S. Lee, D. I. Son, T. W. Kim. Organic electron. 2015, 18, 77.

[195] D. I. Son, T. W. Kim, J. H. Shim, J. H. Jung, D. U. Lee, J. M. Lee, W. I. Park, W. K. Choi, Nano Lett. 2010, 10, 2441.

[196] M. Qian, Y. Pan, F. Liu, M. Wang, H. Shen, D. He, B. Wang, Y. Shi, F. Miao, X. Wang, Adv. Mater. 2014, 26, 3275.

[197] H. Shima, F. Takano, H. Muramatsu, H. Akinaga, Y. Tamai, I. H. Inque, H. Takagi, Appl. Phys. Lett. 2008, 93, 113504.

[198] H. Shima, T. Nakano, H. Akinaga, Appl. Phys. Lett. 2010, 96, 192107.

[199] H. Lv, M. Wang, H. Wan, Y. Song, W. Luo, P. Zhou, T. Tang, Y. Lin, R. Huang, 
S. Song, J. G. Wu, H. M. Wu, M. H. Chi, Appl. Phys. Lett. 2009, 94, 213502.

[200] C. Y. Lin, D. Y. Lee, S. Y. Wang, C. C. Lin, T. Y. Tseng, Surface Coatings Technol. 2008, 203, 628.

[201] T. N. Fang, S. Kaza, S. Haddad, A. Chen, Y. C. Wu, Z. Lan, S. Avanzino, D. Liao, C. Gopalan, S. Choi, S. Mahdavi, M. Buynoski, Y. Lin, C. Marrian, C. Bill, M. VanBuskirk, M. Taguchi, Tech. Dig. Int. Electron Devices Meeting, San Francisco, CA, USA, 2006.

[202] C. B. Lee, B. S. Kang, A. Benayad, M. J. Lee, S. E. Ahn, K. H. Kim, G. Stefanovich, Y. Park, I. K. Yoo, Appl. Phys. Lett. 2008, 93, 042115.

[203] K. M. Kim, B. J. Choi, Y. C. Shin, S. Choi, and C. S. Hwang, Appl. Phys. Lett. 2007, 91, 012907.

[204] S. Seo, M. J. Lee, D. C. Kim, S. E. Ahn, B. -H. Park, Y. S. Kim, I. K. Yoo, I. S. Byun, I. R. Hwang, S. H. Kim, J. S. Kim, J. S. Choi, J. H. Lee, S. H. Jeon, S. H. Hong, B. H. Par. Appl. Phys. Lett. 2005, 87, 263507.

[205] X. Lian, X. Cartoixa, E. Miranda, L. Perniola, R. Rurali, S. Long, M. Liu, J. Sune, J. Appl. Phys. 2014, 115, 244507.

[206] X. Lian, M. Lanza, A. Rodríguez, E. Miranda, J. Suñé, in IEEE Int. Conf. SolidState Integr. Circuit Technol., Guilin, China, 28-31 October 2014.

[207] S. B. Long, X. J. Lian, C. Cagli, X. Cartoix_a, R. Rurali, E. Miranda, D. Jim_enez, L. Perniola, M. Liu, J. Sune, Appl. Phys. Lett. 2013, 102, 183505.

[208] Y. C. Yang, W. Lu, Nanoscale 2013, 5, 10076.

[209] V. V. N. Obreja, C. Codreanu, D. Poenar, O. Buiu, Microelectron. Reliab. 2011, 51,536 .

[210] M. Lanza, M. Porti, M. Nafría, X. Aymerich, E. Whittaker, B. Hamilton, Microelectron. Reliab. 2010, 50, 1312. 
[211] S. H. Seo, J. S. Hwang, J. M. Yang, W. J. Hwang, J. Y. Song, W. J. Lee, Thin Solid Films 2013, 546, 14.

[212] S. S. Hwang, S. Y. Jung, Y. C. Joo, J. Appl. Phys. 2008, 104, 044511.

[213] N. Raghavan, K. L. Pey, K. Shubhakar, M. Bosman, IEEE Electron Device Lett. 2011, 32, 78.

[214] E. A. Miranda, C. Walczyk, C. Wenger, T. Schroeder, IEEE Electron Device Lett. 2010, 31, 609.

[215] J.S. Bunch, S.S. Verbridge, J.S. Alden, A.M. van der Zande, J.M. Parpia, H.G. Craighead, P.L. McEuen, Nano Lett. 2008, 8, 2458.

[216] J. B. Oostinga, H. B. Heersche, X. L. Liu, A. F. Morpurgo, L. M. K. Vandersypen, Nat. Mater. 2008, 7, 151.

[217] H. Tian, H. Y. Chen, B. Gao, S. M. Yu, J. L. Liang, Y. Yang, D. Xie, J. F. Kang, T. L. Ren, Y. G. Zhang, H. S. P. Wong. Nano Lett. 2013, 13, 651.

[218] N. T. Kirkland, T. Schiller, N. Medhekar, N. Birbilis, Corros. Sci. 2012, 56, 1.

[219] L. L. Zhang, R. Zhou, X. S. Zhao, J. Mater. Chem. 2010, 20, 5983.

[220] C. Y. Chen, J. R. D. Retamal, D. H. Lien, M. W. Chen, I. W. Wu, Y. Ding, Y. L. Chueh, C. I. Wu, J. H. He, ACS Nano 2012, 6, 9366.

[221] Q. H. Li, T. Gao, Y. G. Wang, T. H. Wang, Appl. Phys. Lett. 2005, 86, 123117.

[222] C. Y. Chen, C. A. Lin, J. H. He, Nanotechnology 2009, 20, 185605.

[223] W. K. Hong, G. Jo, S. S. Kwon, S. Song, T. Lee, IEEE Trans. Electron Dev. 2008, 55,3020

[224] J. H. He, C. H. Ho, C. Y. Chen, Nanotechnology 2009, 20, 065503.

[225] Z. Fan, D. Wang, P. C. Chang, W. Y. Tseng, J. G. Lu, Appl. Phys. Lett. 2004, 85, 5923.

[226] C. Y. Chen, M. W. Chen, J. J. Ke, C. A. Lin, J. R. D. Retamal, J. H. He, Pure 
Appl. Chem. 2010, 82, 2055.

[227] M. W. Chen, J. R. D. Retamal, C. Y. Chen, J. H. He, IEEE Electron Dev. Lett. 2012, 33, 411 .

[228] V. E. Henrich, P. A. Cox, Surface Science of Metal Oxides, Cambridge University Press, Cambridge, UK, 1994.

[229] H. Jeon, J. Park, W. Jang, H. Kim, S. Ahn, K.-J. Jeon, H. Seo, H. Jeon, Carbon 2014, 75, 209.

[230] L. G. Cançado, A. Jorio, E. M. Ferreira, F. Stavale, C. A. Achete, R. B. Capaz, M. V. O. Moutinho, A. Lombardo, T. S. Kulmala, Ferrari, A. C. Nano Lett. 2011, $11,3190$.

[231] Y. C. Yang, J. Lee, S. Lee, C. H. Liu, Z. H. Zhong, W. Lu, Adv. Mater. 2014, 26, 3693.

[232] S. Yu, H. Y. Chen, B. Gao, J. Kang, H. S. P. Wong, ACS Nano 2013, 7, 2320.

[233] J. Sohn, S. Lee, Z. Jiang, H. Y. Chen, H. S. P. Wong, in IEEE int. Electron Dev. Meeting (IEDM), San Francisco, CA, USA, 15-17 Dec. 2014.

[234] S. Stankovich, D. A. Dikin, G. H. B. Dommett, K. M. Kohlhaas, E. J. Zimney, E. A. Stach, R. D. Piner, S. T. Nguyen, R. S. Ruoff, Nature, 2006, 442, 282.

[235] L. Wang, I. Meric, P. Y. Huang, Q. Gao, Y. Gao, H. Tran, T. Taniguchi, K. Watanabe, L. M. Campos, D. A. Muller, J. Guo, P. Kim, J. Hone, K. L. Shepard, C. R. Dean, Science 2013, 342, 614.

[236] J. H. Chen, C. Jang, S. D. Xiao, M. Ishigami, M. S. Fuhrer, Nat. Nanotechnol. 2008, 3, 206.

[237] L. Gao, W. Ren, H. Xu, L. Jin, Z. Wang, T. Ma, L. P. Ma, Z. Zhang, Q. Fu, L. M. Peng, X. Bao, H. M. Cheng, Nat. Commun. 2012, 3, 699.

[238] D. R. Stewart, D. A. A. Ohlberg, P. A. Beck, Y. Chen, R. S. Williams, J. O. 
Jeppesen, Nano Lett. 2004, 4, 133.

[239] Y. Yang, J. Y. Ouyang, L. P. Ma, R. J. H. Tseng, C. W. Chu, Adv. Funct. Mater. 2006, 16,1001

[240] C. C. Lin, B. C. Tu, C. C. Lin, C. H. Lin, T. Y. Tseng, IEEE Electron Device Lett. 2006, 27, 725 .

[241] C. L. He, F. Zhuge, X. F. Zhou, M. Li, G. C. Zhou, Y. W. Liu, J. Z. Wang, B. Chen, W. J. Su, Z. P. Liu, Y. H. Wu, P. Cui, R. W. Li, Applied Physics Letters 2009, 95, 232101

[242] M. D. Yi, Y. Cao, H. F. Ling, Z. Z. Du, L. Y. Wang, T. Yang, Q. L. Fan, L. H. Xie, W. Huang, Nanotechnology 2014, 25, 185202.

[243] D. Y. Yun, T. W. Kim, Carbon 2015, 88, 26.

[244] D. H. Yoo, T. V. Cuong, S. H. Hahn, Current Appl. Phys. 2014, 14, 1301.

[245] F. Zhuge, B. Hu, C. He, X. Zhou, Z. Liu, R. W. Li, Carbon 2011, 49, 3796.

[246] G. Khurana, P. Misra, N. Kumar, R. S. Katiyar, J. Phys. Chem. C 2014, 118, 21357.

[247] P. Hazra, A. N. Resmi, K. B. Jinesh, Appl. Phys. Lett. 2016, 108, 153503.

[248] S. K. Hong, J. E. Kim, S. O. Kim, B. J. Cho, J. Appl. Phys. 2011, 110, 044506.

[249]s. L. Hong, J. E. Kim, S. O. Kim, S. Y. Choi, B. J. Cho, IEEE Electron Device Lett. $\mathbf{2 0 1 0}, 31,1005$

[250] S. M. Jilani, T. D. Gamot, P. Banerji, S. Chakraborty, Carbon 2013, 64, 187.

[251] G. Venugopal, S. J. Kim, J. Nanosci. Nanotechnol. 2012, 12, 8522.

[252] G. Khurana, P. Misra, R. S. Katiyar, Appl. Phys. Lett. 2013, 114, 124508.

[253] G. N. Panin, O. O. Kapitanova, S. W. Lee, A. N. Baranov, and T. W. Kang, Jpn J. Appl. Phys. 2011, 50, 070110.

[254] H. Tian, H.Y. Chen, T. L. Ren, C. Li, Q. T. Xue, M. A. Mohammad, C. Wu, Y. 
Yang, H.S. Philip Wong, Nano Lett. 2014, 14, 3214.

[255] X. Zhou, Z. Liu, Chem. Commun. 2010, 46, 2611.

[256] S. K. Hong, J.E. Kim, S. O. Kim, B. J. Cho, in 2010 10th IEEE Conference on Nanotechnology 2010, 604.

[257] H. S. Ki, C. B, Jin, in Nanoelectronics Conference (INEC), 2011 IEEE $4^{\text {th }}$ International 2011, 1.

[258] C. Wu, F. Li, Y. Zhang, T. Guo, and T. Chen, Appl. Phys. Lett. 2011, 99, 042108.

[259] O. O. Ekiz, M. Urel, H. Guner, A. K. Mizrak, and A. Dana, ACS Nano, 2011, 5, 2475.

[260] K. S. Vasu, S. Sampath, and A. K. Sood, Solid State Commun. 2011, 151, 1084.

[261] L.H. Wang, W. Yang, Q.-Q. Sun, P. Zhou, H.-L. Lu, S.-J. Ding, and D. Wei Zhang, Appl. Phys. Lett. 2012, 100, 063509.

[262] H. D. Kim, M. J. Yun, J. H. Lee, K. H. Kim, T. G. Kim, Sci. Rep. 2014, 4, 4614.

[263] C. L. He, Z. W. Shi, L.C. Zhang, W. Yang, R. Yang, D. X. Shi, G. Y. Zhang, ACS Nano 2012, 6, 4214.

[264] I. Kim, M. Siddik, J. Shin, K. P. Biju, S. Jung, H. Hwang, Appl. Phys. Lett. 2011, 99, 042101.

[265] X. Dong, W. Huang, and P. Chen, IEEE Trans. Nanotechnol. 2010, 99, 1.

[266] S. K. Hong, J. E. Kim, S. O. Kim, B. J. Cho, J. Appl. Phys. 2011, 110, 044506.

[267] Z. R. Wang, V. Tjoa, L. Wu, W. J. Liu, Z. Fang, X. A. Tran, J. Wei, W. G. Zhu, H. Y. Yud, J. Electrochem. Soc. 2012, 159, 177.

[268] K. C. Chang, R. Zhang, IEEE Electron Device Lett. 2013, 34.

[269] X. L. Li, H. L. Wang, J. T. Robinson, H. Sanchez, G. Diankov, H. J. Dai, J. Am. Chem. Soc. 2009, 131, 15939.

[270] F. Zhao, J. Liu, X. Huang, X. Zou, G. Lu, P. Sun, S. Wu, W. Ai, M. D. Yi, X. 
Y. Qi, L. Xie, J. Wang, H. Zhang, W. Huang, ACS Nano 2012, 6, 3027.

[271] S. K. Pradhan, B. Xiao, S. Mishra, A. Killam, A. K. Pradhan, Sci. Rep. 2016, $6,26763$.

[272] N. T. Ho, V. Senthilkumar, Y. S. Kim, Solid-State Electron. 2014, 94, 61.

[273] B. L .Hu, R. Quhe, C. Chen, F. Zhuge, X. J. Zhu, S. S. Peng, X. X. Chen, L. Pan, Y. Z. Wu, W. Zheng, Q. Yan, J. Lu, R. W. Li, J. Mater. Chem. 2012, 22, 16422

[274] J. C. Jin, J. Lee, E. Lee, E. Hwang, H. Lee, Chem. Commun. 2012, 48, 4235.

[275] G. Liu, X. D. Zhuang, Y. Chen, B. Zhang, J. H. Zhu, C. X. Zhu, K. G. Neoh, E. T. Kang, Appl. Phys. Lett. 2009, 95, 253301.

[276] X. D. Zhuang, Y. Chen, G. Liu, P. P. Li, C. X. Zhu, E. T. Kang, K. G. Noeh, B. Zhang, J. H. Zhu, Y. X.Li, Adv. Mater. 2010, 22, 15, 1731.

[277] L. Valentini, M. Cardinali, E. Fortunti, J. M. Kenny, Appl. Phys. Lett. 2014, 105, 153111.

[278] S. Pinto, R. Krishna, C. Dias, G. Pimentel, G. N. P. Oliveira, J. M. Teixeira, P. Aguiar, E. Titus, J. Gracio, J. Ventura, J. P. Araujo, Appl. Phys. Lett. 2012, 101, 063104.

[279] J. Liu, Z. Yin, X. Cao, F. Zhao, A. Lin, L. Xie, Q. Fan, F. Boey, H. Zhang, W. Huang, ACS Nano 2010, 4, 3987.

[280] CareRAMM public summary http://emps.exeter.ac.uk/media/universityofexeter/emps/careramm/D4.4_Publi c_summary_of_project_results_from_the_third_year_of_the_project.pdf

[281] C. Casiraghi, J. Robertson, A. C. Ferrari, Mater. Today 2007, 10, 44

[282] A. C. Ferrari, Surf. Coat. Technol. 2004, 180, 190. 
[283] P. J. Fallon, V. S. Veerasaamy, C. A. Davis, J. Robertson, G. A. J. Amaratunga, W. I. Milne, J. Koskinen, Phys. Rev. B 1993, 48, 4777.

[284] M. C. Polo, J. L. Andujar, A. Hart, J. Robertson, W. I. Milne, Diamond Relat. Mater. 2000, 9, 663.

[285] A. Sebastian, A. Pauza, C. Rossel, R. M. Shelby, A. F. Rodriguez, H. Pozidis, E. Eleftheriou, New J. Phys. 2011, 13, 013020.

[286] F. Kreupl, R. Bruchhaus, P. Majewski, J. B. Philipp, R. Symanczyk, T. Happ, C. Arndt, M. Vogt, R. Zimmermann, A. Buerke, A. P. Graham, M. Kund, IEDM 2008 Technical Digest 2008, 15 , 521.

[287] P. Peng, D. Xie, Y. Yang, C. Zhou, S. Ma, T. Feng, H. Tian, T. Ren, J. Phys D: Appl. Phys. 2012, 45, 365103.

[288] D. Fu, D. Xie, T. T. Feng, C. H. Zhang, J. B. Niu, H. Qian, L. T. Liu, IEEE Electron Device Letters 2011, 32, 80.

[289] J. Xu, D. Xie, T. Feng, C. Zhang, X. Zhang, P. Peng, D. Fu, H. Qian, T.-1. Ren, L. Liu, Carbon 2014, 75, 255.

[290] Y. Chai, Y. Wu, K. Takei, H.-Y. Chen, S. Yu, P. C. H. Chan, A. Javey, H.-S. P. Wong, IEEE Trans. Electron. Dev. 2011, 58, 3933.

[291] B. Ren, L. Wang, L. Wang, J. Huang, K. Tang, Y. Lou, D. Yuan, Z. Pan, Y. Xia, Vacuum 2014, 107, 1.

[292] K. Antonowicz, A. Jesmanowicz, J. Wieczorek, Carbon 1972, 10, 81.

[293] A. C. Ferrari and J. Robertson, Philosophical Transactions of the Royal Society A-mathematical Physical and Engineering Sciences 2004, 362, 2477.

[294] C. A. Santini, A. Sebastian, C. Marchiori, V. P. Jonnalagadda, L. Dellmann, W. W. Koelmans, M. D. Rossell, C. P. Rossel, E. Eleftheriou, Nat. Communications. 2015, 6,1 . 
[295] H. Chen, F. Zhuge, B. Fu, J. Li, J. Wang, W. Wang, Q. Wang, L. Li, F. Li, H. Zhang, L. Liang, H. Luo, M. Wang, J. Gao, H. Cao, H. Zhang, Z. Li, Carbon 2014, 76, 459 .

[296] V. K. Nagareddy, A. K. Ott , C. Dou, T. Tsvetkova, M. Sandulov, M. F. Craciun, A. C. Ferrari, C. D. Wright, submitted (2016).

[297] S. Zhang, J. Zhou, D. Zhang, B. Ren, L. Wang, J. Huang, L. Wang, Vacuum 2016, 125, 189.

[298] M. Pyun, H. Choi, J. B. Park, D. Lee, M. Hasan, R. Dong, S. J. Jung, J. Lee, D. J. Seong, J. Yoon, H. Hwang, Appl. Phys. Lett. 2008, 93, 212907.

[299] H. Choi, M. Pyun, T. W. Kim, M. Hasan, R. Dong, J. Lee, J. B. Park, J. Yoon, D. J. Seong, T. Lee, H. Hwang, IEEE Electron Dev. Lett. 2009, 30, 302.

[300] D. I. Kim, J. Yoon, J.-B. Park, H. Hwang, Y. M. Kim, S. H. Kwon, K. H. Kim, Appl. Phys. Lett. 2011, 98, 152107.

[301] W. W. Koelmans, T. Bachmann, F. Zipoli, A. K. Ott, C. Dou, A. C. Ferrari, O. Cojocaru-Mirédin, S. Zhang, M. Wuttig, V. K. Nagareddy, M. F. Craciun, A. Alexeev, C. D. Wright, V. P. Jonnalagadda, A. Curioni, A. Sebastian, E. Eleftheriou, Carbon-based resistive memories, IEEE (IMW),1-4 (2016).

[302] T. A. Bachmann, A. M. Alexeev, W. W. Koelmans, F. Zipoli, A. K. Ott, C. Dou, A. C. Ferrari, V. K. Nagareddy, M. F. Craciun, V. P. Jonnalagadda, A. Curioni, A. Sebastian, E. Eleftheriou, C. D. Wright, IEEE NMDC 2016.

[303] F. Kreupl, Carbon Memory Assessment, White paper for the ITRS meeting on emerging research devices (ERD) in Albuquerque, New Mexico, on August 25-26, 2014.

[304] X. Zhao, H. Xu, Z. Wang, L. Zhang, J. Ma, Y. Liu, Carbon 2015, 91, 38.

[305] W. Dai, P. Ke, A. Wang, J. Vac. Sci. Technol. B 2013, 31, 031207. 
[306] J. Park, M. Jo, J. Lee, S. Jung, W. Lee, S. Kim, S. Park, J. Shin, H. Hwang, Microelectron. Eng. 2011, 88, 935.

[307] X. Gao, X. Zhang, C. Wan, J. Wang, X. Tan, D. Zeng, Diamond \& Related Mater. 2012, 22, 37.

[308] A. K. Ott, C. Dou, U. Sassi, I. Goykhman, A. Katsounaros, D. Yoon, X. Chen, J. Wu, A. Lombardo A. C. Ferrari, submitted (2016)

[309] Y. Chai, A. Hazeghi, K. Takei, H. Y. Chen, P. C. H. Chan, A. Javey, and H. S. P. Wong, International Electron Devices Meeting - Technical Digest, 2010, 210.

[310] D. Fu, D. Xie, C.-H. Zhang, D. Zhang, J.-B. Niu, H. Qian, L.-T. Liu, Chin. Phys. Lett. 2010, 27, 098102.

[311] Y. He, J. Zhang, X. Guan, L. Zhao, Y. Wang, H. Qian, Z. Yu, IEEE Transactions on electron devices, 2010, 57, 3434.

[312] S. Qin, J. Zhang, D. Fu, D. Xie, Y. Wang, H. Qian, L. Liu, Z. Yu, Nanoscale 2012, 4, 6658 .

[313] C. D. Wright, P. Hosseini, and J. A. Vazquez Diosdado , Adv. Funct. Mater. $2013,23,2248$

[314] Y. V. Pershin, M. Di Ventra, Advances In Physics 2011, 60, 145.

[315] K. Sangwan, D. Jariwala, I. S. Kim, K. S. Chen, T. J. Marks, L. J. Lauhon, M. C. Hersam, Nat. Nanotechnol. 2015, 10, 403.

[316] P. F. Cheng, K. Sun, Y. H. Hu, Nano Lett. 2016, 16, 572.

[317] X. Zhang, H. Qiao, X. Nian, Y. Huang, X. Pang, J. Mater. Sci. Mater. Electron. 2016, 27, 7609 .

[318] C. X. Hao, F. S. Wen, J. Y. Xiang, S. J. Yuan, B. C. Yang, L. Li, W. H. Wang, Z. M. Zeng, L. M. Wang, Z. Y. Liu, Y. J. Tian, Adv. Funct. Mater. 2016, 26, 2016. 
[319] A. Ambrosi, Z. Sofer, M. Pumera, Chem. Commun. 2015, 51, 8450.

[320] J. Liu, Z. Zeng, X. Cao, G. Lu, L. H. Wang, Q. L. Fan, W. Huang, H. Zhang, Small 2012, 8, 3517.

[321] S. Ali, J. Bae, C. H. Lee, In Proceedings of SPIE 2015, 9553, $95530 \mathrm{~T}$.

[322] K. Ali, J. Ali, S. M. Mehdi, K. Choi, Y. J. An, Appl. Surf. Sci. 2015, 353, 1186.

[323] S. T. Han, Y. Zhou, B. Chen, C. Wang, L. Zhou, Y. Yan, J. Zhuang, Q. Sun, H. Zhang, V. A. L. Roy, Small 2015, 12, 390.

[324] S. M. Shinde, G. Kalita, M. Tanemura, J. Appl. Phys. 2014, 116, 214306.

[325] J. Mangalam, S. Agarwal, A. N. Resmi, M. Sundararajan, K. B. Jinesh, Org. Electron. 2016, 29, 33.

[326] Z. Yin, Z. Zeng, J. Liu, Q. He, P. Chen, H. Zhang, Small 2013, 9, 727.

[327] A. A. Bessonov, M. N. Kirikova, D. I. Petukhov, M. Allen, T. Ryhänen, M. J. a Bailey, Nat. Mater. 2015, 14, 199.

[328] X. Y. Xu, Z. Y. Yin, C. X. Xu, J. Dai, J. G. Hu, Appl. Phys. Lett. 2014, 104, 033504.

[329] K. Qian, R. Y. Tay, V. C. Nguyen, J. X. Wang, G. F. Cai, T. P. Chen, E. H. T. Teo, P. S. Lee, Adv. Funct. Mater. 2016, 26, 2176.

[330] N. D. Zhigadlo, J. Cryst. Growth 2014, 402, 308.

[331] D. Golberg, P. M. F. J. Costa, O. Lourie, M. Mitome, X. Bai, K. Kurashima, C. Zhi, C. Tang, and Y. Bando, Nano Lett. 2007, 7, 2146.

[332] C. W. Chang, D. Okawa, A. Majumdar, and A. Zettl, Science 2006, 314, 1121.

[333] B. Ilhan, M. Kurt, H. Ertuk, Exp. Therm. Fluid Sci. 2016, 77, 272.

[334] P. Y. Huang, C. S. R. Vargas, A. M. V. D. Zande, W. S. Whitney, M. P. Levendorf, J. W. Kevek, S. Garg, J. S. Alden, C. J. Hustedt, Y. Zhu, J. Park, P. L. McEuen, D. A. Muller, Nature 2011, 469, 389. 
[335] A. L. Gibb, N. Alem, J. H. Chen, K. J. Erickson, J. Ciston, A. Gautam, M. Linck, A. Zettl, J. Am. Chem. Soc. 2013, 135, 6758.

[336] Y. Hattori, T. Taniguchi, K. Watanabe, K. Nagashio, ACS Nano 2015, 9, 916.

[337] Y. F. Ji, C. B. Pan, M. Y. Zhang, S. B. Long, X. J. Lian, F. Miao, F. Hui, Y. Y. Shi, L. Larcher, E. Wu, M. Lanza, Appl. Phys. Lett. 2016, 108, 012905.

[338] N. Jain, R. B. Jacobs-Gedrim, B. Yu, Mater. Res. Soc. Symp. Proc. 2014, 1658, DOI: $10.1557 /$ opl.2014.503.

[339] J. D. Wood, S. A. Weels, D. Jariwala, K. S. Chen, E. Cho, V. K. Sangwan, X. L. Liu, L. J. Lauhon, T. J. Marks, M. C. Hersam, Nano Lett. 2014, 14, 6964.

[340] D. Hanlon, C. Backes, E. Doherty, C. S. Cucinotta, N. C. Berner, C. Boland, K. Lee, P. Lynch, Z. Gholamvand, A. Harvey, S. F. Zhang, K. P. Wang, G. Moynihan, A. Pokle, Q. M. Ramasse, N. McEvoy, W. J. Blau, J. Wang, S. Sanvito, D. D. Regan, G. S. Duesberg, V. Nicolosi, J. N. Coleman, Nat. Commun. 2015, 6, 8563.

[341] T. W. Hickmott, J. Appl. Phys. 1962, 33, 2669.

[342] J. G. Simmons, R. R. Verderber, Proc. R. Soc. London Ser. A 1967, 301, 77.

[343] R. Degraeve, B. Kaczer, G. Groeseneken, Microelectron. Reliab. 1999, 39, 1445 .

[344] E. Miranda, J. Sune, R. Rodriguez, M. Nafria, X. Aymerich, Appl. Phys. Lett. 1998, 73,490 .

[345] M. Ahmad, S. A. Han, D. H Tien, J. Jung, Y. Seo, J. Appl. Phys., 2011, 110, 054307.

[346] J. J. Yang, M. X. Zhang, J. P. Strachan, F. Miao, M. D. Pickett, R. D. Kelley, G. M. Ribeiro, R. S. Williams, Appl. Phys. Lett. 2010, 97, 232102.

[347] Y. B. Kim, S. R. Lee, D. Lee, C. B. Lee, M. Chang, J. H. Hur, M. J. Lee, G. S. 
Park, C. J. Kim, U. Chung, I. K. Yoo, K. Kim, , 2011 Symposium on VLSI Technology.

[348] C. H. Cheng, A. Chin, F. S. Yeh, 2010 Symposium on VLSI Technology Digest of Technical Papers 2010, 85 .

[349] Sen Liu, N. D. Lu, X. L. Zhao, H. Xu, W. Banerjee, H. B. Lv, S. B. Long, Q. J. Li, Q. Liu, M. Liu, Adv. Mater. 2016, 0, 1.

[350] X. Cao, X. M. Li, X. D. Gao, W. D. Yu, X. J. Liu, Y. W. Zhang, L. D. Chen, X. H. Cheng, J. Appl. Phys. 2009, 106, 073723.

[351] B. Zhang, G. Liu, Y. Chen, L. J. Zeng, C. X. Zhu, K. G. Neoh, C. Wang, E. T. Kang, Chem. Eur. J. 2011, 17, 13646.

[352] A. Midya, N. Gogurla, S. K. Ray, Current Appl. Phys. 2015, 15, 706.

[353] A. N. Aleshin, P. S. Krylova, A. S. Berestennikova, I. P. Shcherbakova, V. N. Petrova, V. V. Kondratievb, S. N. Eliseeva, Synthetic Metals 2016, 217, 7.

[354] Y. Sun, J. Lu, C. Ai, D. Wen, Phys. Chem. Chem. Phys. 2016, 18, 11341.

[355] A. Thakre, H. Borkar, B. P. Singha, A. Kumar, RSC Adv. 2015, 5, 57406.

[356] S. Valanarasu, I. Kulandaisamy, A. Kathalingam, J. K. Rhee, T. A. Vijayan, R. Chandramohan, J. Nanosci. Nanotechnol. 2013, 13, 6755.

[357] O. O. Kapitanova, G. N. Panin, O. V. Kononenko, A. N. Baranov, T. W. Kang, Journal of the Korean Physical Society 2014, 64, 1399.

[358] G. Khurana, P. Misra, N. Kumar,S. Kooriyattil, J. F Scott, R. S Katiyar, Nanotechnology 2016, 27, 015702.

[359] J. R. Rani, S. I. Oh, J. M. Woo, J. H. Jang, Carbon 2015, 94, 362.

[360] A. D. Yu, C. L. Liu and W. C. Chen, Chem. Commun. 2012, 48, 383.

[361] H. Y. Wu, C. C. Lin, C. H. Lin, Ceram. Int. 2015, 41, S823.

[362] X. Huang, B. Zheng, Z. Liu, C. Tan, J. Liu, B. Chen, H. Li, J. Chen, X. Zhang, 
Z. Fan, W. Zhang, Z. Guo, F. Huo, Y. Yang, L. H. Xie, W. Huang, H. Zhang, ACS Nano 2014, 8, 8695.

[363] C. Tan, X. Qi, Z. Liu, F. Zhao, H. Li, X. Huang, L. Shi, B. Zheng, X. Zhang, L. Xie, Z. Tang, W. Huang, H. Zhang, J. Am. Chem. Soc. 2015, 137, 1565.

[364] Z. Wei, Y. Kanzawa, K. Arita, Y. Katoh, K. Kawai, S. Muraoka, S. Mitani, S. Fujii, K. Katayama, M. Iijima, T. Mikawa, T. Ninomiya, R. Miyanaga, Y. Kawashima, K. Tsuji, A. Himeno, T. Okada, R. Azuma, K. Shimakawa, H. Sugaya, T. Takagi, R. Yasuhara, K. Horiba, H. Kumigashira, M. Oshima, IEEE IEDM, 15-17 Dec, 2008.

\section{FIGURES}




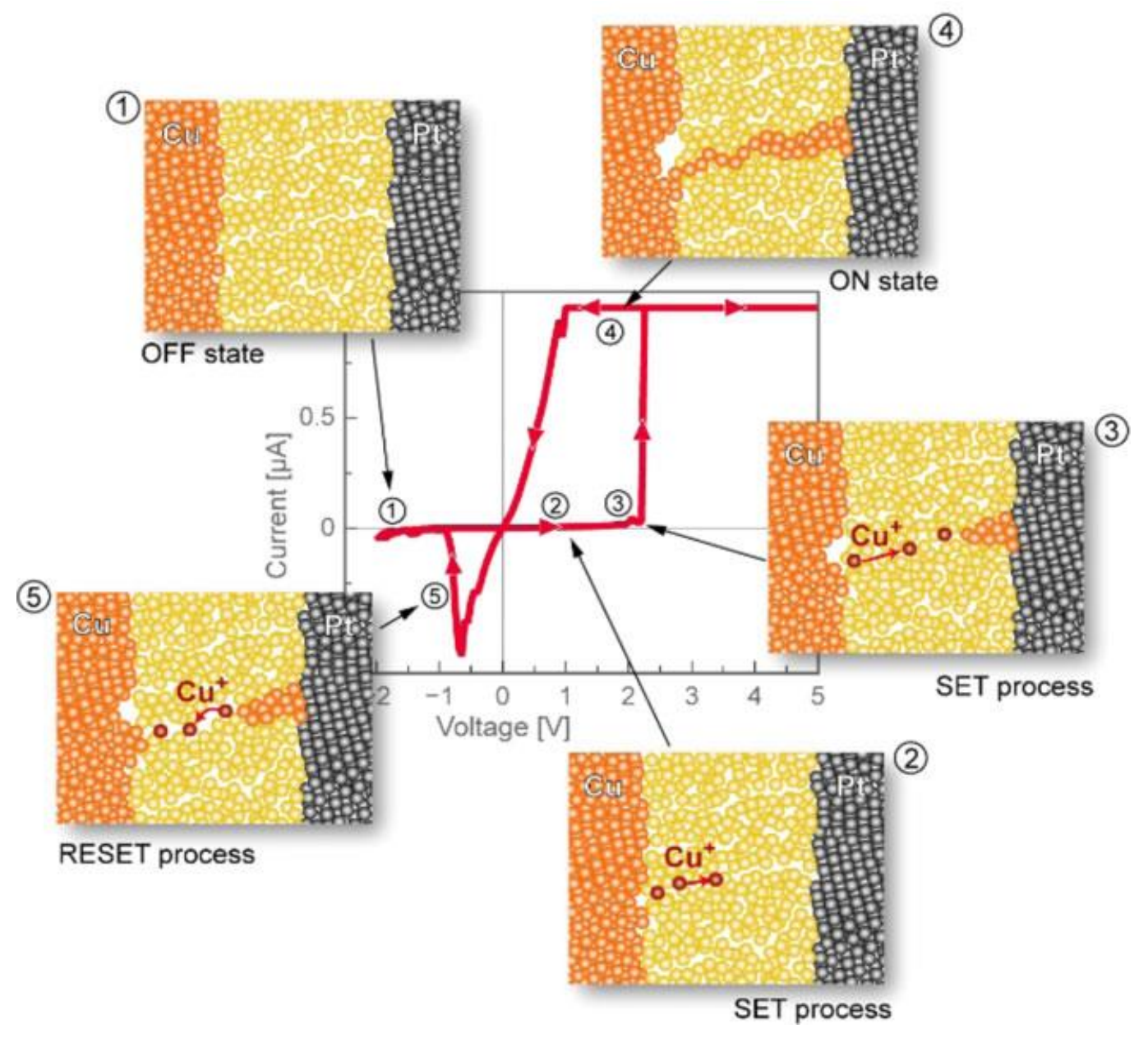

Fig. 1: Current-voltage characteristics of ECM/CBRAM cell with schematic presentation of the related physical processes. Reproduced with permission from [34]. Copyright from IOP Publishing Ltd 2011. 
a

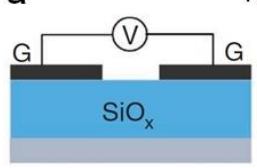

d Vertical GMIM

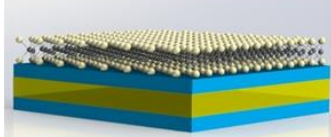

HorizontalMGIGM

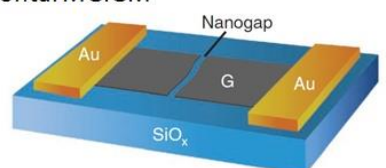

e Vertical MGIM

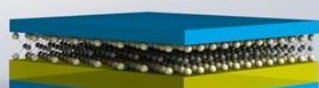

b

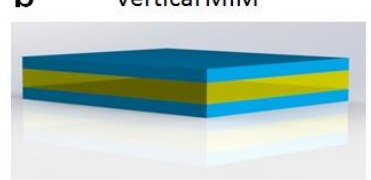

f Vertical MGIGM

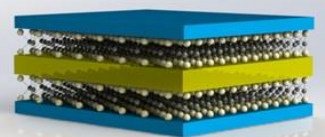

C Vertical GIG

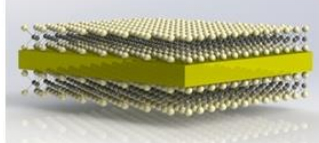

g Vertical MIGIM

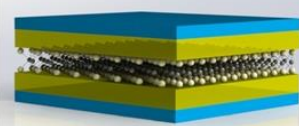

Fig. 2: Different device structures proposed in GRMs-based RRAM technology. M indicates metal, I indicates insulator, and G indicates GRM. The electric field in (b-g) is always applied between the top and bottom layers. 

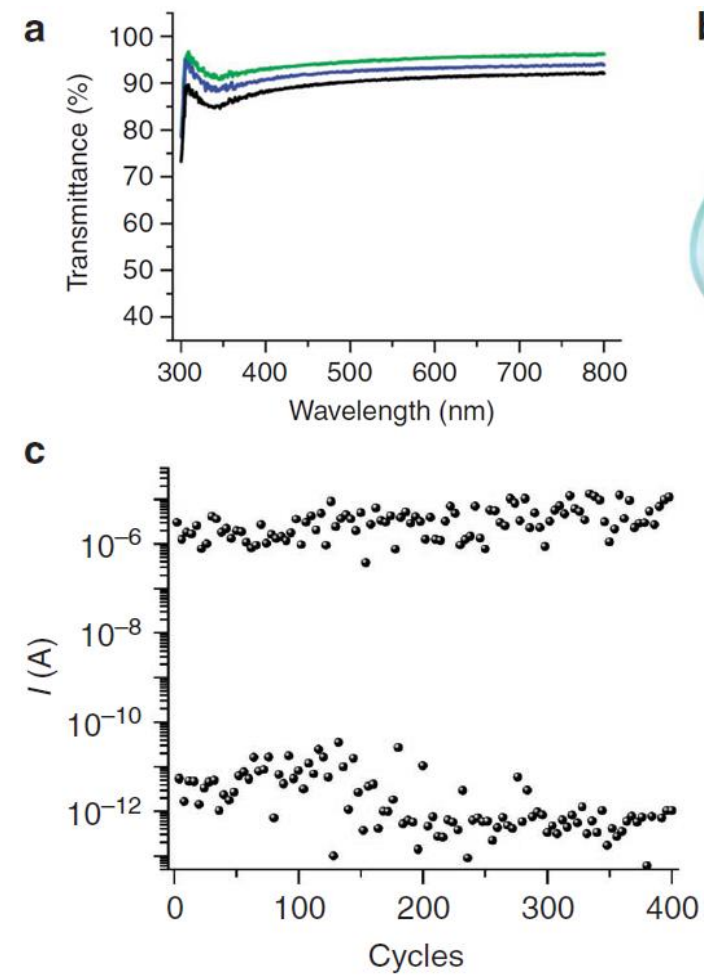

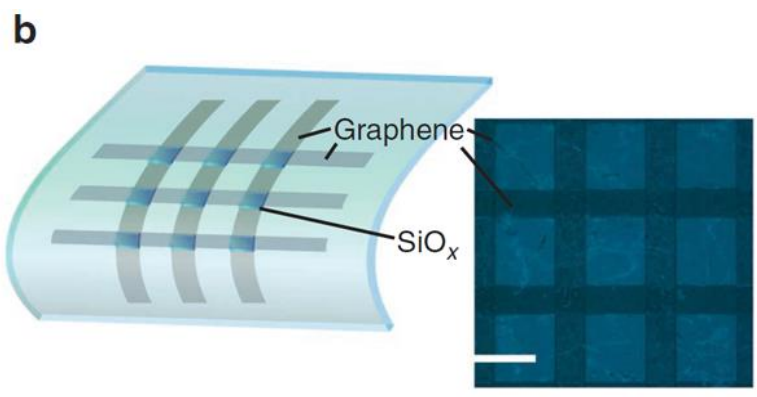

d

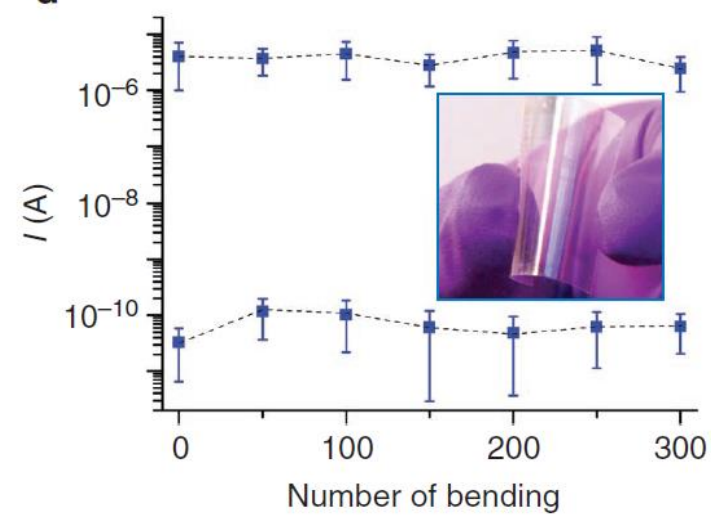

Fig. 3: (a) High transparency of $\mathrm{SLG} / \mathrm{SiO}_{2} / \mathrm{SLG}$ RRAM on glass substrate [105]. (b) (Left panel) Schematic SLG/SiO $x / \mathrm{SLG}$ crossbar structures on a plastic (fluoropolymer) substrate and (right panel) optical image [105]. Scale bar, $20 \mu \mathrm{m}$. (b) Optical image of the SLG/SiOx/SLG pillar structures with the inset showing the schematic image. Scale bar, $100 \mu \mathrm{m}$ [105]. (c) Endurance measured from one of the crossbar devices using +5 and $+14 \mathrm{~V}$ as set and reset voltages. The programming current is not shown here and the memory states (current) were recorded at +1 V. [105] (d) Current levels of both ON and OFF memory states (read at $+1 \mathrm{~V}$ ) from a crossbar device during repeated bending of the plastic substrate to $\mathrm{r}_{\mathrm{b}} \sim 0.6 \mathrm{~cm}$. The inset shows transparent memories using the pillar structures on the plastic substrate. Reproduced with permission from [105]. Copyright from Nature Publishing Group, 2012. 


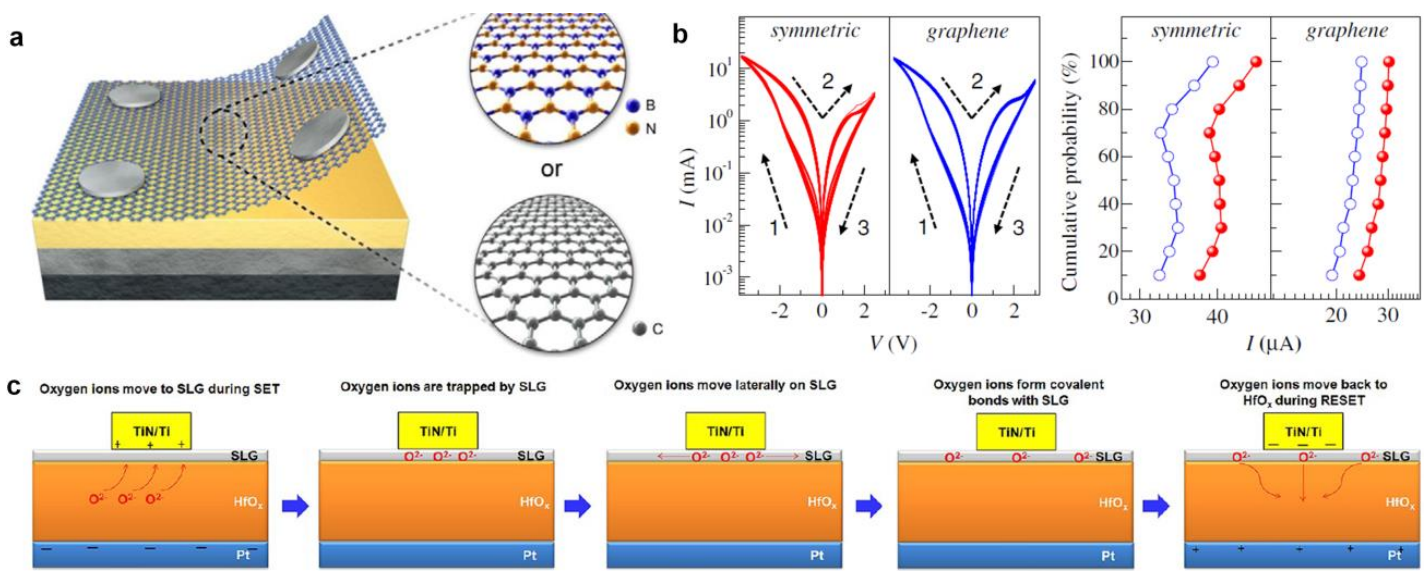

Fig. 4: (a) Schematic of SLG inserted between the top electrode and insulating film of a RRAM cell [107]. (b) Resistance switching I-V characteristics of a symmetric Al$\mathrm{WO}_{3}-\mathrm{Al}$ and a $\mathrm{Al}(\mathrm{SLG})-\mathrm{WO}_{3}-\mathrm{Al}$ device. Cumulative probability of the HRS current at $\pm 0.5 \mathrm{~V}$ for both configurations [107]. (c) Schematic diagrams of oxygen ions movement in MGIM structures. The diagrams represent (from left to right) elementary steps of the process including movement of oxygen ions to SLG during SET, capture of oxygen ions by SLG, movement of oxygen ions laterally on SLG, formation of covalent bond with SLG, followed by movement of oxygen ions back to $\mathrm{HfO}_{\mathrm{X}}$ during reset [217]. (a) and (b) are reproduced with permission of [107]. Copyright from Elsevier 2015. (c) is reproduced with permission from [217]. Copyright from American Chemical Society 2013. 

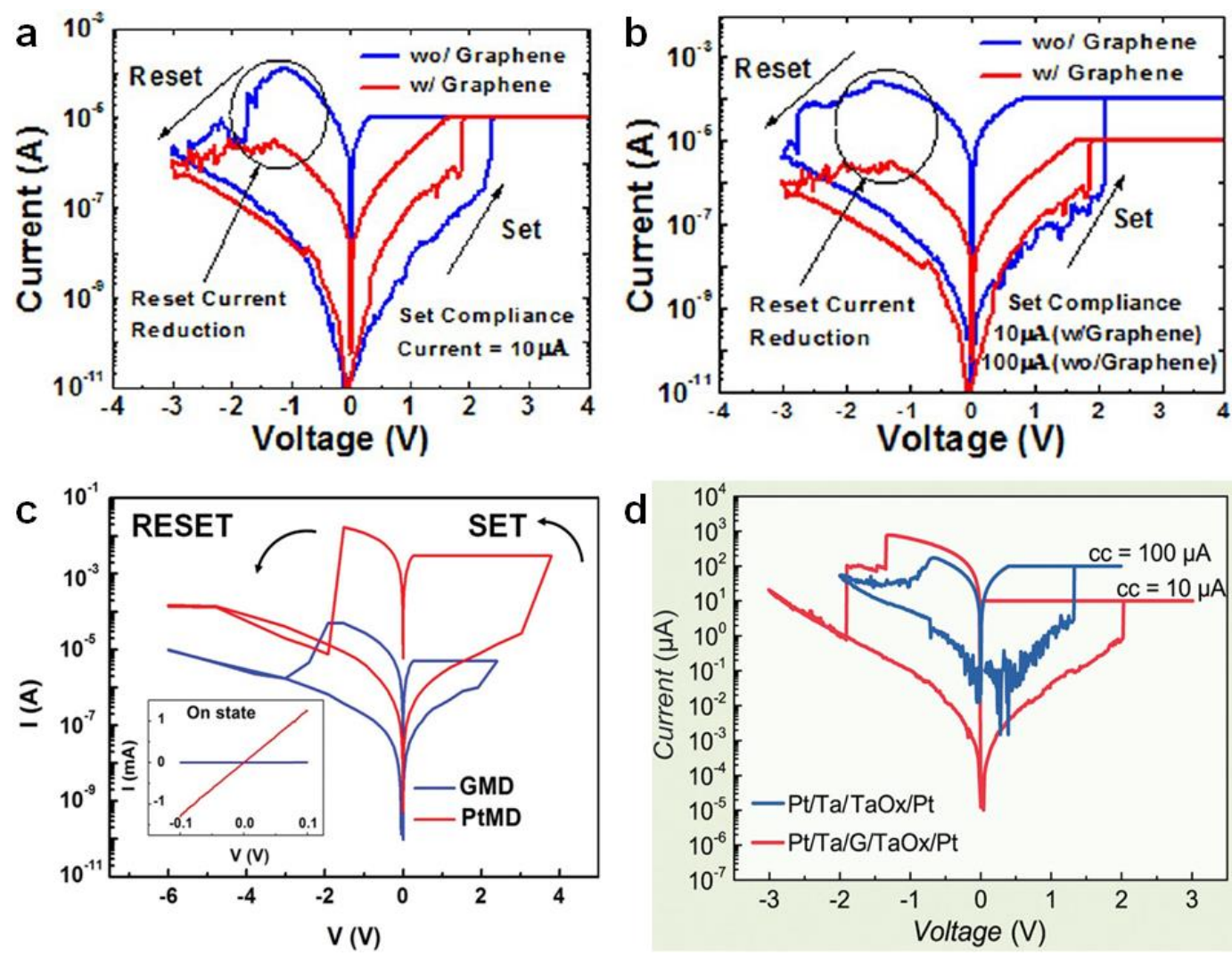

Fig. 5: (a) Typical resistive switching behaviour of $\mathrm{Ti} / \mathrm{SLG} / \mathrm{HfO}_{\mathrm{X}} / \mathrm{Pt}$ (red) and Ti/HfOX/Pt RRAMs under the same current limitation [217]. (b) Typical resistive switching behaviour for the same devices but using optimal testing conditions [217]. 10 and $100 \mu \mathrm{A}$ currents are applied to achieve steady switching. (a) and (b) are reproduced with permission from [217]. Copyright from American Chemical Society 2013. (c) Switching curves of typical $\mathrm{TiO}_{2}$ based memristive devices using SLG and Pt electrodes, with a SET current compliance of $5 \mu \mathrm{A}$ and $3 \mathrm{~mA}$. The arrows point to the switching directions. Inset: small-bias I - V curves for both devices in the ON state, showing different resistance. Reproduced with permission from [196]. Copyright from Wiley-VCH 2014. (d) I-V curve comparison between a $\mathrm{Pt} / \mathrm{Ta} / \mathrm{TaO} / \mathrm{Pt}$ cell with SLG inserted between the $\mathrm{Ta}$ and the $\mathrm{TaO}_{\mathrm{X}}$ layers (red) and one cell without (blue) in logarithmic scale. The cell without SLG needs higher HRS currents for stable switching. That with SLG offers higher $\mathrm{ION}_{\mathrm{ON}} / \mathrm{I}_{\mathrm{OFF}}$ and HRS current reduction. Reproduced with permission from [55]. Copyright from Wiley-VCH 2015. 

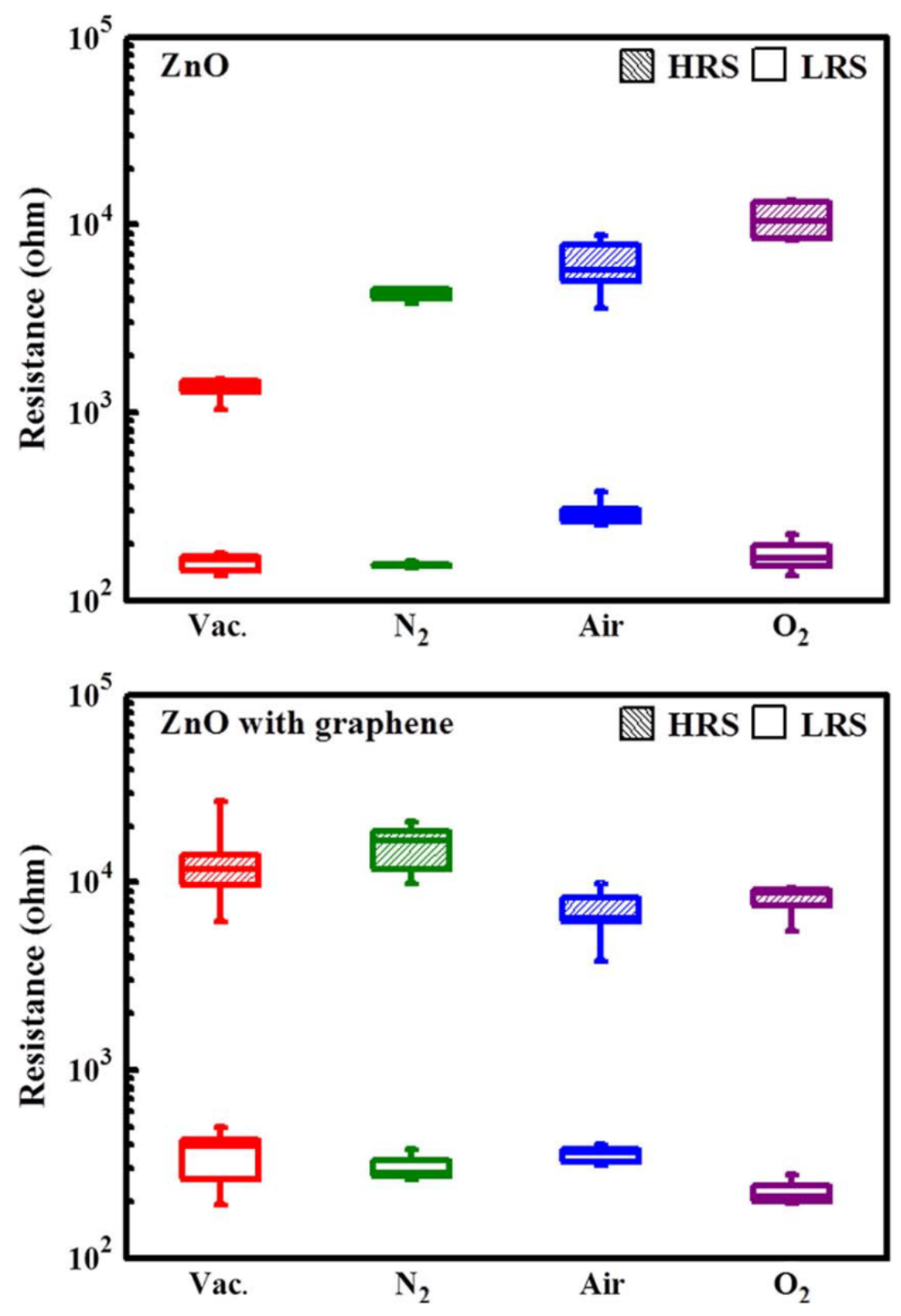

Fig. 6: Atmosphere-dependent resistance in HRS and LRS of ZnO RRAMs with and without SLG electrodes. The bottom and the top of the box are the $25^{\text {th }}$ percentile and the $75^{\text {th }}$ percentile, the band near the middle of the box is the 50th percentile, and the ends of the whiskers represent the $10^{\text {th }}$ percentile and the $90^{\text {th }}$ percentile. Reproduced with permission from [74]. Copyright from IEEE 2013. 


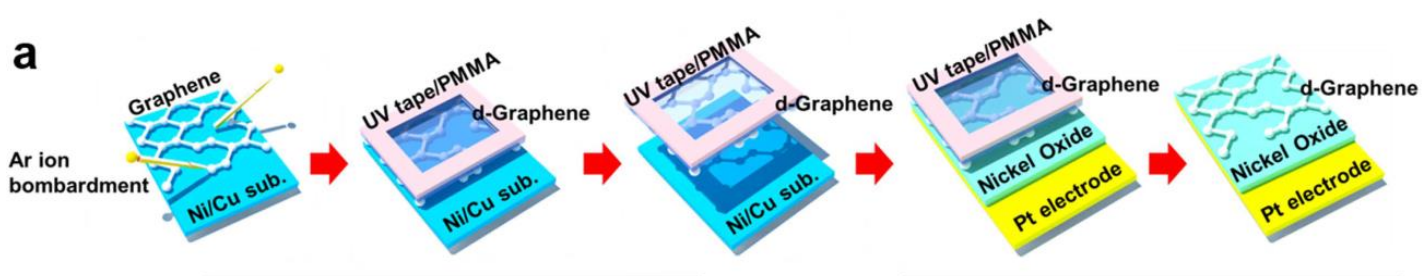

b

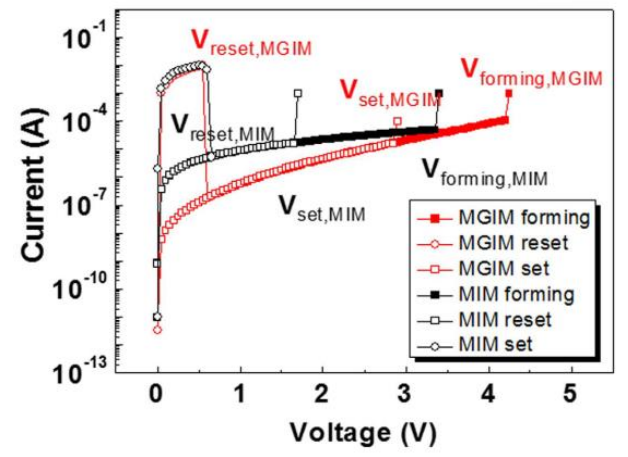

d

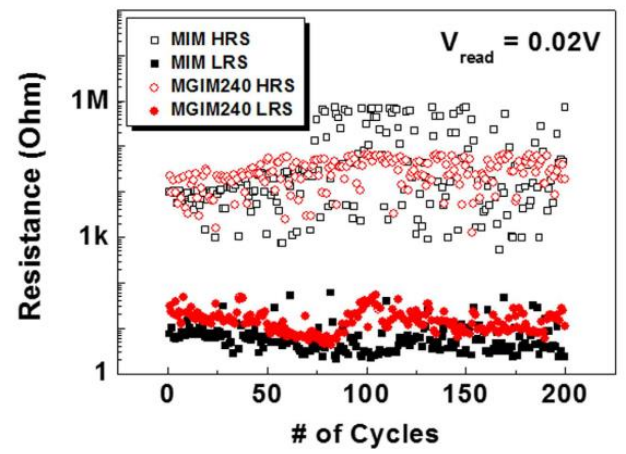

C $\bar{\circ} 100$

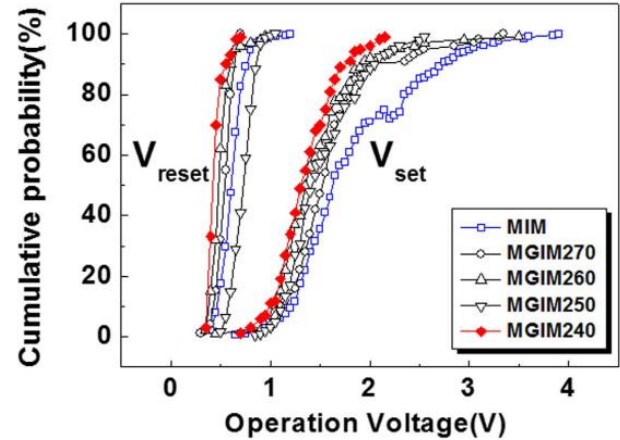

e

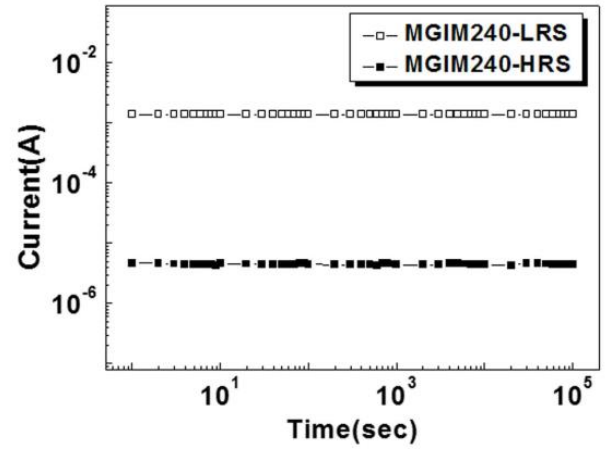

Fig. 7: (a) Illustration of fabrication process for MGIM structure using functionalized

SLG prepared before transfer.[170] (b) Initial current-voltage characteristics of the MGIM and conventional MIM structures.[170] (c) Cumulative probability of switching voltages, Vset and Vreset, for MGIM structures with SLG irradiated with Ar+ ions at $240 \mathrm{eV}$ (MGIM240), $250 \mathrm{eV}$ (MGIM250), $260 \mathrm{eV}$ (MGIM260), and $270 \mathrm{eV}$ (MGIM270) as well as a MIM structure. [170] (d) Change in resistance states for MGIM240 and MIM, measured at room temperature and atmospheric pressure. [170] (e) Retention characteristics of MGIM240 measured at $85^{\circ} \mathrm{C}$ in a vacuum of $1 \mathrm{mTorr}$ as well as ambient atmospheric condition under reading voltage $0.1 \mathrm{~V}$. Reproduced with permission from [170]. Copyright from Nature Publishing group 2015. 

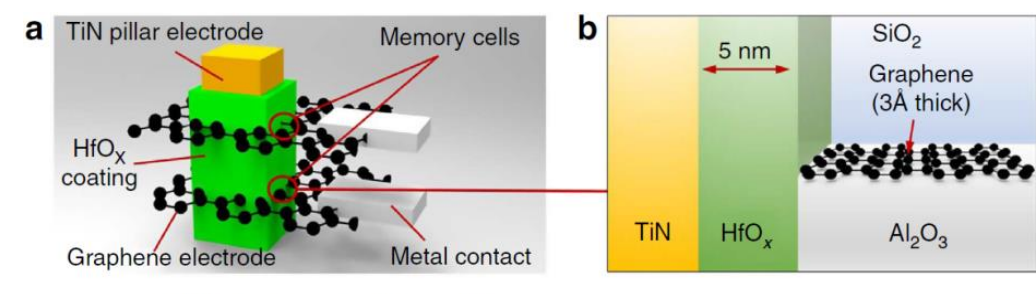

f Pt-RRAM (Pt thickness: $25 \mathrm{~nm}$ )
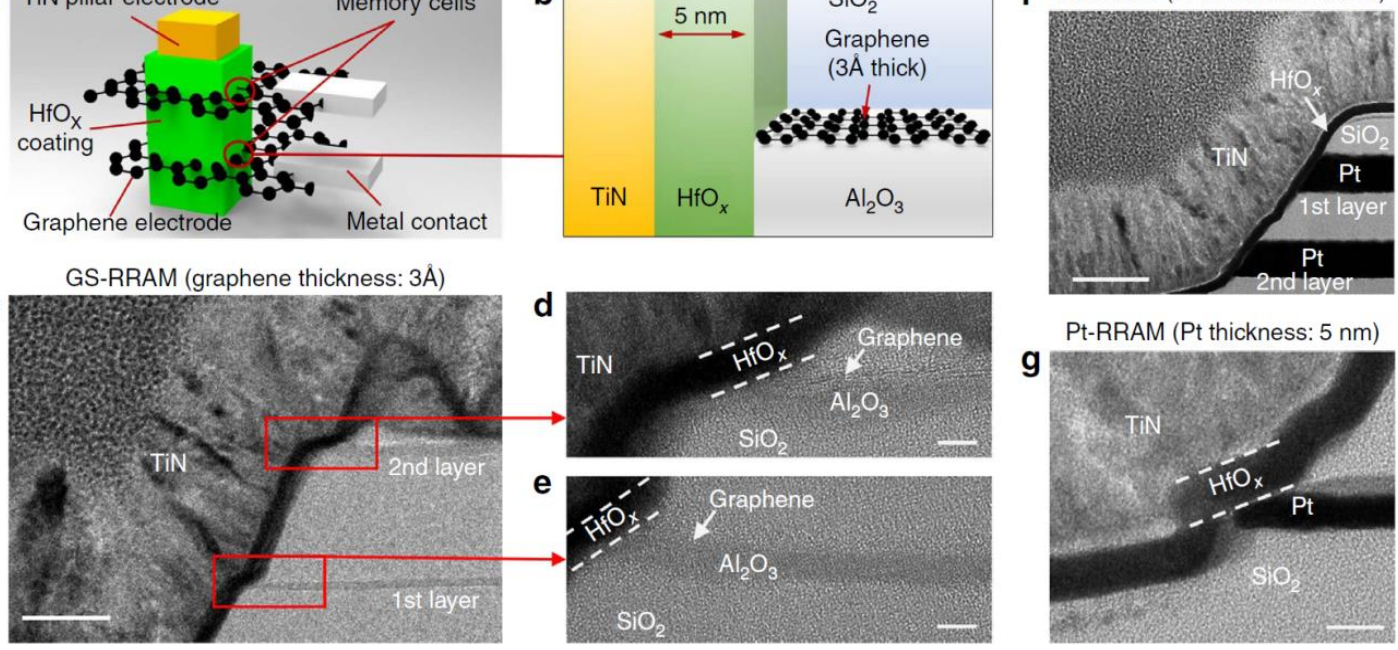

Fig. 8: (a) SLG-based RRAM in a vertical cross-point architecture. The RRAM cells are formed at the intersections of the TiN pillar electrode and the SLG plane electrode. The resistive switching HfOx layer surrounds the TiN pillar electrode and is also in contact with SLG [113]. (b) Schematic cross-section of the SLG-based RRAM [113]. (c) High-resolution TEM image of the two-stack GS-RRAM structure. The RRAM memory elements are highlighted in red. Scale bar, $40 \mathrm{~nm}$ [113]. (d,e) First and second layer of GS-RRAM with SLG on top of $\mathrm{Al}_{2} \mathrm{O}_{3}$. Scale bars, $5 \mathrm{~nm}$ [113]. (f, g) TEM image of the two-stack Pt-based RRAMs. Scale bars, 40nm (f) and 5nm (g). Reproduced with permission from [113]. Copyright from Nature Publishing Group 2015. 
a
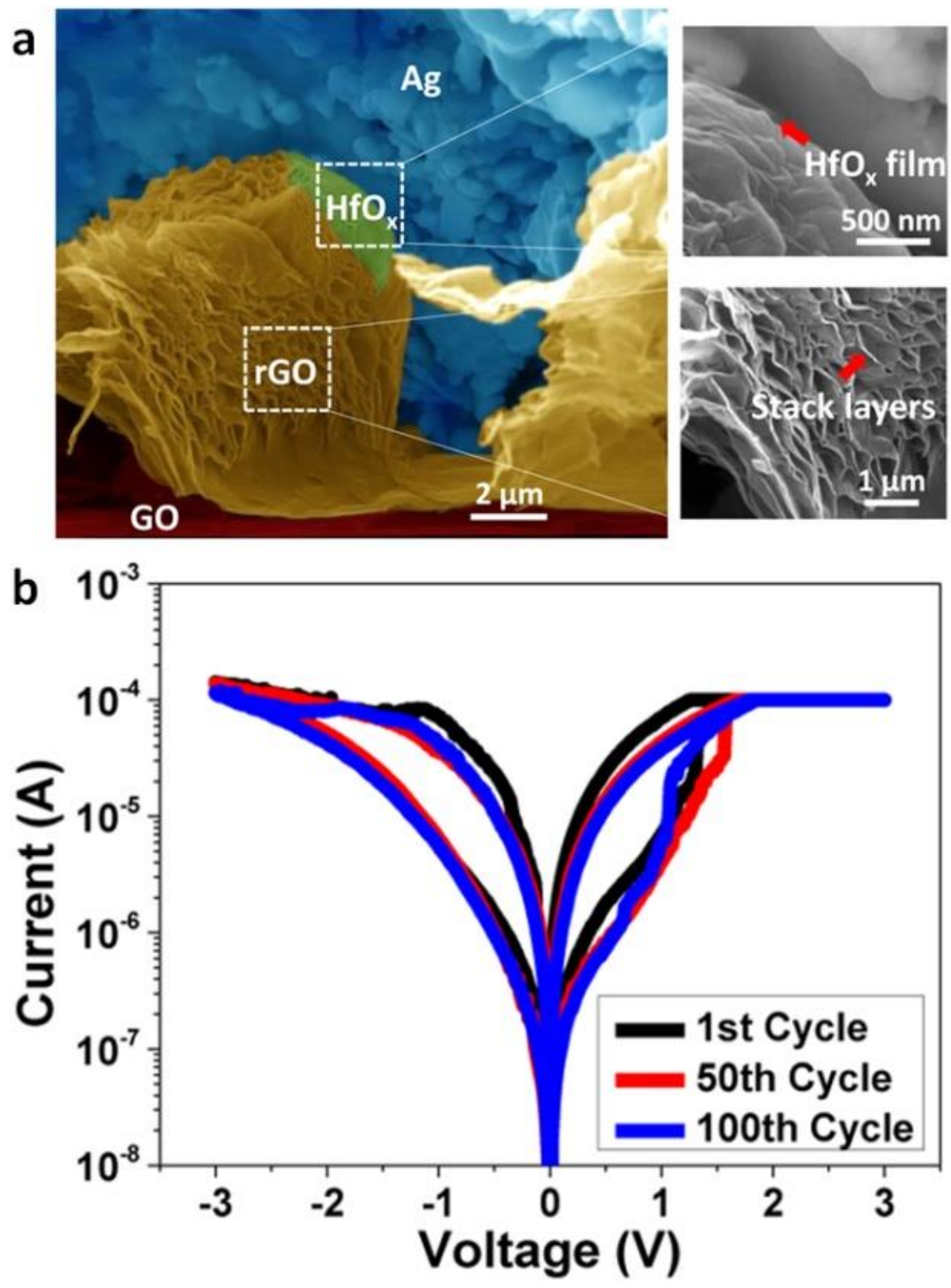

Fig. 9: (a) Cross-sectional SEM image displaying the folded, aggregated and misaligned nature of GRMs used in RRAM technologies. The insets highlight $\mathrm{HfO}_{\mathrm{X}}$ films and stacked RGO layers, respectively [254]. (b) RS behaviour of LSG-RRAM at the first, $50^{\text {th }}$ and $100^{\text {th }}$ cycle, respectively. Reproduced with permission from [254]. Copyright from American Chemical Society 2014. 


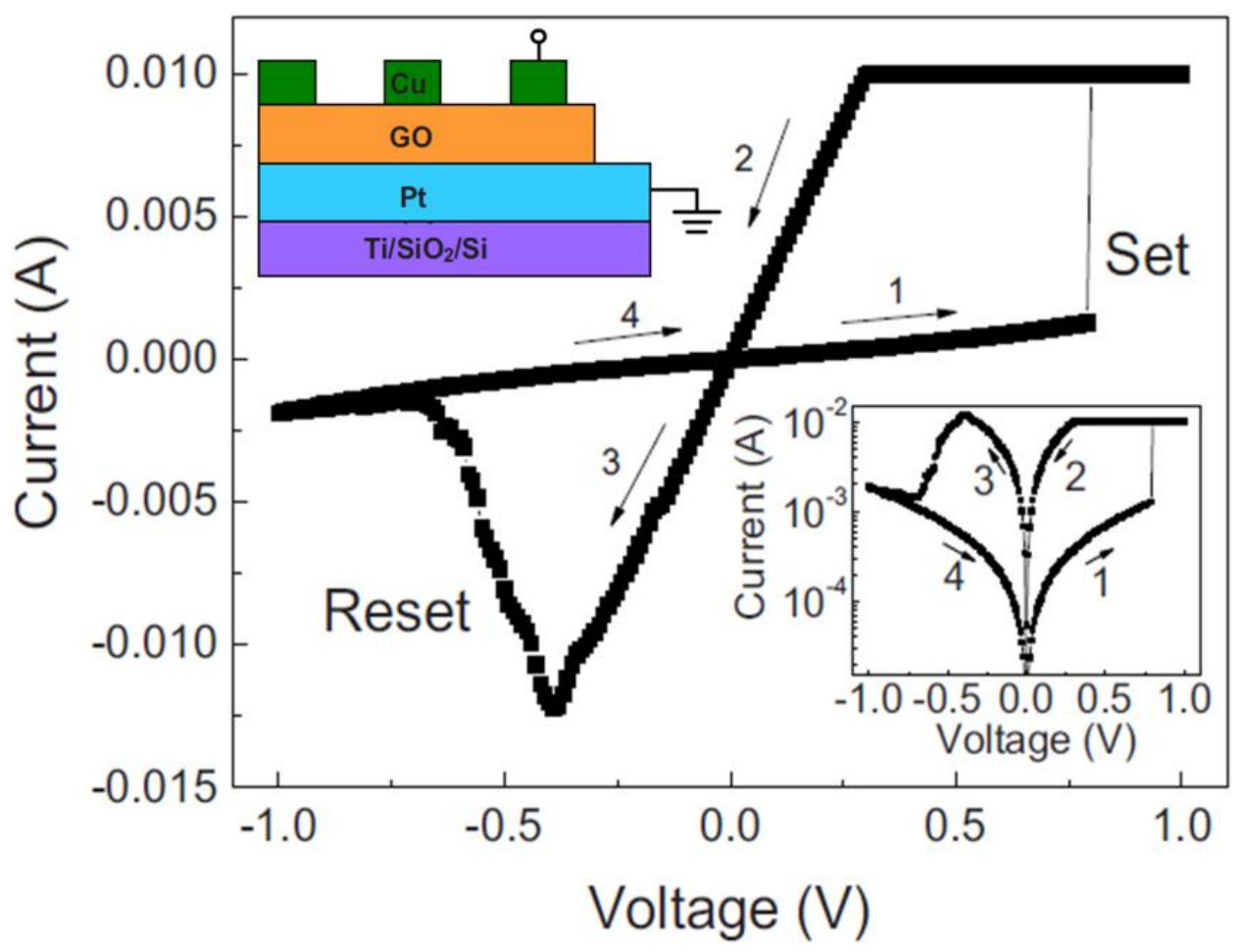

Fig. 10: $I-V$ characteristics of the $\mathrm{Cu} / \mathrm{GO} / \mathrm{Pt}$ RRAM cell showing RS. The arrows indicate the sweep direction. The insets show the $I-V$ characteristics in semilogarithmic scale and the schematic configuration. Modified and reprinted with permission from [241]. Copyright from American Institute of Physics 2009. 

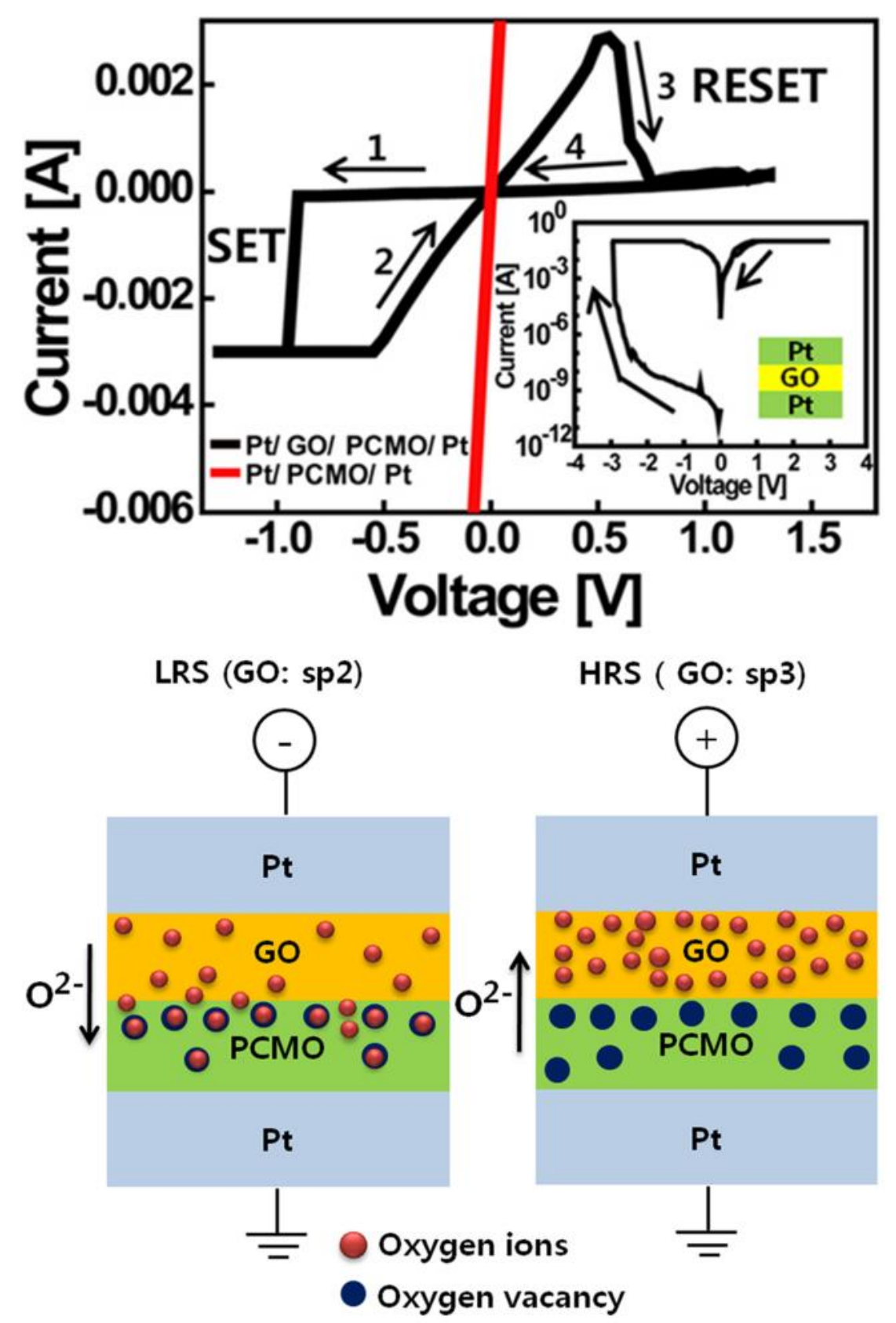

Fig. 11: (Top) Typical $I-V$ hysteresis curves of GO/PCMO and PCMO cells. The inset shows the $I-V$ hysteresis for the $\mathrm{Pt} / \mathrm{GO} / \mathrm{Pt}$ device [264]. (Bottom) Proposed switching mechanism in LRS (left) and HRS (right) for the GO/PCMO devices. Reproduced with permission from [264]. Copyright from American Institute of Physics 2011. 
a

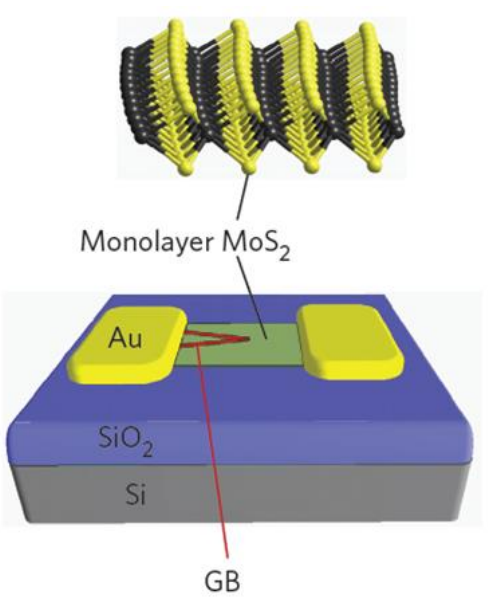

C

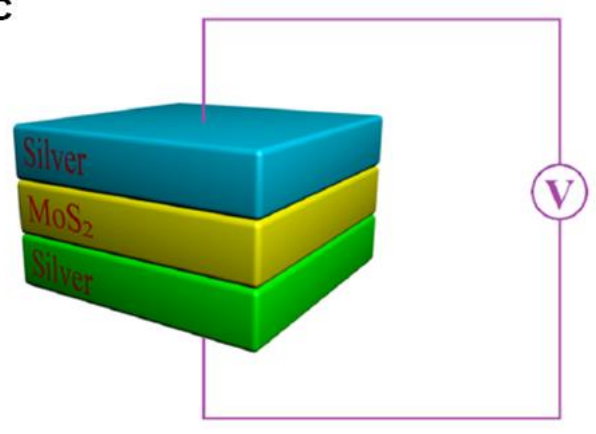

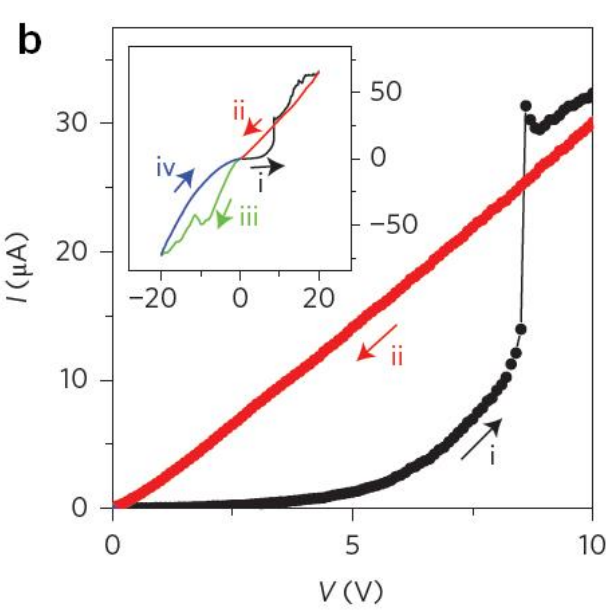

d

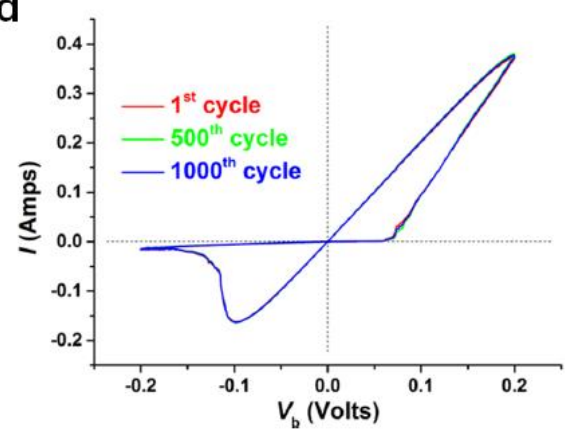

Fig. 12: (a) Schematic horizontal $M_{0} S_{2}$ RRAM cell with two GBs connected to one of the electrodes and intersecting at a vertex within the channel [315]. (b) Partial $I-V$ characteristics of an electroformed intersecting-GB memristor (channel length, $\mathrm{L}=7$ $\mu \mathrm{m})$ obtained immediately after electroforming [315]. The set process occurs at $\mathrm{V}_{\text {set }}=$ 8.3 V with an abrupt twofold increase in current. Inset: Full $I-V$ characteristics of one switching cycle. Measurements were performed at a sweep rate of $1 \mathrm{~V} \mathrm{~s}^{-1}$ and $\mathrm{V}_{\mathrm{g}}=40$ $\mathrm{V}$ under vacuum (pressure $<2 \times 10^{-5}$ torr). The voltage was swept in the order $0 \mathrm{~V} \rightarrow$ $20 \mathrm{~V} \rightarrow 0 \mathrm{~V} \rightarrow-20 \mathrm{~V} \rightarrow 0 \mathrm{~V}$, as shown by the coloured arrows with the four sweeps labelled as i, ii, iii and iv. (a) and (b) are reproduced with permission from [315]. Copyright from Macmillan Publishers Limited 2015. (c) Schematic structure of vertical $\mathrm{Ag} / \mathrm{MoS}_{2} / \mathrm{Ag} \mathrm{RRAM}$ cell from [316]. (d) Typical $I-V$ characteristic of $\mathrm{Ag} / \mathrm{MoS}_{2} / \mathrm{Ag}$ switch at the $1^{\text {st }}\left(\right.$ red), $500^{\text {th }}$ (green), and $1000^{\text {th }}$ (blue) cycle at room temperature. (c) and (d) are reproduced with permission from [316]. Copyright from American Chemical Society 2015. 
a

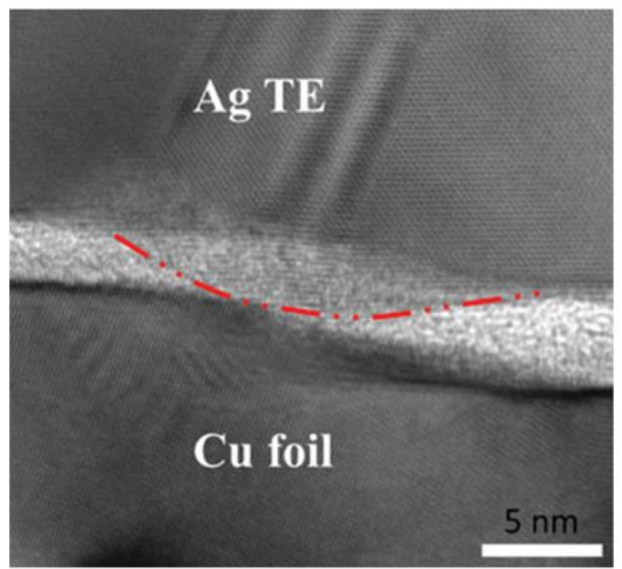

c

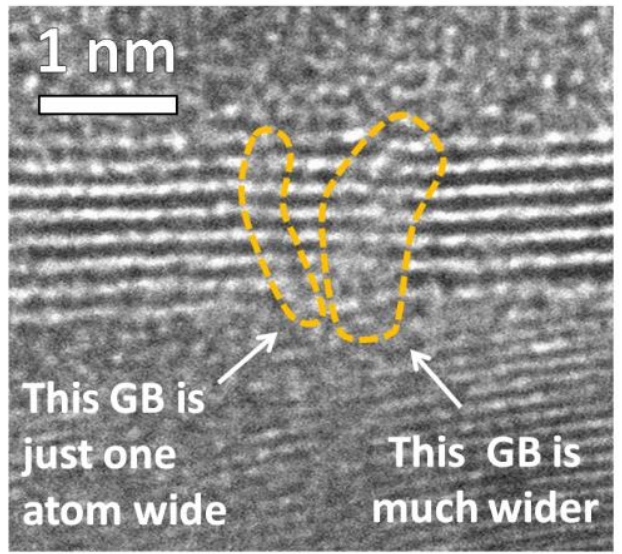

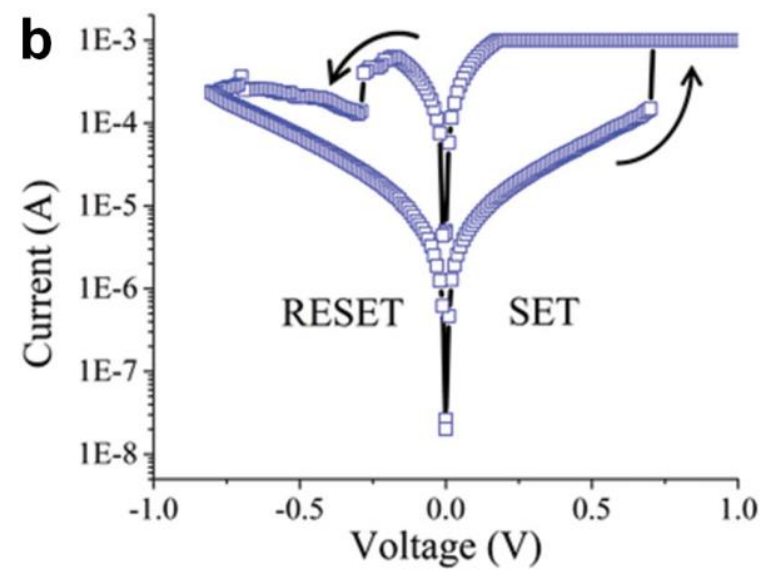

d

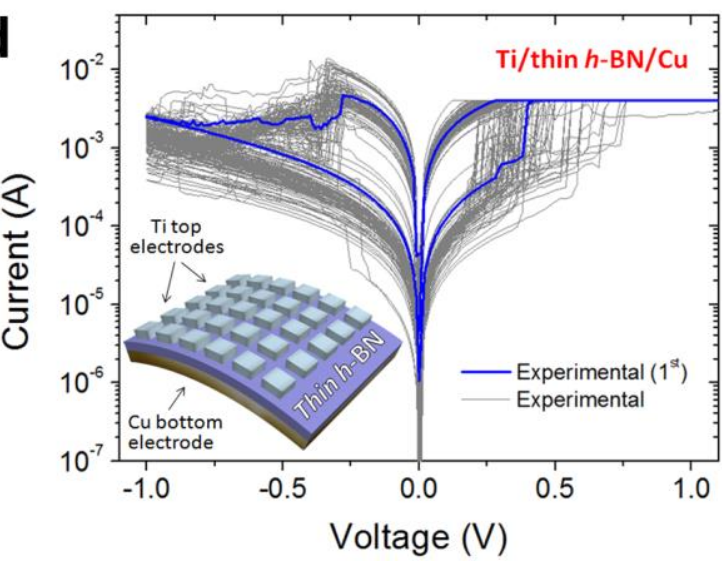

Fig. 13: (a) TEM image of a complete conducting filament. The thinnest region of the filament is at the $h-\mathrm{BN} / \mathrm{Cu}$ foil interface [329]. (b) Switching characteristics of the $\mathrm{Au} / h-\mathrm{BN} / \mathrm{Cu}$ foil/PET devices. (a) and (b) are reproduced with permission from [329]. Copyright from WILEY-VCH 2016. (c) Cross-section TEM image of truly layered Ti/h$\mathrm{BN} / \mathrm{Cu}$ stacks [163]. (d) I-V curve collected on a $100 \mu \mathrm{m} \times 100 \mu \mathrm{m}$ capacitor under a constant bias of $2.5 \mathrm{~V}$. (d) is reproduced with permission from [163]. Copyright from Wiley-VCH 2016. 
a

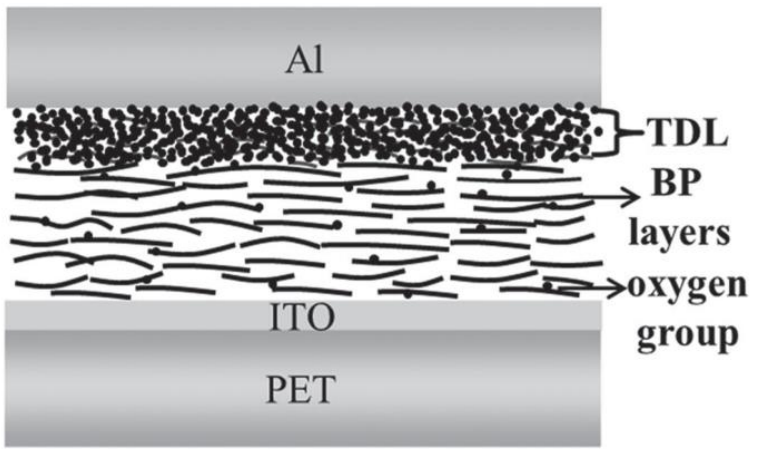

C

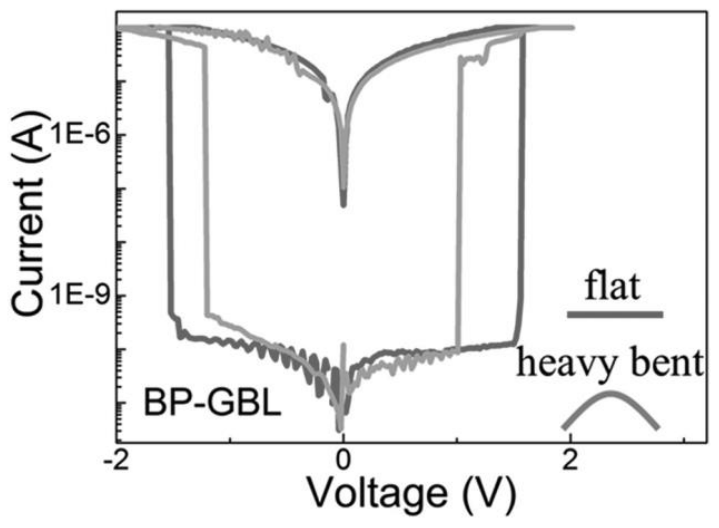

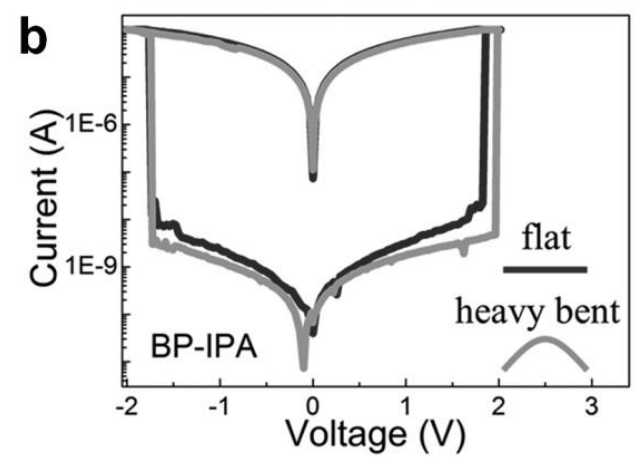

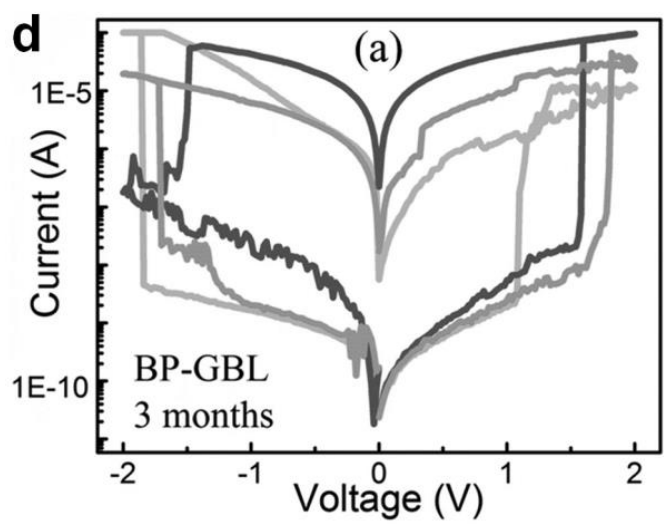

Fig. 14: (a) Shematic illustration of RRAM-BP cross-section. $I-V$ characteristics for the RRAM-BP device of BP-IPA (b), and BP-GBL (c) in the flat and bent conditions [318]. Typical $I-V$ curves obtained in the repeated voltage sweeping cycles for the RRAM-BP devices fabricated with the BP-GBL (d). Reproduced with permission from [318]. Copyright from Wiley-VCH 2016. 


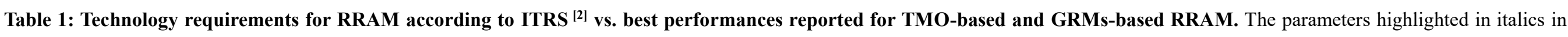

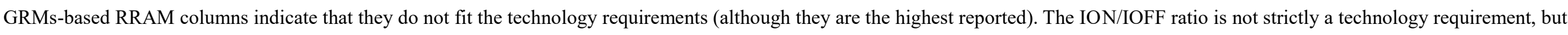
it is a reference parameter usually compared in RRAMs

\begin{tabular}{|c|c|c|c|c|c|c|c|}
\hline \multirow{2}{*}{ Parameter } & \multirow{2}{*}{$\begin{array}{c}\text { Technology } \\
\text { requirements }\end{array}$} & \multicolumn{3}{|c|}{ TMOs based RRAMs } & \multicolumn{3}{|c|}{ GRMs based RRAMs } \\
\hline & & Best performances & Device structure & Ref. & Best performances & Device structure & Ref. \\
\hline \multirow{3}{*}{ Operating voltages } & \multirow{3}{*}{$<1 \mathrm{~V}$} & $0.3 \mathrm{~V}$ & $\mathrm{Ti} / \mathrm{HfO}_{2} / \mathrm{TiN}$ & 41 & $\sim-0.6$ & $\mathrm{ITO} / \mathrm{GO} / \mathrm{Ag}$ & 251 \\
\hline & & $0.1 \mathrm{~V}$ & $\mathrm{Pt} / \mathrm{Ni} / \mathrm{Al}_{2} \mathrm{O}_{3} / \mathrm{SiO}_{2} / \mathrm{Si}$ & 43 & $\sim 0.4 \mathrm{~V}$ & $\mathrm{Ti} / h-\mathrm{BN} / \mathrm{Cu}$ & 163 \\
\hline & & $-0.2 \mathrm{~V}($ set $) / 0.5 \mathrm{~V}$ (reset) & $\mathrm{Pt} / \mathrm{TiO}_{2} / \mathrm{Pt}$ & 111 & $\sim 0.7 \mathrm{~V}$ & $\mathrm{Al} / \mathrm{GO} / \mathrm{Al}$ & 253 \\
\hline \multirow{2}{*}{ Power consumption } & \multirow{2}{*}{$\sim 10 \mathrm{pJ} /$ transition } & $0.1 \mathrm{pJ} /$ transition & TiN/Hf/HfO $/$ /TiN & 31 & $\sim 100 \mathrm{pW}$ & $\mathrm{Gr} / \mathrm{TiOx} / \mathrm{Al}_{2} \mathrm{O}_{3} / \mathrm{TiO}_{2} / \mathrm{Gr}$ & 185 \\
\hline & & $0.1-7 \mathrm{pJ} /$ transition & $\mathrm{Al} / \mathrm{Ti} / \mathrm{Al}_{2} \mathrm{O}_{3} / \mathrm{s}-\mathrm{CNT}$ & 44 & - & - & - \\
\hline \multirow{3}{*}{ Switching times } & \multirow{3}{*}{$<10 \mathrm{~ns} /$ transition } & $300 \mathrm{ps}$ & $\mathrm{TiN} / \mathrm{TiO}_{\mathrm{X}} / \mathrm{HfO}_{\mathrm{X}} / \mathrm{TiN}$ & 32 & $10 \mathrm{~ns}$ (set) / $1 \mathrm{~ns}$ (reset) & $\mathrm{W} / \mathrm{ta}-\mathrm{C} / \mathrm{W}$ & 286 \\
\hline & & $<10 \mathrm{~ns}$ & $\mathrm{Al} / \mathrm{Ti} / \mathrm{Al}_{2} \mathrm{O}_{3} / \mathrm{s}-\mathrm{CNT}$ & 44 & $5 \mathrm{~ns}$ (set) / $5 \mathrm{~ns}$ (reset) & $\mathrm{Pt} / \mathrm{RGO}-\mathrm{th} / \mathrm{Pt}$ & 273 \\
\hline & & $\sim$ ns level & $\mathrm{Cu} / \mathrm{Al}_{2} \mathrm{O}_{3} / \mathrm{aSi} / \mathrm{Ta}$ & 45 & $<10 \mathrm{~s}$ & $\mathrm{PEN} / \mathrm{Ti} / \mathrm{Pt} / \mathrm{GO} / \mathrm{Ti} / \mathrm{Pt}$ & 280 \\
\hline \multirow{5}{*}{ Endurance } & \multirow{5}{*}{$>10^{9}$ cycles } & $10^{12}$ cycles & $\mathrm{Pt} / \mathrm{Ta}_{2} \mathrm{O}_{5-\mathrm{X}} / \mathrm{TaO}_{2-\mathrm{X}} / \mathrm{Pt}$ & 33 & $2 \times 10^{13}$ cycles $@ 75^{\circ} \mathrm{C}$ & $\mathrm{W} / \mathrm{ta}-\mathrm{C} / \mathrm{W}$ & 286 \\
\hline & & $5 \times 10^{9}$ cycles & $\mathrm{Pt} / \mathrm{TaO}_{\mathrm{X}} / \mathrm{Pt}$ & 364 & $10^{8}$ & Al/PFCF/RGO/ITO & 351 \\
\hline & & $>10^{12}$ cycles & $\mathrm{Ta} / \mathrm{TaO}_{\mathrm{X}} / \mathrm{TiO}_{2} / \mathrm{Ti}$ & 111 & $10^{3} *$ & $\mathrm{Ag} / \mathrm{MoS}_{2} / \mathrm{Ag}$ & 316 \\
\hline & & $10^{10}$ cycles & $\mathrm{Pt} / \mathrm{TaO}_{\mathrm{X}} / \mathrm{Ta}$ & 346 & $>650$ & $\mathrm{Ti} / \mathrm{h}-\mathrm{BN} / \mathrm{Cu}$ & 163 \\
\hline & & $10^{11}$ cycles & $\mathrm{W} / \mathrm{AlO} / \mathrm{TaO}_{\mathrm{X}} / \mathrm{ZrO}_{\mathrm{X}} / \mathrm{Ru}$ & 347 & - & - & - \\
\hline \multirow{2}{*}{ Data retention } & \multirow{2}{*}{$>10$ years } & $>10$ years@85 ${ }^{\circ} \mathrm{C}$ & $\mathrm{Pt} / \mathrm{Al}_{2} \mathrm{O}_{3} / \mathrm{HfO}_{2} / \mathrm{Al}_{2} \mathrm{O}_{3} / \mathrm{TiN} / \mathrm{Si}$ & 46 & $>10^{7} \mathrm{~s}(115$ days $)$ & Al/GO/ITO & 249 \\
\hline & & 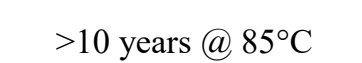 & $\mathrm{Pt} / \mathrm{TaOx} / \mathrm{Pt}$ & 364 & - & - & - \\
\hline
\end{tabular}




\begin{tabular}{|c|c|c|c|c|c|c|c|}
\hline \multirow{2}{*}{ MIM cell Size } & \multirow{2}{*}{$576 \mathrm{~nm}^{2}$} & $5 \mathrm{~nm}^{2}$ & $\mathrm{TaN} / \mathrm{TiN} / \mathrm{Zr} / \mathrm{HfO}_{2} / \mathrm{CAFM}$ tip & 296 & $8.5 \mathrm{~nm}^{2}$ & $\mathrm{Pt} / \mathrm{ta}-\mathrm{C} / \mathrm{C}-\mathrm{AFM}$ tip & 296 \\
\hline & & $10 \mathrm{~nm} \times 10 \mathrm{~nm}$ & $\mathrm{TiN} / \mathrm{Hf} / \mathrm{HfO}_{\mathrm{X}} / \mathrm{TiN}$ & 31 & - & - & - \\
\hline \multirow{2}{*}{$\mathrm{I}_{\mathrm{ON}} / \mathrm{I}_{\mathrm{OFF}}$ ratio } & \multirow{2}{*}{$10^{6}$} & $3 \times 10^{6}$ & $\mathrm{Ni} / \mathrm{GeO} / \mathrm{STO} / \mathrm{TaN}$ & 348 & $\sim 10^{9}$ & $\mathrm{Ag} / \mathrm{ZrO}_{2} / \mathrm{SLG} / \mathrm{Pt}$ & 349 \\
\hline & & $2 \times 10^{6}$ & $\mathrm{Pt} / \mathrm{Gd}_{2} \mathrm{O}_{3} / \mathrm{Pt}$ & 350 & $>10^{6}$ & $\mathrm{Ti} / h-\mathrm{BN} / \mathrm{Cu}$ & 163 \\
\hline
\end{tabular}




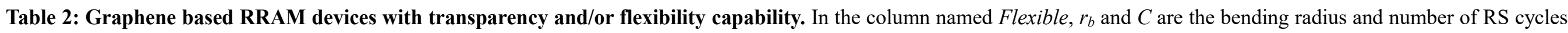

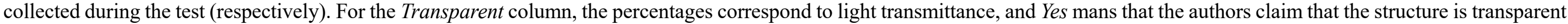
but didn't quantify it. This will be valid for all tables in this manuscript showing such information.

\begin{tabular}{|c|c|c|c|c|c|c|c|c|c|c|c|}
\hline Device structure & $\begin{array}{l}\text { Fabrication } \\
\text { method }\end{array}$ & Device area & IoN/IoFF & $\begin{array}{l}\text { Set V } \\
{[V]}\end{array}$ & $\begin{array}{c}\text { Retention } \\
{[\mathbf{s}]}\end{array}$ & $\begin{array}{c}\text { Endurance } \\
\text { [cycles] }\end{array}$ & $\begin{array}{c}\text { Power } \\
\text { consumption } \\
{[\mu \mathrm{W}]}\end{array}$ & $\begin{array}{c}\text { Switching } \\
\text { time } \\
{[\mathrm{ns}]}\end{array}$ & Transparent & Flexible & Ref. \\
\hline $\mathrm{MLG} / \mathrm{Dy}_{2} \mathrm{O}_{3} / \mathrm{ITO}$ & $\begin{array}{c}\text { CVD } \\
\text { (Transfer) }\end{array}$ & $\begin{array}{c}80-3 \times 10^{4} \\
{\left[\mu \mathrm{m}^{2}\right]}\end{array}$ & $>10^{5}$ & 0.4 & $>10^{4}$ & $>100$ & 4.4 & $\begin{array}{l}60(\text { set}) \\
60(\text { reset })\end{array}$ & $80 \%$ & No & 192 \\
\hline ITO/SLG/ZnO/ITO & $\begin{array}{c}\text { CVD } \\
\text { (Transfer) }\end{array}$ & $\begin{array}{c}200 \mu \mathrm{m} \\
\text { in diameter }\end{array}$ & 20 & - & $10^{4}$ & $>100$ & - & - & Yes & No & 74 \\
\hline $\begin{array}{l}\text { PS/SLG/PMMA/ } \\
\text { SLG/PMMA * }\end{array}$ & $\begin{array}{l}\text { CVD } \\
\text { (Transfer) }\end{array}$ & $\begin{array}{c}500 \mu \mathrm{m} \\
\text { in diameter }\end{array}$ & $\begin{array}{l}\text { L1 } 10^{4} \\
\text { L2: } 10^{6}\end{array}$ & $\begin{array}{l}\text { L1: }-2 \\
\text { L2: }-4\end{array}$ & $10^{4} \mathrm{~s}$ & 1 & - & - & Yes & No & 116 \\
\hline $\begin{array}{l}\text { Al/PMMA/MLG/ } \\
\text { PMMA/ITO/PET }\end{array}$ & $\begin{array}{c}\text { CVD } \\
\text { (Transfer) }\end{array}$ & $\begin{array}{c}18-27 \mu \mathrm{m} \\
\text { in diameter }\end{array}$ & $4.4 \times 10^{6}$ & 3.4 & $1 \times 10^{5}$ & $1.5 \times 10^{5}$ & - & - & Yes & $\begin{array}{c}r_{b}=10 \mathrm{~mm} \\
\mathrm{C}=1.5 \times 10^{5}\end{array}$ & 195 \\
\hline MLG/PI:PCBM/Al & $\begin{array}{c}\text { CVD } \\
\text { (Transfer) }\end{array}$ & - & $\sim 10^{6}$ & 4 & $1 \times 10^{4}$ & $>30$ & - & - & $92 \%$ & $\begin{array}{c}r_{b}=4.2 \mathrm{~mm} \\
\mathrm{C}=1 \times 10^{4}\end{array}$ & 75 \\
\hline $\begin{array}{c}\mathrm{Ti} / \mathrm{Pt} / \mathrm{TiO}_{2} / \mathrm{G} / \mathrm{PEN} \\
\text { (G thickness not mentioned) }\end{array}$ & $\begin{array}{c}\text { CVD } \\
\text { (Transfer) }\end{array}$ & $\begin{array}{l}36 \times 36 \\
{\left[\mu \mathrm{m}^{2}\right]}\end{array}$ & $10^{2}$ & 2 & $10^{6}$ & 1 & $\begin{array}{c}3 \text { (set) } \\
94 \text { (reset) }\end{array}$ & - & Yes & $\begin{array}{c}r_{b}=10 \mathrm{~mm} \\
\mathrm{C}=100\end{array}$ & 196 \\
\hline BLG/SiOX/BLG/ITO & $\begin{array}{c}\text { CVD } \\
\text { (Transfer) }\end{array}$ & $\begin{array}{c}100 \mu \mathrm{m} \\
\text { in diameter }\end{array}$ & $10^{5 * *}$ & 5 & - & 100 & - & - & $90 \%$ & No & 105 \\
\hline BLG/SiOX/BLG/Polymer & $\begin{array}{c}\text { CVD } \\
\text { (Transfer) }\end{array}$ & $\begin{array}{c}100 \mu \mathrm{m} \\
\text { in diameter }\end{array}$ & $10^{6}$ & 5 & - & 400 & - & - & Yes & $\begin{array}{c}r_{b}=12 \mathrm{~mm} \\
\mathrm{C}=300\end{array}$ & 105 \\
\hline
\end{tabular}

* This device shows multilevel RS. Depending on $V_{S E T}$ used the $I_{O N} / I_{O F F}$ ratio changes. We give the parameters for both levels.

** This value is not well supported in Ref. [116], the $I$ - $V$ curve only shows $1-2$ orders of magnitude, while the $R$ vs. $C y c l e$ plot shows $\sim 10^{5}$. The $I$ - $V$ curve should be shown. 
Table 3: Switching in GO based devices

\begin{tabular}{|c|c|c|c|c|c|c|}
\hline Device Structure & Device area & Ion/IofF & $\begin{array}{l}\text { Set V } \\
{[\mathrm{V}]}\end{array}$ & $\begin{array}{c}\text { Retention } \\
{[\mathbf{s}]}\end{array}$ & $\begin{array}{c}\text { Endurance } \\
\text { [cycles] }\end{array}$ & Ref. \\
\hline $\mathrm{Pt} / \mathrm{GO} / \mathrm{Cu}$ & $\begin{array}{c}100 \mu \mathrm{m} \\
\text { in diameter }\end{array}$ & 500 & $\sim 0.7$ & $>10^{4}$ & $>100$ & {$[241]$} \\
\hline $\mathrm{Pt} / \mathrm{GO} / \mathrm{Cu}$ & $\begin{array}{c}100 \mu \mathrm{m} \\
\text { in diameter }\end{array}$ & $\sim 1250$ & $0.8 \sim 1.2$ & $>10^{4}$ & $>100$ & {$[245]$} \\
\hline $\mathrm{Pt} / \mathrm{GO} / \mathrm{Ti}$ & $\begin{array}{c}100 \mu \mathrm{m} \\
\text { in diameter }\end{array}$ & $\sim 650$ & $0.8 \sim 1.2$ & $\sim 10^{5}$ & $>100$ & {$[245]$} \\
\hline $\mathrm{Pt} / \mathrm{GO} / \mathrm{Ag}$ & $\begin{array}{c}100 \mu \mathrm{m} \\
\text { in diameter }\end{array}$ & $\sim 100$ & $0.5 \sim 1$ & $\sim 10^{5}$ & $\sim 100$ & {$[245]$} \\
\hline $\mathrm{Pt} / \mathrm{GO} / \mathrm{Au}$ & $\begin{array}{c}100 \mu \mathrm{m} \\
\text { in diameter }\end{array}$ & $\sim 40$ & $0.6 \sim 0.8$ & $\sim 10^{5}$ & $>100$ & {$[245]$} \\
\hline $\mathrm{Si} / \mathrm{GO} / \mathrm{Al}$ & $\begin{array}{c}600 \times 600 \\
{\left[\mu \mathrm{m}^{2}\right]}\end{array}$ & 110 & -5.5 & $10^{3}$ & $\sim 100$ & {$[250]$} \\
\hline $\mathrm{Ge} / \mathrm{GO} / \mathrm{Al}$ & $\begin{array}{c}600 \times 600 \\
{\left[\mu \mathrm{m}^{2}\right]}\end{array}$ & 76 & -8.7 & $10^{3}$ & $>100$ & {$[250]$} \\
\hline $\mathrm{Al} / \mathrm{GO} / \mathrm{Al}$ & - & $10^{3}$ & 0.7 & - & - & {$[253]$} \\
\hline $\mathrm{ITO} / \mathrm{GO} / \mathrm{Al}$ & $\begin{array}{c}180 \mu \mathrm{m} \\
\text { in diameter }\end{array}$ & $10^{3}$ & -1.6 & $10^{7}$ & $>100$ & [249] \\
\hline $\mathrm{ITO} / \mathrm{GO} / \mathrm{Ag}$ & - & $10^{4}$ & $-0.6 \pm 0.2$ & $>10^{3}$ & - & {$[242]$} \\
\hline ITO/GO/Ag & $\begin{array}{c}80 \mu \mathrm{m} \\
\text { in diameter }\end{array}$ & $<10$ & 0.6 & - & - & [133] \\
\hline $\mathrm{Ag} / \mathrm{GO} / \mathrm{Ag}$ & - & 10 & 6.7 & $>10^{3}$ & - & {$[251]$} \\
\hline $\mathrm{p}-\mathrm{Si} / \mathrm{GO} / \mathrm{Ag}$ & $\begin{array}{l}50 \sim 150 \mu \mathrm{m} \\
\text { in diameter }\end{array}$ & $10^{4}$ & 3.5 & $>10^{3}$ & $>100$ & {$[247]$} \\
\hline $\mathrm{Al} / \mathrm{GO} / \mathrm{Au} / \mathrm{GO} / \mathrm{ITO}$ & - & $10^{2}$ & - & - & $10^{4}$ & {$[243]$} \\
\hline
\end{tabular}


Table 4: Switching in RGO based devices

\begin{tabular}{|c|c|c|c|c|c|c|c|}
\hline Device structure & Device area & ION/IOFF & Set V [V] & Retention [s] & $\begin{array}{c}\text { Endurance } \\
\text { [cycles] }\end{array}$ & $\begin{array}{c}\text { Switching } \\
\text { time } \\
{[n s]}\end{array}$ & Ref. \\
\hline $\mathrm{PET} / \mathrm{ITO} / \mathrm{RGO}+\mathrm{PVA}+\mathrm{Au} \mathrm{NP} / \mathrm{Al}$ & - & $>10^{3}$ & 0.44 & $>10^{4}$ & - & - & {$[352]$} \\
\hline ITO/RGO/ITO & $\begin{array}{c}50 \mu \mathrm{m} \\
\text { in diameter }\end{array}$ & - & 2 & $10^{5} @ 85^{\circ} \mathrm{C}$ & $>10^{5}$ & $\begin{array}{c}30 \text { (set) } \\
30 \text { (reset) }\end{array}$ & {$[262]$} \\
\hline $\mathrm{Au} / \mathrm{RGO} / \mathrm{ITO}$ & - & $10^{3}$ & 2 & $10^{5} \mathrm{~s}$ & - & - & {$[270]$} \\
\hline $\mathrm{Al} / \mathrm{GO} / \mathrm{ITO}$ & $\begin{array}{l}\sim 3 \mathrm{~mm} \\
\text { in diameter }\end{array}$ & $10^{5}$ & - & $>10^{4}$ & - & $\begin{array}{c}25 \text { (set) } \\
25 \text { (reset) }\end{array}$ & {$[260]$} \\
\hline $\mathrm{Al} / \mathrm{RGO} / \mathrm{Al}$ & - & 10 & - & $>10^{6}$ & $>100$ & - & [272] \\
\hline $\mathrm{Al} / \mathrm{RGO} / \mathrm{Al}$ & $\begin{array}{c}100 \mu \mathrm{m} \\
\text { in diameter }\end{array}$ & $10^{2}$ & 0.6 & $>10^{4}$ & $>250$ & - & [271] \\
\hline $\mathrm{Pt} / \mathrm{RGO}-\mathrm{th} / \mathrm{Pt}$ & $\begin{array}{c}100 \mu \mathrm{m} \\
\text { in diameter }\end{array}$ & $>10^{4}$ & $1.9 \sim 3.9$ & $>10^{5}$ & $>350$ & $\begin{array}{c}5(\text { set }) \\
5 \text { (reset) }\end{array}$ & {$[273]$} \\
\hline $\mathrm{Al} / \mathrm{PFCF} / \mathrm{RGO} / \mathrm{ITO}$ & $\begin{array}{c}0.4 \mathrm{~mm} \\
\text { in diameter }\end{array}$ & $10^{4}$ & $-1.2 \mathrm{~V}$ & $10^{4}$ & $10^{8}$ & - & [351] \\
\hline $\mathrm{Al} / \mathrm{RGO}$-ferrocene/ITO & $\begin{array}{l}0.04 \mathrm{~mm} \\
\text { in diameter }\end{array}$ & $10^{3}$ & - & $10^{3} \mathrm{~s}$ & $10^{3}$ & - & {$[274]$} \\
\hline $\begin{array}{c}\mathrm{Ag} / \mathrm{HfO}_{\mathrm{X}} / \mathrm{LSG} \\
\text { (laser-scribed RGO) }\end{array}$ & - & 10 & - & $10^{4}$ & 100 & - & [254] \\
\hline
\end{tabular}


Table 5: Switching in GO and RGO-polymer and mixed structures

\begin{tabular}{|c|c|c|c|c|c|c|}
\hline Device structure & Device area & Ion/IofF & $\begin{array}{l}\text { Set V } \\
{[\mathbf{V}]}\end{array}$ & $\begin{array}{c}\text { Retention } \\
{[\mathrm{s}]}\end{array}$ & $\begin{array}{l}\text { Endurance } \\
\text { [cycles] }\end{array}$ & Ref. \\
\hline ITO/TPAPAM-GO/Al & $0.4 \times 0.4\left[\mathrm{~mm}^{2}\right]$ & $10^{3}$ & -1 & $>10^{4}$ & $10^{8}$ & [276] \\
\hline ITO/GO-PVK/Al & - & $>10^{3}$ & -2 & $>10^{4}$ & $10^{8}$ & {$[275]$} \\
\hline PET/ITO/PVK:Gr(GO)/Al & - & - & $0.2 \sim 0.4$ & - & Not reversible & {$[353]$} \\
\hline $\mathrm{ITO} / \mathrm{PVA}+\mathrm{GO} / \mathrm{Al}$ & $\begin{array}{c}200 \mu \mathrm{m} \\
\text { in diameter }\end{array}$ & $10^{4}$ & -0.75 & $10^{4}$ & $>10^{4}$ & [354] \\
\hline ITO/PVDF-GO/Al & $0.0004\left[\mathrm{~cm}^{2}\right]$ & $10^{4}$ & $3.6 \sim 4.1$ & - & - & {$[355]$} \\
\hline $\mathrm{Al} / \mathrm{CuO} / \mathrm{GO} / \mathrm{CuO} / \mathrm{Al}$ & - & - & 3.0 & - & - & {$[244]$} \\
\hline ITO/PMMA/GO/PMMA/Al & $\begin{array}{c}30 \mu \mathrm{m} \\
\text { in diameter }\end{array}$ & $>10^{3}$ & -1.7 & $10^{4}$ & $>10^{5}$ & {$[356]$} \\
\hline $\mathrm{Gr} / \mathrm{GO} / \mathrm{ZnONR} / \mathrm{Nb}$ & - & $10^{3}$ & - & - & $>50$ & {$[357]$} \\
\hline $\mathrm{ITO} / \mathrm{GOAu} / \mathrm{Al}$ & $\begin{array}{c}200 \mu \mathrm{m} \\
\text { in diameter }\end{array}$ & $10^{6}$ & -1 & $10^{4}$ & $>300$ & [358] \\
\hline $\mathrm{ITO} / \mathrm{GO}-\mathrm{FeO} / \mathrm{Pt}$ & - & $5 \times 10^{3}$ & 0.9 & $10^{5}$ & $>1100$ & {$[359]$} \\
\hline ITO/FPA-rGO/Al & $0.04\left[\mathrm{~mm}^{2}\right]$ & $10^{3}$ & 1.6 & $>10^{3}$ & $>10^{3}$ & {$[274]$} \\
\hline $\mathrm{Al} / \mathrm{GO}-\mathrm{PFCz}-\mathrm{ITO}$ & $0.16 \sim 0.0225\left[\mathrm{~mm}^{2}\right]$ & $10^{3}$ & 0.38 & $>10^{4}$ & $10^{8}$ & {$[351]$} \\
\hline $\mathrm{Au} / \mathrm{PrGODMF} / \mathrm{ITO}$ & - & 100 & - & $>1000$ & 100 & {$[128]$} \\
\hline Ag/PI/GO:PI/PI/ITO & - & 1000 & 5 & 1400 & 130 & [258] \\
\hline $\mathrm{Pt} / \mathrm{GO} / \mathrm{PCMO} / \mathrm{Pt}$ & - & $10^{2}$ & -0.75 & $10^{4}$ & 150 & {$[264]$} \\
\hline Al/PS-b.P4VP-GO/ITO & $0.4 \times 0.4 \mathrm{~mm}^{2}$ & $10^{4}$ & $\sim 6$ & $>10^{4}$ & $10^{8}$ & {$[360]$} \\
\hline Al/P3HT:PCBM/rGO/glass & - & $10^{6}$ & - & - & - & {$[140]$} \\
\hline $\mathrm{Pt} / \mathrm{Zr}: \mathrm{SiO} x / \mathrm{C}: \mathrm{SiO} x / \mathrm{TiN}$ & - & 100 & - & - & - & {$[268]$} \\
\hline rGO/P3HT:PCBM/Al & - & $10^{4}-10^{5}$ & - & - & - & [279] \\
\hline $\mathrm{PET} / \mathrm{rGO} / \mathrm{MoS}_{2}-\mathrm{PVP} / \mathrm{Al}$ & - & $\sim 10^{2}$ & - & - & - & {$[320]$} \\
\hline
\end{tabular}


Table 6: Switching in GO and RGO on flexible substrate

\begin{tabular}{|c|c|c|c|c|c|c|c|}
\hline Device structure & Device area & ION/IOFF & $\begin{array}{c}\text { Set V } \\
{[\mathrm{V}]}\end{array}$ & $\begin{array}{c}\text { Retention } \\
{[\mathrm{s}]}\end{array}$ & $\begin{array}{c}\text { Endurance } \\
\text { [cycles] }\end{array}$ & $\begin{array}{c}\text { Switching } \\
\text { time } \\
{[\mathrm{ns}]}\end{array}$ & Ref. \\
\hline $\mathrm{PET} / \mathrm{ITO} / \mathrm{GO} / \mathrm{Al}$ & $\begin{array}{c}300 \mu \mathrm{m} \\
\text { in diameter }\end{array}$ & 280 & 2.2 & $10^{4}$ & $>100$ & - & {$[261]$} \\
\hline $\mathrm{PES} / \mathrm{Al} / \mathrm{GO} / \mathrm{Al}$ & $50 \mu \mathrm{m} \times 50 \mu \mathrm{m}$ & $>100$ & -2.5 & $5 \times 10^{4}$ & $\sim 100$ & - & {$[126]$} \\
\hline PES/ITO/GO/ITO & $\begin{array}{c}150 \mu \mathrm{m} \\
\text { in diameter }\end{array}$ & 10 & $0.7 \sim 1$ & $10^{5}$ & - & - & {$[361]$} \\
\hline PET/ITO/GO/ZnO nanorods/Al & $\begin{array}{c}200 \mu \mathrm{m} \\
\text { in diameter }\end{array}$ & $\sim 100$ & $1 \sim 4.8$ & $10^{4}$ & $>200$ & - & {$[246]$} \\
\hline $\mathrm{PET} / \mathrm{ITO} / \mathrm{GO} / \mathrm{Al}$ & $\begin{array}{c}200 \mu \mathrm{m} \\
\text { in diameter }\end{array}$ & $\sim 100$ & 3.9 & - & - & - & {$[246]$} \\
\hline $\mathrm{PET} / \mathrm{ITO} / \mathrm{GO} / \mathrm{Ag}$ & $0.026\left[\mathrm{~mm}^{2}\right]$ & 5 & -0.14 & $\sim 10^{3}$ & 13 & - & {$[139]$} \\
\hline $\mathrm{PET} / \mathrm{ITO} / \mathrm{RGO}+\mathrm{PVA}+\mathrm{Au} \mathrm{NP} / \mathrm{Al}$ & - & $>10^{3}$ & -0.44 & $>10^{4}$ & - & - & {$[352]$} \\
\hline $\mathrm{Pt} / \mathrm{RGO}-\mathrm{th} / \mathrm{Pt}$ & $\begin{array}{c}100 \mu \mathrm{m} \\
\text { in diameter }\end{array}$ & $>10^{4}$ & $1.9 \sim 3.9$ & $>10^{5}$ & $>350$ & $<5 \mathrm{~ns}$ & {$[273]$} \\
\hline $\mathrm{Al} / \mathrm{RGO} / \mathrm{Al}$ & $\begin{array}{c}100 \mu \mathrm{m} \\
\text { in diameter }\end{array}$ & $10^{2}$ & -0.6 & $>10^{4}$ & $>250$ & - & {$[271]$} \\
\hline $\mathrm{PEN} / \mathrm{Ti} / \mathrm{Pt} / \mathrm{GO} / \mathrm{Ti} / \mathrm{Pt}$ & $100 \mathrm{~nm} \times 100 \mathrm{~nm}$ & - & 3.5 & $>10^{5}$ & $>10^{3}$ & $<10$ (set) & {$[280]$} \\
\hline $\mathrm{Al} / \mathrm{GO} / \mathrm{ITO}$ & $\begin{array}{c}180 \mu \mathrm{m} \\
\text { in diameter }\end{array}$ & $10^{3}$ & -1.6 & $10^{7}$ & $>100$ & - & [249] \\
\hline
\end{tabular}


Table 7: Hydrogenated amorphous carbon

\begin{tabular}{|c|c|c|c|c|c|c|c|c|c|}
\hline Device structure & Device area & Ion/Ioff & $\begin{array}{l}\text { Set } \mathbf{V} \\
{[\mathrm{V}]}\end{array}$ & $\begin{array}{c}\text { Retention } \\
{[\mathrm{s}]}\end{array}$ & $\begin{array}{c}\text { Endurance } \\
\text { [cycles] }\end{array}$ & $\begin{array}{c}\text { Power } \\
\text { consumption } \\
{[\mu \mathrm{W}]}\end{array}$ & $\begin{array}{c}\text { Critical } \\
\text { field } \\
{[\mathrm{V} / \mathrm{cm}]}\end{array}$ & $\begin{array}{c}\text { Switching } \\
\text { time } \\
{[\mathrm{ns}]}\end{array}$ & Ref. \\
\hline $\mathrm{Cr} / \mathrm{a}-\mathrm{C}: \mathrm{H}:(\mathrm{B}) / \mathrm{Au}$ & - & $10^{2}$ & - & - & - & - & $5 \times 10^{5}$ & - & [84] \\
\hline $\mathrm{Pt} / \mathrm{a}-\mathrm{C}: \mathrm{H} / \mathrm{Cu} \quad(\mathrm{Ag} \text { orAu})^{*}$ & $\begin{array}{c}100 \mu \mathrm{m} \\
\text { in diameter }\end{array}$ & $>100$ & 1.1 & $>10^{5}$ & 110 & - & - & - & [85] \\
\hline TiN/a-C:H/Cu $(\mathrm{Pt}, \mathrm{W}) * *$ & $\begin{array}{l}49 \pm 11 \mathrm{~nm} \\
\text { in diameter }\end{array}$ & $>10^{3}$ & 4.1 & 57,600 & 15 & - & - & $\begin{array}{c}30 \text { (set) } \\
<30 \text { (reset) }\end{array}$ & [86] \\
\hline TiN/a-C: H /Pt & $\begin{array}{c}0.36 \text { to } 16 \\
{\left[\mu \mathrm{m}^{2}\right]}\end{array}$ & 100 & 1.5 & $10,000 @ 85^{\circ} \mathrm{C}$ & $10^{7}$ & - & - & - & [87] \\
\hline
\end{tabular}

* The $\mathrm{Cu}$ electrode has been also replaced by $\mathrm{Ag}$ and $\mathrm{Au}$, and the resulting devices also show resistive switching. It was found that the ON/OFF ratio (R) and switching threshold voltages (V) vary as follows: $\mathrm{R}_{\mathrm{Cu}}>\mathrm{R}_{\mathrm{Ag}}>\mathrm{R}_{\mathrm{Au}}$ and $\mathrm{V}_{\mathrm{Cu}}>\mathrm{V}_{\mathrm{Au}}>\mathrm{V}_{\mathrm{Ag}}$.

** This report used devices with $\mathrm{Cu}$, Pt or $\mathrm{W}$ electrodes. From the paper, it is unclear to which electrode correspond the performances indicated. 
Table 8: Doped amorphous carbon

\begin{tabular}{|c|c|c|c|c|c|c|c|c|}
\hline Device structure & Device area & Ion/IofF & $\begin{array}{l}\text { Set V } \\
{[\mathrm{V}]}\end{array}$ & $\begin{array}{c}\text { Retention } \\
{[\mathbf{s}]}\end{array}$ & $\begin{array}{c}\text { Endurance } \\
\text { [cycles] }\end{array}$ & $\begin{array}{c}\text { Power } \\
\text { consumption } \\
{[\mu \mathrm{W}]}\end{array}$ & $\begin{array}{c}\text { Switching } \\
\text { time } \\
\text { [ns] }\end{array}$ & Ref. \\
\hline $\mathrm{W} / \mathrm{a}-\mathrm{CO}_{\mathrm{x}} / \mathrm{Pt}, \mathrm{Ti}, \mathrm{W}$ & $\begin{array}{c}100 \mathrm{~nm} \\
\text { in diameter }\end{array}$ & $>10^{2}$ & - & $10^{4} @ 85^{\circ} \mathrm{C}$ & $>10^{4}$ & - & $\begin{array}{l}40 \text { (set) } \\
4 \text { (reset) }\end{array}$ & {$[294,301]$} \\
\hline $\mathrm{Pt} / \mathrm{a}-\mathrm{CN}_{0.15} / \mathrm{Cu}$ & $\begin{array}{c}100 \mu \mathrm{m} \\
\text { in diameter }\end{array}$ & 1 & 0.6 & $>10^{6}$ & $10^{3}$ & - & - & [295] \\
\hline $\mathrm{FTO} / \mathrm{a}-\mathrm{C}: \mathrm{Co} / \mathrm{Al}$ & - & 25 & - & $>10^{5}$ & - & - & - & [297] \\
\hline $\mathrm{Pt} / \mathrm{a}-\mathrm{C}: \mathrm{Cu} / \mathrm{Cu}$ & $0.1 \times 0.1\left[\mu \mathrm{m}^{2}\right]$ & $10^{2}$ & 0.7 & $10^{4} @ 85^{\circ} \mathrm{C}$ & $>10^{3}$ & - & - & {$[298,299]$} \\
\hline $\mathrm{Pt} / \mathrm{a}-\mathrm{C}: \mathrm{Cu} / \mathrm{Pt}$ & $30 \times 30\left[\mu \mathrm{m}^{2}\right]$ & - & 0.7 & - & - & - & - & [300] \\
\hline $\mathrm{Pt} / \mathrm{a}-\mathrm{C}: \mathrm{N} / \mathrm{C}-\mathrm{AFM}$ tip & $12 \mathrm{~nm}$ diameter & - & 3 & - & - & - & - & [296] \\
\hline Pt/a-C:Si/C-AFM tip & - & - & 3.5 & - & - & - & - & [296] \\
\hline
\end{tabular}


Table 9: ta-C and a-C

\begin{tabular}{|c|c|c|c|c|c|c|c|c|c|}
\hline Device structure & Device area & ION/IofF & $\begin{array}{c}\text { Set } \\
\text { V [V] }\end{array}$ & $\begin{array}{c}\text { Retention } \\
{[\mathbf{s}]}\end{array}$ & $\begin{array}{c}\text { Enduranc } \\
\mathbf{e} \\
\text { [cycles] }\end{array}$ & $\begin{array}{c}\text { Power } \\
\text { consumption } \\
{[\mu \mathrm{W}]}\end{array}$ & $\begin{array}{c}\text { Critical } \\
\text { field } \\
{[\mathrm{V} / \mathrm{cm}]}\end{array}$ & $\begin{array}{c}\text { Switching } \\
\text { time } \\
{[\mathrm{ns}]}\end{array}$ & Ref. \\
\hline $\begin{array}{l}\text { TiN/a-C }\left(\mathrm{sp}^{2} \text { rich }\right) / \\
\text { C-AFM tip (PtSi) }\end{array}$ & $\begin{array}{l}20 \sim 30 \mathrm{~nm} \\
\text { in diameter }\end{array}$ & - & $1 \sim 2$ & - & $\begin{array}{c}\text { Not } \\
\text { reversible }\end{array}$ & - & - & - & [285] \\
\hline $\mathrm{W} / \mathrm{ta}-\mathrm{C} / \mathrm{W}$ & $\begin{array}{c}150 \mathrm{~nm} \\
\text { in diameter }\end{array}$ & $>10^{3}$ & $1 \sim 3$ & - & $\begin{array}{c}2.3 \times 10^{13} \\
\text { @ } 75^{\circ} \mathrm{C}\end{array}$ & - & - & $\begin{array}{l}10 \text { (set) } \\
1 \text { (reset) }\end{array}$ & {$[286]$} \\
\hline $\mathrm{Ag} / \mathrm{a}-\mathrm{C} / \mathrm{CNT}$ & $0.001\left[\mu \mathrm{m}^{2}\right]$ & $40-200$ & $5.4 \sim 7.5$ & $>10^{6}$ & 31 & - & - & - & [290] \\
\hline $\mathrm{Al} / \mathrm{a}-\mathrm{C} / \mathrm{Cu}$ & - & 3 & $<3$ & $10^{5}$ & - & - & - & - & [291] \\
\hline $\mathrm{Al} / \mathrm{ta}-\mathrm{C} / \mathrm{W}$ & $\begin{array}{c}2500 \\
{\left[\mu \mathrm{m}^{2}\right]}\end{array}$ & 10 & $<1$ & $>10^{5}$ & 120 & - & - & - & [287] \\
\hline $\mathrm{Pt} / \mathrm{a}-\mathrm{C} / \mathrm{Cu}, \mathrm{Ag}$ & $50 \times 50\left[\mu \mathrm{m}^{2}\right]$ & - & $0.18 @ 0 \mathrm{~K}$ & $10^{4} @ 85^{\circ} \mathrm{C}$ & - & - & - & - & {$[306]$} \\
\hline $\mathrm{Pt} / \mathrm{a}-\mathrm{C} / \mathrm{Cu}$ & $\begin{array}{c}500 \mu \mathrm{m} \\
\text { in diameter }\end{array}$ & 100 & 0.1 & $10^{8}$ & - & - & - & - & [304] \\
\hline $\mathrm{Pt} / \mathrm{a}-\mathrm{C} / \mathrm{Cu}$ & $\begin{array}{c}100 \mu \mathrm{m} \\
\text { in diameter }\end{array}$ & $>70$ & 1 & - & 110 & - & - & - & {$[305]$} \\
\hline $\mathrm{Pt} / \mathrm{ta}-\mathrm{C} / \mathrm{W}$ & $\begin{array}{l}50-500 \mathrm{~nm} \\
\text { in diameter }\end{array}$ & $>300$ & 0.8 & - & - & - & $5 \times 10^{7}$ & $\begin{array}{l}50(\text { set }) \\
4 \text { (reset) }\end{array}$ & {$[301,288,289]$} \\
\hline
\end{tabular}


Table 10: Transition Metal dichalcogenides based RRAMs

\begin{tabular}{|c|c|c|c|c|c|c|c|c|c|}
\hline Device structure & Fabrication method & IoN/IOFF & $\begin{array}{c}\text { Retention } \\
{[\mathrm{s}]}\end{array}$ & $\begin{array}{c}\text { Endurance } \\
\text { [cycles] }\end{array}$ & $\begin{array}{c}\text { Power } \\
\text { consumption } \\
{[\mu W]}\end{array}$ & $\begin{array}{c}\text { Switching } \\
\text { time } \\
{[\mathrm{ns}]}\end{array}$ & Transparent & Flexible & Ref. \\
\hline PMMA-MoS $/$ MLG/SiO $2 / \mathrm{Si}$ & $\begin{array}{c}\text { CVD } \\
\text { (Transfer) }\end{array}$ & $2.5 \times 10^{3}$ & - & - & - & - & NO & NO & {$[317]$} \\
\hline $\mathrm{Ag} / \mathrm{MoSe}_{2} / \mathrm{FTO}$ & Hydrothermal & 12 & $>50$ & - & - & - & NO & NO & [315] \\
\hline $\mathrm{Au} / \mathrm{MoS}_{2} / \mathrm{SiO}_{2} / \mathrm{Si}$ & CVD & $10^{3}$ & - & - & - & - & NO & NO & [326] \\
\hline $\mathrm{Ag} / \mathrm{MoS}_{2} / \mathrm{Ag}$ & $\begin{array}{c}\text { LPE } \\
\text { (spin coating) }\end{array}$ & $10^{3}$ & - & $10^{3} *$ & - & - & NO & NO & [316] \\
\hline $\mathrm{Ag} / \mathrm{MoS}_{2}-\mathrm{MoO}_{\mathrm{x}} / \mathrm{Ag}$ & $\begin{array}{c}\text { Modified } \\
\text { Langmuir-Blodgett }\end{array}$ & $>10^{6}$ & - & $>8000 \mathrm{~s}$ & $10 \mathrm{nW}$ & - & NO & YES & {$[327]$} \\
\hline $\mathrm{Al} / \mathrm{MoS} 2-\mathrm{GO} / \mathrm{ITO}$ & $\begin{array}{c}\text { LPE } \\
\text { (spin coating) }\end{array}$ & $10^{2}$ & - & - & - & - & NO & NO & {$[326]$} \\
\hline RGO/ZIF-8 coated $\mathrm{MoS}_{2} / \mathrm{RGO}$ & $\begin{array}{c}\text { LPE } \\
\text { (spin coating) }\end{array}$ & $7 \times 10^{4}$ & - & $1.5 \times 10^{3} \mathrm{~s}$ & - & - & NO & YES & {$[362]$} \\
\hline $\mathrm{RGO} / \mathrm{MoS}_{2}-\mathrm{P} 123 / \mathrm{RGO}$ & $\begin{array}{c}\text { LPE } \\
\text { (spin coating) }\end{array}$ & $5.5 \times 10^{2} \mathrm{~s}$ & $>50$ & $4 \times 10^{3} \mathrm{~s}$ & - & - & NO & NO & [363] \\
\hline $\mathrm{PET} / \mathrm{RGO} / \mathrm{MoS}_{2}-\mathrm{PVP} / \mathrm{Al}$ & $\begin{array}{c}\text { Polymer-assisted } \\
\text { exfoliation }\end{array}$ & $\sim 10^{2}$ & - & - & - & - & NO & YES & {$[320]$} \\
\hline $\mathrm{RGO} / \mathrm{MoS}_{2} / \mathrm{ITO} / \mathrm{Si}$ & Hydrothermal & $10^{4}$ & - & $>5.5 \times 10^{3} \mathrm{~s}$ & - & - & NO & NO & [328] \\
\hline
\end{tabular}

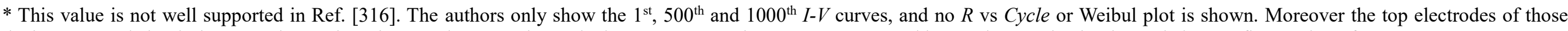
devices are made by drying Ag paint on the spin coated $\mathrm{MoS}_{2}$ using a shadow mast. More rigorous processes and better characterization is needed to confirm such performances. 
Table 11: $h$-BN based RRAM devices.

\begin{tabular}{|c|c|c|c|c|c|c|c|c|c|c|c|}
\hline Structure & $\begin{array}{c}\text { Fabrication } \\
\text { method }\end{array}$ & $\begin{array}{l}\text { Bipolar RS } \\
\text { under } \\
\text { positive set }\end{array}$ & $\begin{array}{c}\text { Forming } \\
\text { process } \\
\text { needed }\end{array}$ & $\begin{array}{l}\text { VSET [V] } \\
\text { ISET [A] }\end{array}$ & $\begin{array}{l}\text { VRESET [V] } \\
\text { IRESET [A] }\end{array}$ & ION/IofF & $\begin{array}{c}\text { Endurance } \\
\text { cycles }\end{array}$ & $\begin{array}{l}\text { Retention } \\
\text { time }\end{array}$ & $\begin{array}{l}\text { Bipolar RS } \\
\text { under } \\
\text { negative set }\end{array}$ & $\begin{array}{l}\text { Threshold } \\
\text { RS }\end{array}$ & Ref. \\
\hline $\mathrm{Ti} / \mathrm{hBN} / \mathrm{Cu}$ & $\begin{array}{c}\text { CVD } \\
\text { (no transfer) }\end{array}$ & YES & NO & $\begin{array}{c}0.4 \mathrm{~V} \\
4 \times 10^{-4} \mathrm{~A} \\
\end{array}$ & $\begin{array}{c}-0.3 \mathrm{~V} \\
4 \times 10^{-3} \mathrm{~A} \\
\end{array}$ & 10 & $>350$ & - & NO & YES & {$[163]$} \\
\hline $\mathrm{Ti} / \mathrm{hBN} / \mathrm{Cu}$ & $\begin{array}{c}\text { CVD } \\
\text { (no transfer) }\end{array}$ & YES & NO & $\begin{array}{c}0.7 \mathrm{~V} \\
4 \times 10^{-6} \mathrm{~A}\end{array}$ & $\begin{array}{l}-0.7 \mathrm{~V} \\
10^{-2} \mathrm{~A}\end{array}$ & $10^{4}$ & $>600$ & - & YES & YES & {$[164]$} \\
\hline $\mathrm{Ti} / \mathrm{hBN} / \mathrm{CuNi}$ & $\begin{array}{c}\text { CVD } \\
\text { (no transfer) }\end{array}$ & YES & YES & $\begin{array}{c}0.7 \mathrm{~V} \\
4 \times 10^{-3} \mathrm{~A}\end{array}$ & $\begin{array}{c}-0.4 \mathrm{~V} \\
2 \times 10^{-2} \mathrm{~A}\end{array}$ & 15 & - & - & NO & NO & {$[163]$} \\
\hline $\mathrm{Ti} / \mathrm{hBN} / \mathrm{CuNi}$ & $\begin{array}{c}\text { CVD } \\
\text { (no transfer) }\end{array}$ & YES & YES & $\begin{array}{c}6 \mathrm{~V} \\
10^{-3} \mathrm{~A}\end{array}$ & $\begin{array}{c}-2 \mathrm{~V} \\
10^{-1} \mathrm{~A}\end{array}$ & $10^{6}$ & - & - & YES & NO & {$[163]$} \\
\hline $\mathrm{Ti} / \mathrm{hBN} / \mathrm{ITO}$ & $\begin{array}{c}\text { CVD } \\
\text { (transfer) }\end{array}$ & YES & NO & $\begin{array}{c}0.4 \mathrm{~V} \\
2 \times 10^{-4} \mathrm{~A}\end{array}$ & $\begin{array}{l}-0.3 \mathrm{~V} \\
10^{-3} \mathrm{~A}\end{array}$ & 10 & $>180$ & - & NO & NO & {$[163]$} \\
\hline $\mathrm{Ti} / \mathrm{MLG} / \mathrm{hBN} / \mathrm{MLG} / \mathrm{Au}$ & $\begin{array}{c}\text { CVD } \\
\text { (transfer) }\end{array}$ & YES & YES & $\begin{array}{l}2.3 \mathrm{~V} \\
10^{-3} \mathrm{~A}\end{array}$ & $\begin{array}{c}-0.6 \mathrm{~V} \\
4 \times 10^{-2} \mathrm{~A}\end{array}$ & $10^{3}$ & $>450$ & $4 \times 10^{4} \mathrm{~s}$ & NO & NO & {$[163]$} \\
\hline $\mathrm{Al} / \mathrm{hBN} / \mathrm{WO}_{3} / \mathrm{Al}$ & $\begin{array}{c}\text { CVD } \\
\text { (transfer) }\end{array}$ & - & - & - & - & $<10$ & $\sim 80$ & $3 \times 10^{4}$ & - & - & {$[107]$} \\
\hline $\mathrm{Ag} / \mathrm{hBN} / \mathrm{Cu} / \mathrm{PET} *$ & $\begin{array}{c}\text { CVD } \\
\text { (no transfer) }\end{array}$ & - & YES & - & - & 100 & 550 & $3 \times 10^{3} \mathrm{~s}$ & - & - & [329] \\
\hline $\mathrm{Au} / \mathrm{Ti} / \mathrm{hBN} / \mathrm{Cu}$ * & $\begin{array}{c}\text { CVD } \\
\text { (no transfer) }\end{array}$ & - & YES & - & - & - & $>100$ & - & - & & [329] \\
\hline $\mathrm{Au} / \mathrm{Ti} / \mathrm{SLG} / \mathrm{hBN} / \mathrm{SiO}_{2} / \mathrm{Si}$ & MC & - & - & - & - & $10^{3}$ & - & $10^{5} \mathrm{~s}$ & - & - & {$[338]$} \\
\hline
\end{tabular}

* The layered structure of the BN in Ref. [329] is not well supported. From their cross sectional TEM pictures it looks like an amorphous hBN film (see Figure 13). 
Table 12: Black phosphorous based RRAM devices

\begin{tabular}{|c|c|c|c|c|c|c|c|c|c|}
\hline Device structure & $\begin{array}{l}\text { Fabrication } \\
\text { method }\end{array}$ & Ion/Ioff & $\begin{array}{c}\text { Retention } \\
{[\mathbf{s}]}\end{array}$ & $\begin{array}{c}\text { Endurance } \\
\text { [cycles] }\end{array}$ & $\begin{array}{c}\text { Power } \\
\text { consumption } \\
{[\mu \mathrm{W}]}\end{array}$ & $\begin{array}{c}\text { Switching } \\
\text { time } \\
\text { [ns] }\end{array}$ & Transparent & Flexible & Ref. \\
\hline Al/TDL/BP/ITO/PET & $\begin{array}{c}\text { LPE } \\
\text { (spin coating) }\end{array}$ & $\sim 3 \times 10^{5}$ & - & $10^{5} \mathrm{~s}$ & - & - & NO & YES & [318] \\
\hline (PET)/Au/BPQD-PVP/Ag & $\begin{array}{c}\text { LPE } \\
\text { (spin coating) }\end{array}$ & $6 \times 10^{4}$ & - & $1100 \mathrm{~s}$ & - & - & NO & YES & [119] \\
\hline
\end{tabular}




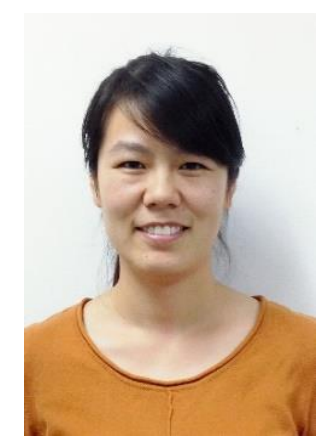

Fei Hui received a Bachelor degree in Chemistry from Huanghuai University in 2013. She is currently pursuing her $\mathrm{PhD}$ at Soochow University. Her research mainly focuses on two dimensional materials and their integration in resistive random access memories. Fei Hui has developed a patent on graphene-coated nanoprobes that has received 1M\$ investment. In 2016 she received the Royal Society of Chemistry travel award.

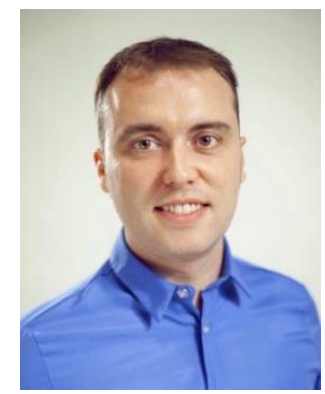

Mario Lanza is Young 1000 Talent Professor and research group leader at Soochow University. He received his $\mathrm{PhD}$ in Electronic Engineering in 2010 at the Universitat Autonoma de Barcelona. During his PhD, he was visiting scholar at the Deggendorf Institute of Technology under a DAAD grant (where he worked in a project for with Infineon Technologies), and at The University of Manchester under a Ministry of Education grant. He was NSFC postdoctoral fellow at Peking University, and Marie Curie postdoctoral fellow at Stanford University. His research focuses on the 
development of advanced electronic devices using graphene and related materials. Prof. Lanza has published over 75 research papers, including Science and Advanced Materials, and is a member of the editorial board of Nature Scientific Reports and Wiley-VCH (CRT). In 2016 he was ranked world top 2 Young Investigator in the field of Nanotechnology by Elsevier. 